\title{
Antibiotic resistance and the commensal flora: role of the commensal flora in the development and spread of antimicrobial resistance
}

Citation for published version (APA):

Nys, S. S. M. (2005). Antibiotic resistance and the commensal flora: role of the commensal flora in the development and spread of antimicrobial resistance. [Doctoral Thesis, Maastricht University]. Maastricht University Press. https://doi.org/10.26481/dis.20050909sn

Document status and date:

Published: 01/01/2005

DOI:

10.26481/dis.20050909sn

Document Version:

Publisher's PDF, also known as Version of record

Please check the document version of this publication:

- A submitted manuscript is the version of the article upon submission and before peer-review. There can be important differences between the submitted version and the official published version of record.

People interested in the research are advised to contact the author for the final version of the publication, or visit the DOI to the publisher's website.

- The final author version and the galley proof are versions of the publication after peer review.

- The final published version features the final layout of the paper including the volume, issue and page numbers.

Link to publication

\footnotetext{
General rights rights.

- You may freely distribute the URL identifying the publication in the public portal. please follow below link for the End User Agreement:

www.umlib.nl/taverne-license

Take down policy

If you believe that this document breaches copyright please contact us at:

repository@maastrichtuniversity.nl

providing details and we will investigate your claim.
}

Copyright and moral rights for the publications made accessible in the public portal are retained by the authors and/or other copyright owners and it is a condition of accessing publications that users recognise and abide by the legal requirements associated with these

- Users may download and print one copy of any publication from the public portal for the purpose of private study or research.

- You may not further distribute the material or use it for any profit-making activity or commercial gain

If the publication is distributed under the terms of Article $25 \mathrm{fa}$ of the Dutch Copyright Act, indicated by the "Taverne" license above, 


\section{Antibiotic Resistance and the Commensal Flora}

Role of the commensal flora in the development and spread of antimicrobial resistance 
(6) Sita Nys, Genk 2005

ISBN $90-9019752-4$

Production: Datawyse, Maastricht, The Netherlands 


\title{
Antibiotic Resistance and the Commensal Flora
}

\author{
Role of the commensal flora in the development and spread of \\ antimicrobial resistance
}

\section{PROEFSCHRIFT}

Ter verkrijging van de graad van doctor

aan de Universiteit Maastricht, op gezag van de Rector Magnificus, Prof, mr. G.P.M.F Mols, volgens het besluit van het College van Decanen, in het openbaar te verdedigen op vrijdag 9 september 2005 om 16,00 uur door Sita Sabine Margaretha Nys 


\section{Promotor}

Prof. dr. CA Bruggeman

\section{Co-promotor}

Dr. EE Stobberingh

\section{Beoordelingscommissie}

Prof. dr. GJ Dinant (voorzitter)

Prof. dr. ir. PA van den Brandt

Dr. J Fiolet

Prof, dr. J Scheres

Prof. dr. J van der Zee

Financial support by ZonMW [Project number 97-1-104], De Stichting Werkgroep Antibioticabeleid (SWAB) and Brasserie Oriënt, Genk (België) is gratefully acknowledged. 

Chapter 1 General Introduction \& Outline of the Thesis.

Chapter 2 Erythromycin resistance in the commensal throat flora of patients visiting the general practitioner: a reservoir for resistance genes for potential pathogenic bacteria.

International Joumal of Antimicrobial Agewts (Available online 15 June 2005)

Chapter 3 Antibiotic resistance of faecal $E$. coll in healthy volunteers of nine developing countries.

Joumal of Antimicrobial Chemotherapy (2004) 54,952-955

Chapter 4 Effect of hospitalization on the antibiotic resistance of fecal

Enterococcus faecalis of surgical patients over time.

Microbial Drug Resistance (2005) 11(2), 154-158

Chapter 5 Acute uncomplicated lower urinary tract infections in general

practice: clinical and microbiological cure rates after three versus five day treatment with trimethoprim; a randomized-controlled trial. Accepted for publication in European Journal of General Practice

Chapter 6 Urinary tract infections in general practice patients: diagnostic tests versus bacteriological culture.

Subnitted in Journal of Antimicrobial Chemotherapy

Chapter 7 Acute uncomplicated urinary tract infections in community-. dwelling elderly females: care as usual of the general practitioner and antimicrobial resistance.

Submitted in Clinical Microbiology and Infection

Chapter 8 General Discussion \& Summary.

Nederlandse Samenvatting

Dankwoord

Carriculum vitue

List of Publications 
ARI

ATC

bp

$\mathrm{cfu} / \mathrm{ml}$

CLSI

DDD

DNA

erm

GI-tract

GP

mef

MIC

MLS

mRNA

NCCLS

$\mathrm{NHG}$

NIVEL

NPV

PCR

PFGE

PPV

RIVM

RUTI

SWAB

UTI

WHO acute respiratory tract infection

Anatomic Therapeutic Chemical

base pair

colony forming units per milliliter

Clinical and Laboratory Standards Institute

defined daily doses

deoxyribonucleic acid

erythromycin ribosome methylase

gastro-intestinal tract

general practitioner

macrolide efflux

minimal inhibitory concentration

macrolide, lincosamide, streptogramins

messenger ribonucleic acid

National Committee of Clinical Laboratory Standards

Dutch College on General Practitioners

Netherlands Institute for Health Service Research

negative predictive value

polymerase chain reaction

pulsed-field gell electrophoresis

positive predictive value

The national Institute of Public health and the Environment recurrent urinary tract infections

The Dutch Foundation of the Working Party on Antibiotic policy urinary tract infection

World Health Organization 
$\therefore \quad \therefore \quad \therefore$ 


\section{Chapter 1}

General Introduction \& Outline of the Thesis 
CHATE I 


\section{The commensal flora}

The human commensal flora comprises all the natural bacteria that live in and on a healthy person. This commensal flora is exceedingly complex and consists of more than 500-1000 different bacterial species. ${ }^{1,2}$ Little is known about the associations between humans and their normal flora, but they are thought to be dynamic interactions rather than associations of mutual indifference. Both host and bacteria are considered to derive benefit from each other, and the associations are mostly mutualistic. The host obtains from the normal flora certain nutritional benefits, stimulation of the immune system and colonization strategies that exclude potential pathogenic micro-organisms at the site, called colonization resistance. ${ }^{3-5}$ The bacteria on the other hand derive from their host a supply of mutrients, a stable environment, a constant temperature, and protection. For these reasons, different commensal bacteria are located at specific anatomical colonization sites. Within one host, e.g. humans, variation in the commensal microorganisms has been observed related to factors as age, ${ }^{6}$ gender and dietary factors. However, within limits of these fluctuations, the bacterial flora of humans is sufficient constant to give a general description of the situation. The normal human flora comprises of about $10^{4}$ bacteria/ $/ \mathrm{cm}^{2}$ on the skin, $10^{10}$ bacteria/ml inhabit the upper respiratory tract and $10^{14} \mathrm{cfu} / \mathrm{ml}$ colonize the gastro-intestinal tract (GI-tract). The fatter two reservoirs which are those with the largest body surface area $^{7}$ will be explained below in more detail.

\section{The respiratory tract}

The respiratory tract of a human being can be divided into two parts: the upper and the lower respiratory tract. The lower respiratory tract is essentially sterile. The upper respiratory tract on the other hand, is coated with a biofilm containing many different bacterial species. Among these are potential pathogens like Streptococcus pyogenes and Streptococcus pnetumoniae, but also many harmless streptococci and other species. The upper respiratory tract forms a barrier preventing microbes from reaching and colonizing the lower respiratory tract. The resident commensals, like alpha-hemolytic throat streptococci have been shown to inhibit growth of potentially pathogenic bacteria present in the same area." Among these resident commensals inhabiting the nasopharyngeal area are the viridans group streptococci which colonize the mouth and throat area ${ }^{9,10}$ and are able to inhibit the adherence of other bacteria to the mucosal surfaces through the production of specific proteases. "Streptococcus pneumoniae, the infecting agent in for example community-acquired pneumoniae ${ }^{12}$ and otitis media, ${ }^{13}$ is another common colonizer of the mouth and throat area. Pneumococcal disease however is caused when the host-bacterium balance is disturbed for example in patients with an impaired immune system due to illness. Streptococcus pyogenes, the etiological agent of acute streptococcal pharyngitis ${ }^{112}$ and necrotizing fasciitis, ${ }^{14}$ is a natural inhabitant of the 
humati throat as well which can easily move to the site of infection and from there spread to other parts of the body.

The commensal bacteria are equally affected by antimicrobial treatment as pathogenic bacteria and the selective pressure for the development of antibiotic resistance will, thus be as great among the commensal flora as among pathogens. Therefore, the commensal throat flora is considered a large reservoir of resistance (genes) from where these genes might be transferred to (potentially) pathogenic bacteria. ${ }^{15}$ Monitoring the prevalence of antimicrobial resistance (genes) in the commensal throat streptococci is a good indicator for the resistance that might be present in (potentially) pathogenic micro-organisms of the respiratory tract.

\section{The gastro-intestinal tract}

The human and its gastro-intestinal micro-flora are inevitably linked. About $10^{14}$ bacteria per gram feces inhabit the human alimentary tract, ${ }^{5}$ which is about tenfold greater than the total number of host eukaryotic cells in the human body. The human Gl-tract offers a relatively non-hostile enviromment with an abundance of nutrients for the residling bacteria. Along the tract, the luminal milieu varies per envirommental niche resulting in the presence of aerobic, facultative anaerobic and/or anaerobic microorganisms. ${ }^{16}$ Likewise, the human host benefits from products of the bacterial metabolism such as short-chain fatty acids and from the contributions that the bacterial flora makes to the immune and non-immune host defense.'

More than 500 bacterial species colonize the GI-tract and all of these enter the tract via the mouth with swallowed food. ${ }^{16}$ Hardly any bacteria $\left(10^{3} / \mathrm{ml}\right.$, mostly lactobacilli) can be found in the gastric fluid due to low pH and the presence of proteolytic enzymes which kill most ingested micro-organisms. ${ }^{1,2}$ The proximal small intestine has a bacterial flora of $10^{5}-10^{7}$ bacteria/ml, consisting mainly of lactobacilli and enterococci. The distal part of the small intestine on the other hand contains greater numbers of bacteria $\left(10^{8} / \mathrm{ml}\right)$ and additional species including coliforms and Bacteroides spp. The large intestine contains a high density of living bacteria, which achieve concentrations up to $10^{12}-10^{14}$ cells/g of luminal content.' Anaerobic bacteria outnumber aerobic bacteria by actor of 100-1000. Pre-dominant genera in the human intestinal flora are among others the Bacteroides, Bifidobacterium, and Clastridum species. Aerobes (facultutive anaerobes) such as Escherichia coli, Enterobacter spp., Enterococcus spp., Klebsiella spp. Lactobacillus spp., Proteus spp. and others are among the sub-dominant Hora." 2

Even thougli representing the sub-dominant species of the gut flora, these (facultative) aerobes and more specific the most common species among them, i.e. $E$. colf and enterococci, ${ }^{\text {t6 }}$ are considered good indicator bacteria to study the prevalence of antimicrobial resistance in the normal flora of healthy volunteers. 17 


\section{Antibiotic use}

Antibiotics are widely used in humans to treat and prevent infections. The principal goal of the antibiotic use in the treatment of infections is eradication of the pathogen as quickly as possible with minimal adverse effects on the host. ${ }^{\text {is }}$ Most antibiotic prescriptions $(\sim 80 \%)$ in the developed countries are from the community, ${ }^{1 \% 20}$ espacially from general practitioners (GPs). In most parts of the world beta-lactam agents play a major role, but sulphonamides (with or without trimethoprim), macrolides, lincosamides and streptogramins (the MLS-group), fluoroquinolones, tetracyclines, aminoglycosides and glycopeptides are also widely used, some in the community and some mainly in hospitals. ${ }^{18.22 .23}$ In addition, it has been repeatedly demonstrated that $30-60 \%$ of the use of antimicrobial agents is inappropriate, with consequent waste of resources. ${ }^{24}$

Antibiotic use in the community is important as it is a risk factor for the development of antibiotic resistance not only outside the hospital setting but also for the spread into the hospital. Nevertheless, international and world-wide studies on antibiotic prescriptions and sales as well as international comparisons of the antibiotic use have only been performed the last decade (Figure 1). ${ }^{22,23,25,26}$ To make such comparative studies possible the data should be classified according to the Anatomic Therapeutic Chemical classification system ${ }^{27}$ and expressed in defined daily doses (DDD, a unit based on the average daily dose used for the main indication of the drug in adults).

In the studies of Cars et al., ${ }^{22}$ Rönning et al., ${ }^{23}$ and Goossens et al. ${ }^{26}$ who compared nonhospital antibiotic use data in 15,18 and 26 European countries respectively, a large variation in the antibiotic use between the different countries was found as well as large percentages of inappropriate antibiotic use in many countries. However, these studies did find that the antibiotic prescription rate in general practice in The Netherlands is very low. The antibiotic use in The Netherlands will be discussed in more detaill further in this paragraph.

To obtain comparable data on antibiotic use, antibiotic sales and the effectiveness of the antibiotic use in developing countries is even harder than in the industrialized countries. There are several reasons for this. In most developing countries antibiotics can be purchased without a prescription of a physician. Furthermore, prescriptions made by physician are not always appropriate due to a lack of well-educated health care workers. ${ }^{28}$ Continuing medical education is time consuming and it involves great expenses. In addition, antibiotics are readily available from drugstores and roadside market stalls without any control. ${ }^{29}$ These unofficial sources are generally more accessible than officiall ones (hospital pharmacies). Also, medicines can be bought in these drug outlets per tablet or capsule rather than in complete (5-, 7- or 10-day) courses because many drugs are expensive. ${ }^{30}$ When the prescribed drugs are out of stock an (inappropriate) altemative drugs is sold by the unqualified drug sellers. Furthermore, when symptoms disappear treatment is discontinued by the patient and left-over capsules will be saved for self-medication when another infection is suspected. These 
factors all make it very hard to perforn studies in developing countries on the relation between amtibiotic use and antibiotic resistance. Some of the limited data that are avallable on antibiotic use in some of the developing countries will be discussed at the end of this section.

Figure1. The comparison of antibotic use in the non-hospital setting of 15 European countries.

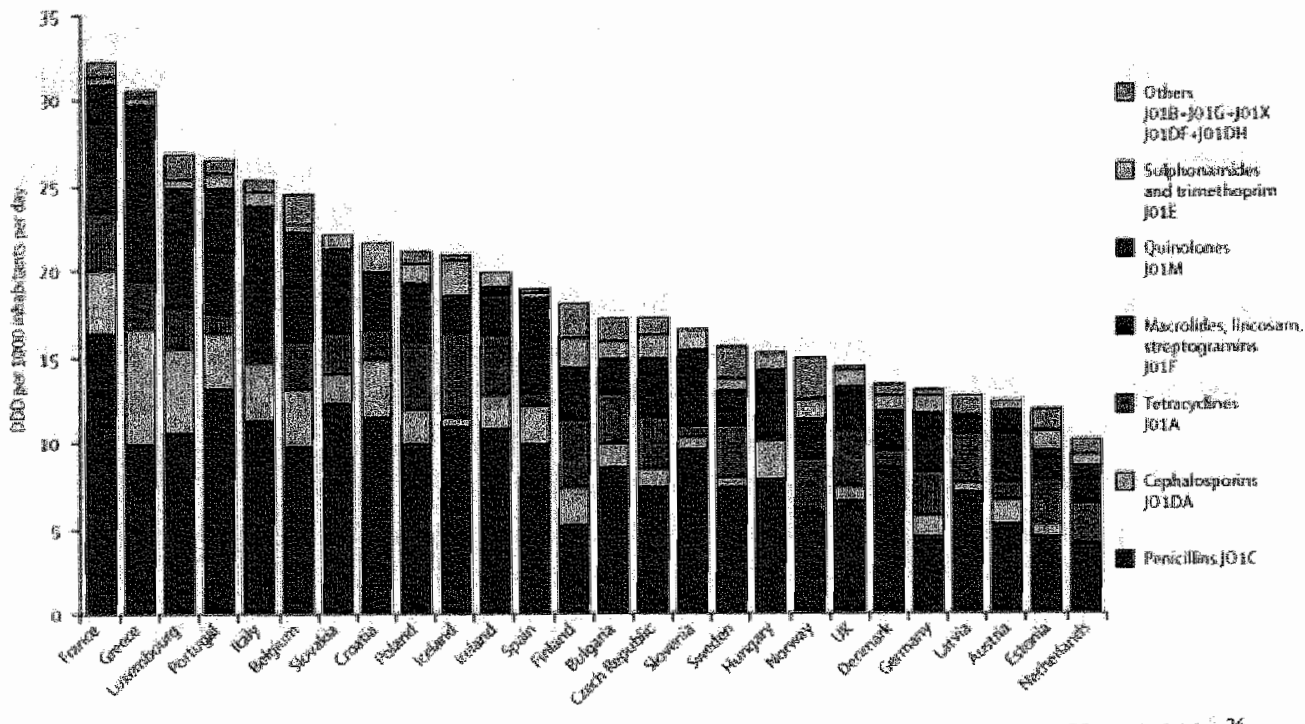

From Goossens Het al. $2005^{26}$

\section{The Netherlands}

The use of antimicrobial agents in human medicine can be divided in extramural antibiotic use, e.g. the antibiotic use in the community mainly by the GPs and intramural antibiotic use in hospitals and nursing homes. Of the total human consumption of antimicrobial agents, $\sim 80 \%$ is prescribed in the community ${ }^{19-21}$

In the annual report (NethMap 2004) of the Dutch Working Group on Antibiotic Policies (SWAB) ${ }^{25}$ the consumption of antimicrobial agents in primary health care (1998-2002) as well as the hospitals use (1998-2001) has been described. The total antibiotic use in the community bas remained almost constant during this period of time. Tetracyclines (mainly doxycycline) together with penicillin with extended spectrum (amoxicillin), combinations of penicillins with beta-lactam inhibitors (co-amoxiclav) and macrolides were the agents mostly prescribed in the community in 2002 . In the hospitals on the other hand the total amount of antibiotics used increased from 47.8 DDD per 100 patient days in 1998 to $54.7 \mathrm{DDD} / 100$ patient days in 2001 . All penicillins combined represented more than half of all hospital antibiotic use in 2001 in The Netherlands. 


\section{Developing Countries}

Approximately 4 billion people, or $80 \%$ of the total global population, live in developing areas of the world ${ }^{31}$ and these countries suffer enomously from the burden of infectious disease. However, the per capita drug expenditure is much lower because the per capita income in these countries is much lower ${ }^{29}$ as compared to the industrialized countries. According to the WHO developing countries spend up to $40 \%$ of their total health care budget on drugs vs. $11 \%$ in the developed nations. ${ }^{31}$

A study on the availability of antibiotics ${ }^{32}$ and the antibiotic prescribing pattern ${ }^{33}$ in Ghana showed that the antibiotics most commonly available (co-trimoxazole, metronidazole, tetracycline, penicillin $\mathrm{V}$ and amoxycillin) were also the least expensive ones. In a household and drugstore survey in $\mathrm{Mexico}^{34}$ the most frequently purchased agents were amino-penicillins, neomycin, natural penicillins (penicillin $\mathrm{G}$ ) and tetracyclines, the latter two most frequently without a prescription. Also in a study from Manila, the Philippines, ${ }^{30}$ the majority of antibiotics $(66 \%)$ were purchased without a prescription and again the agents most frequently sold were amino- and natural penicillins. Furthermore a Nigerian study showed that almost half of the samples tested $(\mathrm{n}=581)$ did not contain the appropriate amount of active ingredient. ${ }^{35} \mathrm{~A}$ recent surveillance in Kenya monitoring the overall antimicrobial use over a 5 year period (1997-2001) described that the mean yearly national antibiotic use in humans, obtained from import licenses and manufacturers' records, during this 5 year period was 20.21 DDD/1000 inhabitants/day. ${ }^{36}$ As this number includes all drugs for both the use in the community and the hospitals in Kenya it can not be compared to the data in Europe as the latter studies express their hospital antibiotic use in DDD/100 patient-days. Penicillins, tetracyclines, and trimethoprim again were the agents mostly used.

Thus although there are (limited) data avallable on the antimicrobial use in the developing countries most of them report only the agents prescribed most, but hardly any data on the DDD/1000 inhabitants/day were found, excepted for one study in Kenya. ${ }^{36}$ So, no trends in consumption or sales could be detected nor could a comparison be made with the data in the European countries.

\section{Antibiotic resistance}

Bacterial resistance to antimicrobial agents is an important obstacle for the successful treatment of bacterial infections, leading not only to treatment failure, but also to prolonged morbidity and even mortality. ${ }^{37}$ Resistance is considered to be present if bacteria are not susceptible to a clinically relevant concentration of an antibiotic and/or the bacteria possess a mechanism or property which will render the antibiotic ineffective. Bacteria can be intrinsically resistant or unsusceptible which means that a whole species or genus of bacteria is not susceptible to a particular drug. A bacterium of 
a nomally susceptible species to a certain antimicrobial agent might become resistant to this agent by mutation ${ }^{33}$ or acquisition of new exogenous genes which is called acquired resistance. ${ }^{39-42}$ Antibiotic resistance due to chromosomal mutations could occur spontaneously in replicating bacteria due to the imperfect fidelity of DNA replication, and is therefore not influenced by the presence of antimicrobial agents. Resistance by the acquisition of new exogenous genes on the other hand, refers to the prior existence of a resistance gene in a reservoir that is acquired by another bacterium ${ }^{43}$ through transformation, transduction or conjugation. ${ }^{44}$

Once resistance has occurred in a few bacteria of a population they might be selected for when the conditions in the environment change in their benefit. Furthermore, once established in a population these resistant bacteria and their resistance genes might be spread throughout different populations. Mechanisms by which resistance emerges and the selection, dissemination, and transfer of resistance (genes) will be further described below. Resistance present in the commensal flora and surveillance of antibiotic resistance are enlightened as well.

\section{Resistance mechanisms}

Resistance genes, acquired exogenous genes or chromosomal mutations resulting in new resistance genes, in turn give rise to several biochenical mechanisms. These mechanisms include among others reduced permeability of the bacterial cell by alteration or elimination of the entry port (aminoglycosides), pumps that actively export the antimicrobial agent out of the bacterial cell (tetracyclines, fluoroquinolones), and alteration or inactivation of the drug target (erythromycin, tetracyclines, fluoroquinolones) or the drug itself (aminoglycosides, chloramphenicol, beta-lactams) by degrading or chemically modifying enzymes. ${ }^{37,41,45}$

\section{Selection by antibiotic use}

At any point of time a minority of strains resistant to a certain antibiotic may be present in a population. Whether these resistant strains survive and replicate in this population clepends on the selective pressure placed on them. ${ }^{40}$ Mostly they disappear as spontaneously as they have emerged. Due to increasing antibiotic use susceptible bacteria will be eliminated and the resistant ones will proliferate at the expense of the susceptible strains and the majority of the population will become resistant. ${ }^{46}$ However, susceptible bacteria might be reintroduced after disappearance of the selective pressure of the antibiotic use for two reasons: introduction of new susceptible strains from the enviromment and because resistant bacteria are less 'fit'. ${ }^{47,48}$ Small numbers of resistant strains will remain present, certainly after repeated exposure to antibiotics. This means that antibiotic use will cause a rise in the number of resistant bacteria in the endogenous flora of exposed individuals and populations. ${ }^{15}$ These (resistant) commensal bacteria in 
an individual or a population form a large reserwoir of resistance genes which consequently increases the risk of transfer of their resistance genes to (potentially) pathogenic micro-organisms:

\section{Dissemination of antibiotic resistance}

Next to the selection of antibiotic resistant bacteria, the dissemination of these resistant strains and their resistance genes is a very important factor in the spread of antimicrobial resistance. There are two different aspects of dissemination that may lead to colonization with drug-resistant bacteria or transfer of resistance genes to the commensal flora. First, dissemination can be caused by direct contact between individuals. For indireet dissemination a third party is involved in the process of the spread of resistance. For example among inpatients this spread might occur via healthcare workers or medical equipment in hospitals. ${ }^{43,50-52}$ In turn, resistance acquired in the hospital might be spread into the community after discharge of the patient and vice versa, resistance obtained by a patient in the community might be introduced into the hospital after admission. ${ }^{21}$ In addition, increasing international travel provides great opportunities for both pathogenic and non-pathogenic antibiotic-resistant strains to be carried over long distances to other cotntries, thus further aiding the dissemination of resistant bacteria. ${ }^{53-55}$

Other factors influencing the spread of antibiotic resistant bacteria or resistance genes from one host to another are high population density (crowding in nursing homes, day care centers, hospitals, large cities), ${ }^{37,56,57}$ high antibiotic use (hospital settings), use of inappropriate antimicrobial agents and poor hygiene and sanitary facilities as well as drugs of substandard quality (developing countries) ${ }^{29,43,53,54,58,59}$ and antibiotic use in animals via the food chain. ${ }^{43,53}$

\section{Transfer of resistance}

Resistance genes, located on the bacterial chromosome or on plasmids, can transfer by conjugation to other bacteria and even to other species. The resistance genes found on plasmids (R-plasmids) are embedded in small, mobile DNA units called transposons which can easily hop within one bacterium between the plasmid and its chromosome and even from bacterium to bacterium. ${ }^{38,42,45,40}$ The potential for the spread of resistance is related to the bacterial host ranges of these transposons, their efficiency of transfer * and the ballance of their particular advantageous and disadvantageous properties. ${ }^{42,43}$ Transfer of resistance (genes) has been described between bacteria belonging to the same species and between micro-organisms of different species as well. ${ }^{5}$ Also, resistant bacteria from animal origin may transfer their resistance genes either to bacteria pathogenic for humans or to the commensal flora of humans through direct contact (for example with pet animals) or indirectly through meat products. ${ }^{49}$ 
Many mobile antibiotic resistance elements encode multiple resistance determinants which provides selective advantages to bacteria in a broad range of clinical settings: ${ }^{43}$

\section{Antibiotic resistance in the commensal flora}

In general, potentially pathogenic bacteria differ little in their basic cellular biology from commensal bacteria. These fundamental cellullar processes, like transcription of the mRNA through ribosomes or the cell wall assemblage, are targets of classical antimicrobial agents. ${ }^{60}$ This results in the elimination of both the benign commensal bacteria at the pathogens by antimicrobial therapy. ${ }^{60}$ So, administration of antimicrobial agents prescribed for the treatment of infections can cause disturbances in the ecological balance between the host and its endogenous micro-organismis. The incomplete absorption of orally administered drugs for example or the secretion of an antimicrobial agent into the intestinal lumen maintain the presence of a low-dose antibiotic pressure which can influence the intestinal micro-flora at different habitats. As a consequence, antibiotic resistant bacteria in the normal flora may increase in numbers ${ }^{3}$ and constitute an enormous reservoir of resistance genes for (potentially) pathogenic bacteria, ${ }^{5,50}$ the latter being considered only the "tip of the resistance iceberg, "Moreover, the level of resistance in the normal flora is considered a good indicator for the selection pressure exerted by antibiotic use in that population. ${ }^{17,61}$

Investigation of the prevalence of resistance of certain indicator bacteria like $E$. coli and enterococei in the intestinal tract and streptococci in the respiratory tract of humans makes it possible to compare the prevalence of antimicrobial resistance and resistance genes in different populations and over time. In this way, surveillance studies of antimicrobial resistance in the normal flora can serve as an early warning system for the antibiotic resistance problems to be expected in potentially pathogenic micro-organisms.

\section{Surveillance of antimicrobial resistance}

The aim of survelllance is to monitor the prevalence and degree of antimicrobial resistance and resistance genes being expressed in and transmitted through various populations of microbes. ${ }^{62}$ Surveillance of antimicrobial susceptibility will therefore improve empirical antimicrobial treatment in both the community and the hospital. Furthermore, surveillance studies will guide antimicrobial policy makers and all those involved in the use of antibiotics. In addition, these studies will monitor prospectively the activity and the usefulness of available agents, identify resistance problems and monitor changes in resistance patterns and track the spread of significant resistance patterns. ${ }^{44}$ These surveillances can either be carried out to detect differences in the resistance prevalences of clinical isolates or in the prevalence of resistance in the endogenous flora of different populations. It is widely considered that most infections in a population result from the commensal flora carried within a population. ${ }^{63}$ Moreover, 
resistant bacteria of the normal flora not only constitute an enormous reservoir of resistance genes for (potentially) pathogenic bacteria, but also the level of resistance in the endogenous flora is considered to be a good indicator for the selection pressure exerted by antibiotic use on a population and for resistance problems to be expected in potential pathogens. ${ }^{17,61}$

\section{Urinary tract infections}

An acute uncomplicated urinary tract infection (UTI) is one of the most common infections in women ${ }^{64}$ and is characterized by the presence of dysuria, frequent and/or urgent urination and pyuria alone or in combination. ${ }^{65}$ An acute uncomplicated UTI occurs primarily in healthy, pre-menopausal, non-pregnant women with an apparently normal urinary tract. It is estimated that 1 out of 3 women of 24 years of age has experienced at least one UTI episode and as many as $60 \%$ of women report having had a UTI in their lifetime. ${ }^{66,6 \%}$ Approximately $44 \%$ of the patients will experience at least one recurrence in the $\mathbb{2}$-month follow-up after the index UTI. ${ }^{68}$

Most uropathogens originate from the commensal gut flora ${ }^{69}$ and enter the bladder in an ascending route via the urethra with an interim phase of per-urethral and distal urethral colonization. ${ }^{64,70}$ Vaginal colonization is a prerequisite to bladder infection and factors that increase the risk of UTl generally do so in part by facilitating vaginal colonization. In the majority of the acute uncomplicated community acquired UTIs Escherichia coli is the most likely candidate bacterium as uropathogen. ${ }^{7173}$ The remaining uropathogens include Staphylococcus saprophyticus, mainly in young, healthy female patients, Enterococcus faecalis, and Proteus spp. ${ }^{74}$ Klebsiella spp, Pseudomonas spp, and Enterobacter spp. are less frequent causes of an acute uncomplicated UTI.

\section{Management of urinary tract infections}

An acute uncomplicated urinary tract infection is usually empirically treated by the GP based upon the complaints of the patient without urine culture or susceptibility testing. ${ }^{n}$ The GP can additionally perform a urinary dipstick test, ${ }^{65}$ i.e. the nitrite and leukocyteesterase tests, directly on the urine and the result will predict or rule out a UTI. This method has replaced microscopy because it is fast, cheap and very convenient for the GP. A positive mitrite test performed on fresh urine can almost certainly predict a UTI whereas a negative nitrite tests does not rule out a UTI. However, a negative nitrite test combined with a negative leakocyte-esterase tests does rule out the presence of a UTJ in the majority of the cases. ${ }^{75}$

In the Netherlands for the treatment of acute uncomplicated UTIs trimethoprim and nitrofurantoin are the drugs of choice according to the guidelines of the Dutch College on General Practitioners (NHG) ${ }^{75}$ and preferably prescribed as a 3 -day course of $3 \mathrm{DD}$ 
and 1 DD respectively for nitrofurantoin $(100 \mathrm{mg}$ ) and trimethoprim $(300 \mathrm{mg})$. In case of recurrent UTT another agent is chosen and therapy will be preceded by culture and susceptibility testing.

\section{Recurrent urinary tract infections}

Approximately $45 \%$ of the patients suffering from a UTI will experience one or more recurrent infections in the year following the index UTI ${ }^{68}$ A recurrent UTI (RUTI) is defined as 3 or more symptomatic UTIs in the past year or 2 such episodes in the past 6 months. ${ }^{76}$ RUTHs form a substantial burden for the health-care system in terms of costs, sick leave, and morbidity. ${ }^{77}$ In most cases, women suffering from RUTIs will receive low-dose prophylactic antimicnobial regimens for several months. This strategy consists of daily or thrice-weekly subtherapeutic doses of an antimicrobial agent effective for the treatment of an established. UTI. ${ }^{76.77}$

A study on host risk factors predictive of RUTIs in young women (18-30 years) found that botli maternal history of UTIs and childhood onset of eystitis were associated with 2-4 fold increased risk for RUTIs. This suggest that (inherited) genetic factors may be important in women with recurrent infections. ${ }^{76}$ Furthermore, sexual intercourse; intercourse frequency, and contraceptive exposure were also associated with RUTIs.

\section{Urinary tract infections in the elderly}

It has been shown that the frequency of bacteriuria increases with advancing age for both men and women. ${ }^{7 \%}$ Also, the prevalence of bacteriuria is very high in the more impaired elderly who require institutional care because of functional deficits and coexisting illnesses. ${ }^{78}$ The contributing factors for bacteriuria in the non-institutionalized elderly women include loss of the estrogen effect on the genitourinary mucosa and the depletion of vaginal colonization of Lactobacilli, ${ }^{80}$ increased residual urine, and genitourinary abnormalities such as cystocoeles, rectocoeles and bladder diverticula.

The etiology of UTIS in the elderly is in general distinct from that in younger women. $E$. coli, still the most prevalent uropathogen in these women, is proportionally less frequent detected, ${ }^{79}$ but more Protens spp. and Klebsiella spp. can be found.

\section{Antibiolic resistance in uropathogens}

As with many community-acquired infections, antimicrobial resistance among pathogens that cause conmunity-acquired acute uncomplicated urinary tract infections is increasing. 81.82 Many sudies on the antimicrobial susceptibility of community acquired uropathogens however repont data from selected isolates, i.e. isolates derived from urine specimens send to the laboratory by the general practitioner after prior treatment failure or after recurrent UTI episodes. As a consequence, the antibiotic 
susceptibility percentages determined for those "selected" uropathogens will be lower. ${ }^{83.84}$ However for the empiric treatment of acute uncomplicated UTIs it is important for the GP to have actual data on the susceptibility of "unselected" uropathogens.

Trends for reduced antibiotic susceptibility of $E$. coli both world-wide as well as in the Netherlands have been described. For instance resistance for beta-lactans such as ampicillin and first generation cephalosporins increased in the past decade and now approaches $40 \%$ in the US. ${ }^{81,82}$ In Europe however, a recent study showed that the resistance percentages of $E$. coli for ampicillin ranged from $\sim 20 \%$ in the North to $-50 \%$ in the Western and Southern countries. ${ }^{85}$ Nitrofurantoin has retained in witro activity against most uropathogenic $E$. coli isolates world-wide. ${ }^{81,82,85,86}$ Trimethoprim+\% sulfamethoxazole underwent the most substantial change over time and approached $\sim 20 \%$ in the US in the late nineties. ${ }^{82,86,87}$ In Europe also for this agent an increasing trend was observed ranging from $5-10 \%$ in the North to $15-20 \%$ in the Southern countries. ${ }^{85}$ Resistance to fluoroquinolones remained low in community-acquired isolates ${ }^{82,86}$ However in 2003 in Spain it has reached $15 \%$ in the $E$. coli isolated from UTIs. ${ }^{8.5}$ 


\section{Aims of the study}

The last decades an increase in antibiotic resistant bacteria has been observed worldwide. Most studies on antimicrobial resistance however, did focus on the increasing antibiotic resistance of elinical isolates, i.e. bacteria isolated as causative agents of an anfection. Little is known on the prevalence of antimicrobial resistance of bacteria that belong to the human commensal flora.

Therefore, in this thesis the prevalence of antimicrobial resistance and the influence of a variable selective pressure on the prevalence of resistance of the commensal flora was determined. The studies focused on the respiratory tract and the gastro-intestinal tract as a reservoir of antibiotic resistant micro-organisms and the urinary tract as site of infections caused by (resistant) micromorganisms of the latter reservoir.

For the respiratory traet the prevalence of macrolide resistance among commensal throat streptococci was determined. In addition, the genes encoding for this resistance were characterized and the ability to transfer the resistance gene involved (ermB) was assessed. Transfer of resistance was studied in an in vitro model mimicking the in who situation of close contact.

The influence of the selective antibiotic pressure on the prevallence of antimicrobial resistant faecal E. coli was studied in the gastro-intestinal tract of healthy volunteers in several developing countries in Latin-America, the Sub-Saharan Africa and Asia. The resistance prevalence was compared between urban and non-urban populations for both the Eastern and Western hemisphere.

Furthermore, the influence of hospitalization, i.e. high antibiotic use and crowding of patients on the prevalence of antibiotic resistance in faecal Enterococcus faecalis isolates of patients after discharge was assessed in three university-affiliated hospitals in The Netherlands. Antibiotic resistance acquired by the patient during hospital stay might be disseminated into the community after discharge from the hospital. Therefore, this acquired resistance is a risk for an increase in the prevalence of resistance in the extramural situation, i.e. the commensal flora of people residing in the community.

The human gastro-intestinal tract serves as reservoit of micro-organisms causing urinary tract infections (UTIs) through the ascending route. The antimicrobial resistance present in these commensal faecal bacteria poses a risk for antibiotic resistant uropathogens. "Therefore, the prevalence of antimicrobial resistance in unselected $E$. coli isolates from female patients with complaints of an acute uncomplicated UTT of all ages was determined. These data are important for the setup of national guidelines for the empiric treatment of urinary tract infections. 


\section{Outline of the Thesis}

In this thesis several aspects of the role of the commensal flora in the development and spread of antimicrobial resistance have been enlightened. In Chapter 1, the Genenal Introduction, a description of the human commensal llora and more specific the most prevalent micro-organisms of the normal flora of the respiratory and gastro-intestinal tract was given. Furthermore, surveillances of antibiotic use in European and developing countries were described. In addition, several features of antibiotic resistance were discussed. Finally, as urinary tract infections are caused by ascending bacteria from the gut the etiology and the managenent of UTIs together with some characteristics of recurrent UTIs and antimicrobial resistance in uropathogens were described.

As part of an ongoing national surveillance study of acute respiratory tract infections (the ARI-EL study) the prevalence of macrolide resistance was determined in the commensal throat flora for the period October 2000 till December 2002 (Chapter 2). In addition, the transfer of macrolide resistance genes from commensal streptococi to a potential pathogenic bacterium was studied in vitro.

Besides the respiratory tract, the gastro-intestinal tract forms a second large reservoir of commensal bacteria and very likely thus antimicrobial resistance (genes). To assess the magnitude of this reservoir in circumstances that provide a variable antibiotic selection pressure a study was conducted in uine different developing countries, i.e. Mexico, Peru, Venezuela, Curaçao, Ghana, Tanzania, Zimbabwe, Kenya and The Philippines (Chapter 3). The populations in these countries live close together, have poor hygienic and sanitary facilities and in most countries there is no defined antibiotic policy which all contributes to the selection and dissemination of antibiotic resistance within these populations. Therefore, the prevalence of antibiotic resistance of faecal Escherichia coli isolated from healthy volunteers living in urban and rural areas of these nine developing countries was determined.

The hospital environment is another setting with a high selective pressure for resistance, i.e. high antibiotic use and crowding of patients. Therefore the effect of hospitalization on the prevalence of antibiotic resistance in the gut flora of patients admitted to the surgical wards of three university-affiliated hospitals in The Netherlands was followed in time from admission to six month after discharge in order to measure the effect of a hospital stay after discharge, i.e. after disappearance of the selective pressure of the antibiotic use (Chapter 4).

The commensal (resistant) bacteria of the intestinal flora are an important source of micro-organisms able to cause an infection at otherwise sterile body-sites like the bladder. Through the ascending route these commensal gut bacteria, and especially $E$. coli, can reach the bladder and cause urinary tract infections. Urinary tract infections are very common in female patients and several antibiotic treatment regimens of different duration are suited for therapy. Recently some debate has been going on to increase the 
length of treatment from 3 days to 5-7 days. Therefore, in Chapter 5, "Acute uncomplicated urinary tract infections in general practice: self-reported and microbiological cure rates after three versus five day treatment with trimethoprim: a fandomized-controlled trial the differences in cure rate for respectively a three-day and a five-day course of trimethoprim were determined. Trimethoprim resistance in the isolated $E$. coll betore therapy and 1 and 3 days after therapy was compared for both treatment regimens.

The NHG-guidelines for antimicrobial therapy for UTIs empirically prescribed by the general practitioner in The Netherlands are based on national susceptibility data. Most studies on antibiotic resistance in uropathogens howewer, are performed on selected isolates, i.e. isolates send in by the GP for susceptibility testing after prior therapy failure. The prevalence of antibiotic resistance among these selected isolates will probably be higher as compared to that of unselected uropathogens. Therefore, a national study on acute uncomplicated. UTIs has been performed to determine the prevalence of resistance from unselected uropathogenic $E$. coli isolates from female patients of all ages. In female patients between 11-70 years of age the accuracy of the diagnostic tests, i.e. the nitrite and leukocyte-esterase test performed by the general practitioners when an acute uncomplicated UTI was expected, and the prescribing behavior of the GP were evaluated (Chapter 6) and compared with the bacteriological culture results. The antimicrobial susceptibility of the $E$. coll isolates was determined and compared between patients of different age groups. In Chapter 7. Acute uncomplicated urinary tract infections in community dwelling elderly female patients in The Netherlands" urinary tract infections in non-institutionalized elderly women over the age of 70 years were analyzed. The care as usual of the general practitioner, i.e. the performance of the nitrite and leukocyte-esterase tests and the prescription rate, were compared with the bacteriological culture results. Furthermore antimicrobial susceptibilities of the uropathogens most frequently isolated were determined for the different age groups. 


\section{References}

1. Guaner, F. Malagelada, J. R. (2003). Gut thora in health and disease Lowcel 361, 512-519.

2. Tlaskalova-Hogenova; H, Stepankova, R, Hudoovic, T, at at. (2004). Commensal bacteria (normal microflora), mucosal immunity and chronic inflammatory and autoimmune diseseses. Inmunol Lett 93, 97-108.

3. Sullivan, A., Edlund, C. \& Nord, C. E. (2001). Efrect of antimicrobiall agents on the ecological balance of human microflora. Lancet Infect Dis 1, 101-114.

4. Barza, M. \& Trawers, K. (2002). Excess infections due to antimicrobial resistance: the "Attributable Fraction". Clim Lufect Dis 34 Suppl 3, S126-130.

5. Andremont, A. (2003). Conmensal flora may play key role in spreading antibiotic resistance. ASM news 69,601-607

6. Blaut, M., Collins, M. D., Welling, G. W., at al. (2002). Molecular biological methods for studying the gut micrabiota: the EU human gut flora project. Br J Nutr 87 Suppl 2, \$203-211.

7. Bengmark, S. (1998). Ecological control of the gastrointestinal tract. The role of probiotic flora. Gut 42,2-7.

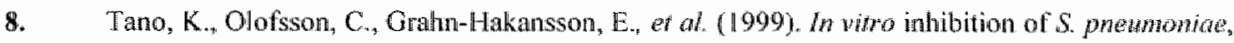
nontypable $H$. influenzas and $M$. cathorratis by alpha-hemolytic streptococci from healtiy children. Int J Pediatr Otorymolaryngol 47, 49-56.

9. Kononen, E., Jousimies-Somer, H., Bryk, A.x of al. (2002). Establisshnent of streptococei in the upper respiratory tract: longitudinal changes in the mouth and nasopharynx up to 2 years of age. J Med Microbiol 51,723-730.

10. Achour, W., Guemi, O., Malbruny, B., et al. (2004). Phenotypic and molecular characterization of macrolide and streptogramin resistance in Streptococcks mitis from neutropenic patienis. of Antimicrob Chemother 54, 117-121.

11. Kirkeby, L., Rasmussen, T. T., Reinholdt, I., er al (2000). Immunoglobullins in nasal secretions of healthy humans: structural integrity of secretory immunoglobulin $\mathrm{Al}(\mathrm{IgA} I)$ and occurrence of neutralizing antibodies to IgA 1 proteases of arasal bacteria. Clin Diagn Lab Immino/ 7, 31-39.

12. Anzueto, A. \& Norris, S. (2004). Clarithronycin in 2003: sustained efficacy and safery in an ent of rising antibiotic resistance. Int J Antimicrob Agents $24,1-17$.

13. Bean, D. C. $\|$ kram, R. B. \& Klena, J. D. (2004). Molecular characterization of penticilin nonsusceptible Sireptococcus pneamonice in Christchurch, New Zealand. 1 Antimicrob Chewother 54, 122-129.

14. Reinert, R. R., Lutticken, R., Bryskier, A.n ef al. (2003). Macrolide-resistant Sheptococcus phetunonicae and Sireptococcus pyogenes in the pediatric population in Germany during 20002001. Antimicrob Agents Chemother 47, 489-493.

15. Jonsson, M., Qvarnstrom, Y., Engstrand, L., et al. (2005). Clarithromycin treatment selects for persistent macrolide-resistant bacteria in throat conmensal flora. Int J Antimicrob Agents 25, 6874.

16. Farthing, M. 1. (2004). Bugs and the gut: an unstable martiage. Best Pract Res Clin Gastroenterol 18, 233-239. 
17. Wan den Bogaran, A. E. (1997). Antmictobial resistance-reliation to human aind anmal exposure to antibiotics. Antwilcrob Chemolher 40,453-454.

18. Phillipis, Lasewell, $\mathrm{M}$, Cox, $\mathrm{T}$, ef al (2004). Does the use of antibiotics in food animals pose

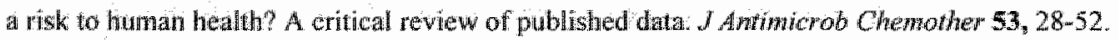

19. Alustu, D. 1., Krisunsson, K. G. Anderson, R. M. (1999). The rellatonship between the wolume of antimicrobial constimption in human commuities and the frequency of resistance. Proc Nat

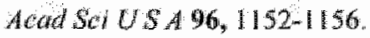

20. Sorensen, T. L. \& Monmet, D. (2000). Control of antibiotic wse in the community: the Danish expertence Infed Control Hosp Exidewitol 21, 387-389.

21. Stobleringh, E. E. De Kaelug, A. \& Rosmalen, C. F. H. (2001). The more you lase it the more you lose in phamaceutich weekblad $136,804-808$.

22. Cars, O., Molstad, S. \& Melander; A. (2001). Variation in antibiotic use in the Furopean Union. Lancet 357, 1851:1853.

23. Ronning; M., Blix, H. S, Strom, H., et al. (2003). Problems in collecting comparable national drug use data in Europe: the example of antibacterials. Er I CHin Phamocol 58, 843-849.

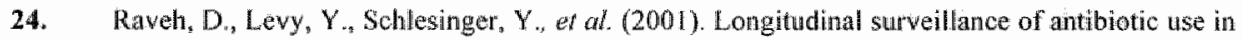
the hospitat. Qim 94, 141-152.

25. SWAB. NothMap 2004-Consumption of antinicrobial agents and antimucrobial resistance among medically important bacteric in the Netherlands.

26. Goossens, H., Ferech, M., Vander Stichele, R., et al. (2005). Outpatient antibiotic use in Europe anc association with resistance: a cross-national database study. Lencet $365,579-587$.

27. ATC (1999). Index whth DDDs. Osllo: WHO Collaborating Centre for Drug Statistics Methodology"

28. Bexell, A., Lwando, E., won Hofsten, B., et al (1996). Improwing drug use through continuing education: a randomized controlled trial in Zambia. J Clin Epidemiol 49, 355-357.

29. Okeke, 1. N., Lamikana, A. \& Edelman, R. (1999). Socioeconomic and behavional factors leading 10 acouired bacterial resistance to antibiotics in developing countries. Emerg Infect Dis 5 , $18-27$

30. Lansang; M. A. Lucas Aquino, R., Tupasi, T. E, ef al (1990). Purchase of antibiotics without prescription in Manila, the Philippines. Inappropriate choices and doses. I Clin Epidemol 43, $61-67$.

31. Isturiz, R. E. \& Carbon, C. (2000). Antibiotic use in developing countries. Imfect Compol Hosp Eprdemol 21, 394-397.

32. Bosu, W. K. \& Mabey, D. (1998). The avaliability and cost of antibiotics for treating PlD in the Certral Region of Ghana and implications for compliance with national treatment guidelines. Wht ISD ADS $9,551-553$.

33. Bosu, W. K. \& Ofon-Acjel, D. (1997), Survey of antbiotic prescribing pattern in govenment healh foilities of the Wassa west district of Ghana. East Afr Med J 74, 138-142.

34. Calwa, 1. B Bojalil, R. (1996). Antibiotic use in a periturban community in Mexico: a housethold and drugstore survey. Sow Sci Hed 42, 1121-1128. 
35. Taytor, R. B., Shakoor, 0 , Behrens, R. H, of al (2001). Pharnacopoeial cuality of drugs supplied by Nigerian pharmacies. Lancet 357, 1933-1936.

36. Mitema, E. S. \& Kikuvi, G. M. (2004). Surveillance of the overall use of antimicrobial drugs in humans over a 5 year period $(19972001)$ in Kenya. I Animicrob Chemother $54,966-967$.

37. Murray, B. E. (1991). New aspects of antimicrobial resistance and the resulting therapeutie dillemmas. Infect Dis 163, 1184-1194.

38. Gold, H. S. Moellering, R. C. Jr: (1996). Antimicrobialladrug resistance. $N$ Engl J Med 335, $1445-1453$.

39. Kummerer, K. (2004). Resistance in the environment. I Antomicob Chenother 54, 31:-320.

40. van den Bogaard, A. (2000). Dissertation: Public health aspects of bacterial resistance in food animals.

41. Davies, J. E. (1997). Origins, acquisition and dissemination of antibiotio resistance determinants. Ciba Found Symp 207, 15-27; discussion 27-35.

42. OBrien, T. F. (2002). Emergence, spread, and environmental effect of sintimicrobial resistance: how use of an antimicrobial anywhere can increase resistance to any antimicrobial anywhere else. Clin Irfect Dis 34 Suppl 3, S78.84.

43. Hooper, D. C. (2001). Minimizing potential resistance: the molecular view-a comment on Courvalin and Trieu-Cuot. Clin Infeot Dis 33 Suppl 3, S157 1 «160.

44. Wise, R. (2004). The relentless rise of resistance? $J$ Antimicrob Chemather 54, 306-310.

45. El-Tahawy, A. A. (2004). The crisis of antibiotic-resistance in bacteria. Saudi Med J 25, 837842.

46. Smith, D. L., Harris, A. D., Johnson, J. A., et al. (2002). Animal antibiotic use has an carly but important impact on the emergence of antibiotic resistance in human commensal bacteria. Proc Natl Acad Sci U S A 99, 6434-6439.

47. Baquero, F., Negri, M. C., Morosini, M. I., et al. (1998). Antibiotic-selective environments. Clin Infect Dis: 27 Suppl 1, S5-11.

48. Cosgrove, S. E. \& Carmeli, Y. (2003). The impact of antimicrobial resistance on health and economic outcomes. Clin Fifect Dis 36, 1433-1437.

49. van den Bogaard, A. E. \& Stobberingh, E. E. (1999). Antibiotic usage in animals: impact on bacterial resistance and public health. Dragg 58, 589-607.

50. Murray, B. E. (1992). Problems and dilemmas of antimicrobial resistance. Pharnacatherapy 12, 86S-93s

51. File, T. M., Jn. (1999). Overview of resistance in the 1990s. Chest 1.15, 3S-8S.

52. Murthy, R. (2001). Implementation of strategies to control antimicrobial resistance. Chesi 119, $405 \mathrm{~S}-411 \mathrm{~S}$.

53. Okeke, 1. N. \& Edelman, R. (2001). Dissemination of antibiotic-pesistant bacteria across geographic borders. Clin finfect Dis 33, 364-369.

54. Anyes, S. G., Tait, S., Thomson, C. J. ef al. (1992). The incidence of antibiotic resistance in aerobic faecal flora in South India. J Antinticrob Chemother 29,415-425.

55. Lewy, S. B. (2001). Antibiotic resistance: consequences of inaction. Clin Iffect Dis 33 Suppl 3 , S124-129. 
56. Wise, $\mathrm{R}$, Hart $\mathrm{T}, \mathrm{Cars}, \mathrm{O}$, et al, $(1998)$. Antimicrobial resistance, Is a major threat to public heralth. Brinj 317, 609-610.

57. Bruinsma, N. Hutchinson, J. M. Van Den Bogaard, A. E., et al. (2003). Influence of population density on antibiotic resistance, $\mathrm{f}$ Antwrycrob Chemother 51, 385-390.

58. Grenet, $\mathrm{K}_{\text {. }}(2004)$. Artibacterial resistance, way ampis anerindians, French guy ana. Ennerg Infect Dis $10,1150-1153$.

59. Bruinsma, N. frilius, P. M. Van Den Bogaard, A E., et al (2003). Hospitalization, a risk factor for antibiotic-resilstant Escherichia coli in the community? I Antimicrob Chemother 51, 1029 . 1032.

6i0. Summers, A. O. (2002), Generally overlooked fundamentals of bacterial genetics and ecology. Clin Infeed Dis 34 Suppl 3, $\$ 85-92$.

61. Lester, S. C., del Pjlar Pla, M., Wang, F, er al. (1990). The carriage of Escherichia coli resistant to antimicrobial agents by healthy children in Boston, in Caracas, Venezuela, and in Qin Pu, China. N Engl I Med 323, 285-289.

62. Masterton, R. G. (2000). Surveillanee studies: how can they help the management of infection? $y$ Antimicrob Chemother 46 Suppl T2, 53-58.

63. Brainsma, N. (2002). Dissertation-Antibiotic Resistance in the Community.

64. Hooton, T. M., Besser, R., Foxman, B., ef al (2004). Acute uncomplicated cystitis in an era of increasing antibiotic resistance: a proposed approach to empirical therapy. Chin Infect Dis 39, 75 80.

65. Fihn, S. D. (2003). Clinical practice. Acute uncomplicated urinary tract infection in women. $N$ Engl J Med 349, 259 -266.

66. Foxman, B. (2002). Epidemtology of urinary tract infections: incidence, morbidity, and economic costs. Am J Med 113 Suppl 1A, 5S-13S.

67. Foxman, B., Barlow, R., D'Arcy, H., et al (2000). Urinary trat infection: self-reported incidence and associated costs. Ann Epidemiol 10, 509-515.

68. Ikaheimo, $R_{n}$ Sitonen, A., Heiskanen, $T$., et al. (1996). Recurrence of urinary tract infection in a primary care seting: analysis of a l-year follow-up of 179 women. Clin Infect Dis 22, $91-99$.

69. Muratani, T, Matsumoto, T. (2004). Bacterial resistance to antimicrobials in urinary isolates. Inv J Animicrob Agense 24 Suppl 1, S28.31.

70. Hooton, T, M, (2000). Pethogenesis of urinary tract infections: ain update. $J$ Antimicrob Chernother 46 Suppll 1, I-7; discussion 63.65.

71. Gupta, K. Hooton, T. M. \& Stamm, W. E. (2001). Increasing antimicrobial resistance and the managenent of uncomplicated community-acquired urinary tract infections. An Intern Med $135,41-50$.

72. Sotelo, T. \& Westney, O. L. (2003). Recurrent urinary tract infections in women. Curr Womens Noolth Rep 3, 313m-318

73. Kaper, J. B. Nataro, I. P. \& Mobley, H. L. (2004). Pathogenic Escherichia coli. Nat Rev Microbial 2, 123-140. 


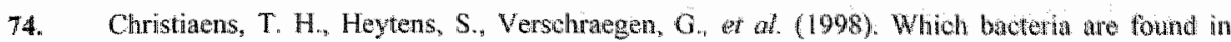
Belgian women whth uncomplicated umary tract infections in primisy heath oare, and what is their susceptibility pattern anno $95-96$ ? Acto Chi Belg 53, $134-188$.

75. Wiersmai, T. I. \& Timmermans, A. E. (2001). [Summary of the "Uninaty tract infections"

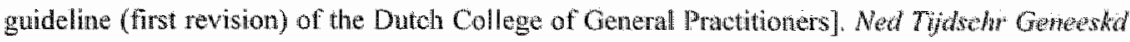
$145,735-739$.

76. Scholes, D., Hooton, T. M., Robents, P. L., et al. (2000). Rishl factors for recurent urinary that infection in young women. J Infect Dis $182,1177-1182$.

77. Stapleton, A. (1999), Prevention of recument urimary-tract infections in women. Lamcet 353, 7-8.

78. Boscia, J. A., Kobasa, W. D. Knight, R. A. et at. (1986). Epidemiology of bacteriuria in an elderly ambulatory population. Am $/ \mathrm{Med} 80,208-214$.

79. Nicolle, L. E. (1994). Urinary tract infection in the elderly. I Antmowob Chemother 33 Suppl A. 99.109

80. Maloney, C. (2002). Estrogen \& recurrent UTI in postmenopausal women. Am $J N_{w h} 102,44-$ 52.

81. Gupta, K., Scholes, D. \& Stamm, W. E. (1999). Imcreasing prevalence of antimichobial resistance among uropathogens causing acute uncomplicated cystitis in women. Jama 281, 736-738.

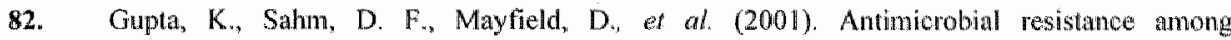
uropathogens that cause community-acquired urinary tract infections in women: an nationwide analysis. Clin Infect Dis 33,89-94.

83. Goettsch, W., wan Pelt, W., Nagelkerke, N. ef al. (2000). Increasing resistance to Muoroquinolones in Escherichia coli from urinary tract infections in the Netherlands. I Antimicrob Chenothen 46, 223-228.

84. Fluit, A. C., Jones, M. E, Schmitz, F. J., et al. (2000). Antimicrobial resistance among trinary tract infection (UTD) isolates in Europe: results from the SENTRY Antimnicrobial Surveillance Program 1997. Antonie Van Leewwenhoek 77, 147-152.

85. Kahlmeter, G. (2003). An international survey of the antimicrobial susceptibility of pathogens from wncomplicated wrinary tract infections: the ECOSEMS Project. I Anwicrob Chemorher 51,69-76.

86. Karlowsky, I, A. Jones, M. E., Thomsberry, C, at (2001). Prevalence of antimicnobial resistance among urinary tract pathogens isolated from fente oupatients adoss the US in 1999. Int J Animicrob Agents 18, 121-127.

87. Sabm, D. F., Thomsberry, C., Mayfield, D. C., at al. (2001). Multidrug-resistant urinary tract isolates of Escherichia coli: prevalence and patient demographios in the United States in 2000 Antimicrob Agens Chemother 45, 1402-1406. 


\section{Chapter 2}

Erythromycin resistance in the commensal throat flora of patients visiting the general practitioner: a reservoir for resistance genes for potential pathogenic bacteria. 
CHATTH 2 


\section{Abstract}

Antibiotic resistance in the commensal flora often precedes that in the pathogenic flora and is a reservoir for resistance genes. Unfortunately, little is known about the prevalence and mechanisms of resistance in the commensal throat flora in the Netherlands as well as the transfer of the resistance genes from the commensal bacteria to potential pathogenic strains.

From October 2000 until December 2002 the prevalence and mechanism of erythromycin resistance was determined in the commensal streptococcal throat flora of patients with an acute respiratory tract infection (ARI) and in control patients matched by age presenting to general practitioners participating in a GP network of the Continuous Morbidity Registration of the NIVEL. Their patient population accounts for about $1 \%$ of the Dutch population and is representative according to age, gender, regional distribution and degree of urbanization.

The prevalence of resistance to 1 and $16 \mathrm{mg} / \mathrm{L}$ erythromycin was $57 \%$ and $20 \%$ respectively. The percentage of the total commensal flora resistant within each patient ranged from $1-100 \%$ with a median of $1 \%$. The mef $A$ gene was predominantly found among isolates on the $1 \mathrm{mg} / \mathrm{L}$ plates; the erm $B$ gene was present in $64 \%$ of the isolates on the $16 \mathrm{mg} / \mathrm{L}$ plates. Erythromycin resistance was transferred from a commensal streptococcus isolate to a clinical Streptococcus pnewnomioe strain with a frequency of $1 \times 10^{-9}$.

Macrolide resistant streptococci were present in the commensal throat flora in the majority of GP patients in The Netherlands although in most patients in relatively low numbers of the total commensal flora. Judicious use of macrolide therapy will control the increase in number of patients with detectable macrolide resistant flora as well as the relative contribution of the macrolide resistant flora to the total commensal flora per patient. This is important to prevent transfer of resistance genes and to keep these antibiotics for therapy in the future.

\section{Introduction}

Respiratory tract infections have in most cases a viral etiology for which antimicrobial therapy is not beneficial. However, up to $60 \%$ of the patients with a common cold in general practice receive an antimicrobial treatment. 'Consequently, the normal bacterial flora of the upper respiratory tract is often exposed to antibiotics. ${ }^{2}$ Resistant commensal flora might be selected each time an antibiotic is administered irrespective of the infection it should cure. ${ }^{3}$ Through this selection, resistant commensal streptococci platy a significant role as reservoir of antimicrobial resistance genes and might transfer different resistance traits to more pathogenic micro-organisms like Streptococcus pnewmoniae and Streptococcus pyogenes." To date, only two studies in The Netherlands 
have addressed the problem of resistance in commensal throat flora. ${ }^{5,6}$ These studies were directed at the problem of resistance in the commensal throat flora after clarithromycin and/or azithromycin therapy in placebo controlled double blind studies in specific populations.

For years, macrolides have been an effective alternative for the treatment of infections due to Gram-positive micro-organisms especially in case of allergy to beta-lactam antibiotics. However, the development of an increase in macrolide resistance has limited the use of these antimicrobial agents. ${ }^{7}$ Resistance to macrolides in streptococci is mainly due to two resistance mechanisms: modification of the ribosomal target of the antibiotic due to methylation or mutation and efflux of macrolides. Methylation is encoded by the $\operatorname{erm} B$ gene (MLS $\mathrm{B}_{\mathrm{B}}$-phenotype) and efflux is mediated by the mefA gene (M-phenotype). $M e f A$ is presently used to refer to the genes originally named mefE and mefA by Suttcliffe et al ${ }^{8,9}$ Strains with a MLS ${ }_{B}$-phenotype usually show high-level resistance to macrolides, lincosamides and streptogramin $B$, whereas strains with a M-phenotype express low-level resistance to 14 - and 15-membered macrolides only but no crossresistance to other antimicrobial agents. ${ }^{10,11}$ So far, ribosomal methylation remains the most widespread mechanism of resistance to macrolides and lincosamides. ${ }^{7}$

The purpose of this study was to determine the prevalence of erythromycin resistance (genes) in the commensal streptococcal flora of patients with or without an acute respiratory tract infection (ARJ) attending their general practitioner (GP) participating in a GP network of the Continuous Morbidity Registration of the NIVEL in The Netherlands. Furthermore, the mechanisms of erythromycin resistance, i.e. the presence of mefA and/or ermB genes was determined as well as the possibility to transfer erythromycin resistance (genes) from a commensal streptococcal isolate to Streptococcus pneumoniae.

\section{Materials and Methods}

\section{Sample collection}

As part of an ongoing national surveillance study of acute respiratory tract infections (the ARI-EL study) organized by the National Institute of Public Health and the Environment (RIVM) throat swabs were collected from GP patients with or without complaints of an acute respiratory tract infection from October 2000 till December $2002 .^{12}$ The samples were collected by 67 GPs from 45 practices of the GP network of the Continuous Morbidity Registration of the NIVEL. Their patient population accounts for about $1 \%$ of the Dutch population and is representative according to age, gender, regional distribution and degree of urbanization. Patients with a diagnosed ARI (case) were included if it was their first visit to the doctor in this episode of ARI, the complaints started not more than five days before the doctor visit and no antimicrobial 
agents nor antivirals were used in the previous two weeks. Within seven days after a patient with ARI was inchuded, a control patient without ARI in the last two weeks was asked to participate. Furthermore, the control patient had to be in the same age category of the case, may not belong to the same household as the case, and may not have used any antimicrobiall agents nor antivirals in the previous two weeks. ${ }^{12}$

The specimens collected were analyzed at the RIVM for respiratory viruses and for respiratory bacteria at the Regional Laboratory of Public Health in Tilburg. Samples were then forwarded to the Microbiological Laboratory of The University Hospital Maastricht for further analysis of the commensal streptococcal throat flora. Upon arriwal they were suspended in $3 \mathrm{ml}$ of sterile saline $(0,9 \% \mathrm{NaCl}, w / \mathrm{v})$. Five-hundred microliter of this suspension was centrifuged at $14000 \mathrm{rpm}$ for 10 mimutes, the pellet was suspended in $1 \mathrm{ml}$ of $0,7 \%$ peptone (w/v) with $30 \%$ glycerol (v/v) and stored at $-20^{\circ} \mathrm{C}$ until further analysis.

\section{Determination of the erythromycin resistance phenotype}

The total indigenous oropharyngeal flora, i.e. alpha-hemolytic and non-luemolytic streptococci, was cultured to determine resistance to erythromycin. After thawing, the samples were centrifuged at $14000 \mathrm{rpm}$ for 10 minutes and the pellet was suspended in $500 \mu \mathrm{l} 0,9 \% \mathrm{NaCl}(\mathrm{w} / \mathrm{v})$. Then, $40 \mu \mathrm{l}$ of tenfold dilutions were inoculated using a spiral plater (Eddy Jet, ILL Instruments, I.K.S., Leerdam, The Netherlands) onto Columbia agar (Oxoid, CM 331, Basingstoke. England) plates supplemented with 5\% sheep blood and containing 0,1 and $16 \mathrm{mg} / \mathrm{L}$ erythromycin. Of the samples showing growth after overnight incubation at $37^{\circ} \mathrm{C}$ colonies with the morphology of streptococci were counted. Per swab, only the colonies growing on the agar plate with the highest concentration of erythromycin (i.e. isolates of the $1 \mathrm{mg} / \mathrm{L}$ plates showing growth only on this plate or isolates of the $16 \mathrm{mg} / \mathrm{L}$ plates in case of growth on both antibiotic containing plates) were subcultured and stored at $-70^{\circ} \mathrm{C}$ untill further analysis of the resistance genes.

The prevalence of resistance for each concentration of erythromycin was calculated as the ratio between the number of samples showing growth at that specific concentration erythromycin and the total number of samples tested multiplied by $100 \%$.

\section{Detection of the erythromycin resistance genes}

For the identification of the different erythromycin resistance genes (ermB and mefA), total DNA was extracted from bacteria grown on blood agar plates (Oxoid, Basingstoke, England). PCR was performed with in a Perkin-Elmer Cetus GeneAmp PCR systen 9600 ( Perkin-Elmer, Norwalk, Conn.) yielding PCR products of 425 bp and 348 bp respectively for $\operatorname{erm} B$ and $m e f A$ as described previously. ${ }^{8,13,14}$ Positive control strains for erm $B$ JH2-2:Tn1 $545^{14}$ and $m e f A / E$ O2J1175 13 were included in each run. 


\section{Conjugation experiment}

The bacterial strain used as donor of the erythromycin resistance gene $\operatorname{erm} \mathrm{B}$ was a rifampicin-susceptible isolate from this study. A clinical erythromycin-susceptible $S$. pneimonice strain made rifampicin $(25 \mathrm{mg} / \mathrm{L}$ ) resistant was used as recipient. Transfer of the resistance gene was performed in suspension with both donor and recipient grown to the late exponential phase and then mixed at a donor/recipient ratio of 1.5 . As a control, each of the donor and recipient strains were mixed with $0.9 \% \mathrm{NaCl}$ in a ratio 1:5. After centrifugation of the mating mixtures, the pellet was suspended in $0.5 \mathrm{~mL}$ $\mathrm{NaCl}(0.9 \%$, w/v) and plated on Columbia agar plates (CM331, Oxoid, Basingstoke, England) supplemented with $5 \%$ sheep blood, containing both erythromycin $(16 \mathrm{mg} / \mathrm{L})$ and rifampicin $(25 \mathrm{mg} / \mathrm{L})$. The inoculated plates were incubated at $5 \% \mathrm{CO}_{2}$ and $37^{\circ} \mathrm{C}$. Putative transconjugants were characterized for the presence of the erm $\mathrm{B}$ gene by PCR and by pulsed-field gel electrophoresis (PFGE) to detect clonallity with the recipient $S$. pneumoniae strain. The frequency of transfer was expressed as the number of transconjugants after mating per recipient colony forming units (cfu) in the mating mixture. The stability of the transconjugant was determined by five successive platings on blood agar without antibiotics.

\section{Pulsed-field gel electrophoresis}

In short, agarose plugs containing bacterial chromosomal DNA were digested with Smal (Invitrogen, reference 15228-018, Breda, The Netherlands) for $6 \mathrm{~h}$ at $37^{\circ} \mathrm{C}$. Pulsedfield gel electrophoresis was carried out on a CHEF-DRII cell (Bio-Rad Laboratories, Richmond, CA) as described previously with minor modifications. ${ }^{15}$ The gel was stained with ethidium bromide for $15 \mathrm{~min}$ and photographed under UV irradiation. The restriction endonuclease digest patterns were visually compared and interpreted using the criteria of Tenover et al. ${ }^{16}$

\section{Results}

\section{Sample collection}

Of the 678 patients participating in the study, $60 \%$ were female. The age distribution of the participants was not significantly different from the distribution in the Dutch population, although the 0 - to 4-year-olds were underrepresented and the 14- to 44-yearolds were overrepresented. ${ }^{12}$ 


\section{Determination of the erythromycin resistance phenotype}

Indigenous oropharyngeal flora, i.e. alpha-haemolytic and non-haemolytic streptococei, was present in all collected swabs (Table 1). The flora of $292(43 \%)$ patients showed no resistance to either concentration erythromycin tested. On the $1 \mathrm{mg} / \mathrm{L}$ agar plates $57 \%$ of the samples showed growth and $20 \%$ were able to grow on the $16 \mathrm{mg} / \mathrm{L}$ agar plates. The proportion of erythromycin resistant streptococci in the total commensal throat flora of each patient ranged from $1-100 \%$ with a median of $1 \%$. Furthermore, in $3 \%$ of the patients $>50 \%$ of the total commensal streptococcal flora were erythromycin resistant $(1 \mathrm{mg} / \mathrm{L})$.

Table 1. Culture results of the oropharyngeal swabs and erythronycin resistance prevalence $(\%)$ of the streptococcal isolates.

\begin{tabular}{ll}
\hline & Total \\
\hline Number of patients & 678 \\
\hline Number of samples with growth on $1 \mathrm{mg} / \mathrm{L}$ plates & 386 \\
Number of samples with growith on $16 \mathrm{mg} / \mathrm{L}$ plates & 138 \\
\hline Prevalence of resistance for $1 \mathrm{mg} / \mathrm{L}$ & $57 \%$ \\
Prevalence of resistance for $16 \mathrm{mg} / \mathrm{L}$ & $20 \%$ \\
\hline
\end{tabular}

\section{Detection of the erythromycin resistance genes}

The majority of the isolates showing growth only on the $1 \mathrm{mg} / \mathrm{L}$ erythromycin plates $(78 \%)$ carried the mef $\mathrm{A}$ resistance gene. For the isolates on the highest erythromycin concentration plates the ermB gene was found in the majority of the samples $(64 \%)$. Isolates of the higher erythromycin concentration also showed more often the combination of both $\operatorname{erm} \mathrm{B}$ and mef $\mathrm{A}$ genes $(9 \%)$ as compared to the isolates from the 1 $\mathrm{mg} / \mathrm{L}$ agar plates (2\%).

\section{Conjigation experiment}

Erythromycin resistance was successfully transferred from the randomly chosen commensal streptococcus isolate (ermB positive) to a clinical $S$. pneumoniae strain $\left(\right.$ ery $^{\mathrm{S}}$, rif $^{\mathrm{R}^{\mathrm{R}}}$ ) with a frequency of $\pm 1 \times 10^{-9}$. The identification of the transconjugant was confirmed by API strep and was similar to that of the acceptor strain. Furthermore, the ermB gene was detected in the transconjugant by $\mathrm{PCR}$ and $\mathrm{PFGE}$ of both the recipient and transconjugant showed identical restriction patterns. No spontaneous mutations in the control experiments were detected. All the transconjugants were stable as 
erythronycin resistance remained after 5 consecutive platings on antibiotic free agar plates.

Table 2. PCR results of the erythromycin resistant streptococcal isolates.

\begin{tabular}{ccccccc} 
Concentration & & \multicolumn{3}{c}{ Number (percentage) of isolates with the resistance gene } \\
\cline { 3 - 6 } erythromycin & $\mathbf{n}^{*}$ & $e r m B$ & mefA & ermBtmefAt & ermB-mefA- \\
\hline \multicolumn{1}{l}{$1 \mathrm{mg} / \mathrm{L}$} & 294 & $29(10)$ & $230(78)$ & $5(2)$ & $30(10)$ \\
\hline $16 \mathrm{mg} / \mathrm{L}$ & 188 & $121(64)$ & $42(22)$ & $16(9)$ & $9(5)$ \\
\hline
\end{tabular}

"number of isolates assayed by PCR

\section{Discussion}

The present study is to the best of our knowledge one of the few studies dealing with macrolide resistance in the commensal flora of general practice patients in The Netherlands. The prevalence of macrolide resistance in the majority of the patient population and the transferability of macrolide resistance by conjugation to potentially pathogenic micro-organisms with a frequency of $1 \times 10^{-9}$ underscore the relevance of the commensal flora as source of antibiotic resistance genes. Furthermore, this transfer of resistance genes by conjugation is a process equal to the in vivo situation as bacteria of the commensal throat flora are also found in close proximity of one another.

The two published other studies in The Netherlands on commensal flora were primarily directed at the effect of clarithromycin and/or azithromycin on the appearance of resistance in the commensal flora in a double blind placebo-controlled fashion. ${ }^{5.6}$ In the study by Berg et al. 296 patients with documented coronary artery disease were randomized to receive either two weeks of slow rellease (SR) clarithromycin or placebo for two weeks. SR clarithromycin had a major effect on the appearance of resistance in the commensal throat flora, which persisted for at least 8 weeks after end of therapy. Matute et al. ${ }^{6}$ did not find any effect of a 3-day course of azithromycin or 7-day course of clarithromycin on the commensal throat flora in each of 6 healthy volunteers. Explanations for the lack of effect of the tested macrolides in the latter study are the small number of participants and the shorter duration of therapy.

The resistance percentage in our study was lower than the $71 \%$ macrolide-resistant viridans group streptococci (the predominant species of the oropharyngeal commensal flota) found in Belgian healthy volunteers in $2003^{17}$ and the rate reported in Spain in $20011^{9}$ These results are in accordance to the lower antibiotic use in general ${ }^{18}$ and especially in macrolides ${ }^{19}$ in The Netherlands compared to both other countries. Also, in out study the resistance prevalence was determined in the total commensal streptococcal 
throat flora as compared to only a selected sub-population of this flora in both studies which might have resulted in higher resistance percentages compared to our results.

Twenty percent of the patients in our study carried streptococci resistant to thigh concentration of erythromycin $(16 \mathrm{mg} / \mathrm{L})$. As the majority of the streptococci growing on the $16 \mathrm{mg} / \mathrm{L}$ agar plates $(64 \%)$ carried the ermB gene it seems that in the population studied resistance to a high erythromycin concentration is correlated with the MLSBphenotype that confers cross-resistance to macrolides, lincosamides and streptogramins. The same relation was also found by Pérez-Trallero et al. ${ }^{9}$ Furthermore, similar as in our study their study showed that all commensal streptococci with the M-phenotype had low MICs for macrolides, clindanycin and streptogramin B. In our isolates $80 \%$ of the isolates growing only on the $1 \mathrm{mg} / \mathrm{L}$ agar plates contained the mef $\mathrm{A}$ gene.

In $5 \%$ of the isolates growing on the higher concentration of erythromycin and $10 \%$ of the isolates on the lower concentration, none of the resistance genes studied were detected. The mechanism(s) of resistance in these isolates are therefore unknown. This finding might imply the existence of other resistance genes or mechanisms. For the lower erythromycin resistant strains a likely explanation might be an altered secretion pathway for the antimicrobial agent or a modified entry. For the higher erythromycin resistant strains the ermA gene, subclass ermT R might be responsible for the MLS $S_{3-}$ phenotype as this gene is known to code for the iMLS $S_{\mathrm{B}}$-phenotype in $S$. pyogenes isolates, ${ }^{20}$ and in beta-hemolytic streptococci group B, C, G. ${ }^{4.21}$

A limitation of the study was the identification of the isolates by morphology only. However, the aim of the study was to determine the prevalence of erythromycin resistance in the total commensal streptococcal flora. Thus the morphology only was sufficient to distinguish between streptococci and non-streptococci (mostly staphylococci).

The present results confirmed that the commensal throat flora forms a large reservoir of resistance genes able to transfer respectively their erythromycin resistance genes by horizontal gene transfer to a potential pathogenic S. pmetwomiae which consequently becomes resistant to commonly used antimicrobials. How often this occurs depends on the number of genes involved in resistance, the ability of these genes to be transferred, the prevalence of pathogenic bacteria, the prevalence of resistant commensal throat flora, and the relative contribution of resistant flora to the total commensal flora. The latter two factors are influenced by the use of antibiotics. The transfer is relatively easy for macrolide resistance as this is often encoded by one gene only, often located on transposons $^{22,23}$ and the transconjugants were resistant to the same erythromycin concentration as the donor strain. "Thus potential pathogenic bacteria like $S$. pnetmoniae might become resistant by horizontal gene transfer to commonly used antimicrobials (macrolides in case of penicillin allergy). How often this occurs depends on the number of genes involved in resistance, the ability of these genes to be transferred, the prevalence of pathogenic bacteria, the prevalence of: resistant throat flora, and the relative contribution of resistant flora to the total commensal flora. The latter two 
factors are influenced by the use of antibiotics. The transfer is relatively easy for macrolide resistance as this is often encoded by one gene only, which is often located on transposons. ${ }^{22,23}$ As shown in a previous study ${ }^{24}$ mefE could be transferred with a frequency of $1 \times 10^{7}$ from viridans group streptococci to $S$ pnewnonicie by transformation. Transformation however is considered an in who phenomenon with pre-competent 8 . pnemonice R6 cells and total genomic donor DNA. Whether this situation occurs also in vivo is questionable. The conjugation experiment in this study was assayed with bacterial donor and recipient strains mixed in suspension to mimic the in wivo situation. Close contact between micro-organisms, not pre-treated to get competent cells is very likely a common situation in vivo.

Although in The Netherlands macrolide resistance in Gram-positive potential pathogenic bacteria is still relatively low, it is increasing. ${ }^{25}$ Judicious use of macrolide antibiotics is essential to keep macrolides as alternatives for penicillins in the future especially in patients with severe forms of allergy to beta-lactam antibiotics.

\section{Acknowledgements}

We would like to thank all the patients and general practitioners willing to participate in the study. Furthermore we would like to thank Kim Spee for his technical assistance.

\section{References}

1. Makela, M. J., Putakkka, T., Ruuskanen, $\mathrm{O}$. et al. (1998). Viruses and bacteria in the etiology of the common cold. $J$ Clim Microbiol 36, 539-542.

2. Diaz-Mejia, J. J., Carbajal-Saucedo, A \& Amabile-Cuewas, C. F. (2002). Antibiotic resistance in oral commensal streptococci from healthy Mexicans and Cubans: resistance prevalence does not mirror stnibiotic usage. FEMS Microbiol Lett 217, 173-176.

3. Andremont, A. (2003). Commensal fora may play key role in spreading antibiotic resistance. ASM news 69, 601-607.

4. Seppala, H., Haanpera, M., Al-Juhaish, M. ef al. (2003). Antimicrobial susceptibility patterns and macrolide resistance genes of viriclans group streptococei from normal flora. $J$ Antiwacrob Chemother 52, 636-644

5. Berg, H. F., Thise, J. H., Scheffer, G. J., et at (2004). Emergence and Persistence of Macrolide Resistace in Oropharyngeal Flora and Elimination of Nasal Carriage of Staplylococus aureus atter Therapy with Slow-Release Clarithromycin: a Randomized, Double-Blind, PlaceboControlled Study. Antimicrob Agents Chemother 48, 4183-4188.

6. Matute, A. J., Schurink, C. A., Krijnen, R. M. et al. (2002). Double-blind, placebo-controlled study comparing the effect of azithromycin with clarithromycin on oropharyngeal and bowel microflora in volunteers. Eur.J Clin Microbiol Infect Dis 21, 427-431. 
7. Leclercq, R. (2002). Mechanisms of resistance to macrolides and lineosanudes natuve of the resistance elements and their clinical implications. Clin fofee o Dis 34, 482492

8. Sutcliffe, J., Tait-Kamradt; A. Wondrack, L. (1996). Streptococers phewmoniae and Streptococcus pyogenes resistant to macrolides but sensitwe to clindanycin a common resistance pattern mediated by an efflux system. Amtimicrob Agrents Chemother $40,1817-1824$.

9. Perez-Trallero, E., Vicente, D., Montes, M., et al. (2001). High proportion of pharyngeal carriess of commensal streptococci resistant to erythromycin in Spanish aduits. Antimonob Cheworher $48,225-229$.

10. Hoban, D. J., Wierzborwski, A. K., Nichol, K., er al. (2001.). Macrolide-nesistant Streprococcus pneumoniae in Canada during 1998-1999: prevalence of mef(A) and erm(B) and susceptibilities to ketolides. Antimicrob Agents Chemother $45,2147-2150$.

11. Reinert, R. R., Al-Lahham, A., Lemperle, M. el at. (2002). Emergence of macrolide and penicillin resistance among invasive pneumococcall isolates in Germany. I Arwimicrob Chemother 49, 61-68.

12. wan den Brandhof, W. E., Bartelds, A. L. M., Peeters, M. F. ef al. (2002). ARI-EL. al case-control study on acute respiratory infections in general practitioner patients. Interim report of Oct. 2000 through Sept. 2001. RIVM rapport $217617006 \mathrm{http}: / /$ www.rivm.nl/bibliotheek/.

13. Sutcliffe, J., Grebe, T., Tait-Kamrad, A., ef al. (1996). Detection of erythromycin-resistant determinants by PCR. Amtimicrob Agents Chemother 40, 2562-2566.

14. Jensen, L. B., Frimodt-Moller, N. \& Aarestrup, F. M. (1999). Presence of erm gene classes in Gram-positive bacteria of animal and human origin in Denmark. FEMS Microbiol Lert 170, 151158.

15. Chiou, C. S., Liao, T. L., Wang, T. $H_{n}$ ef at. (2004). Epidemiology and molecular characterization of Streptacoccus pyogeres recovered from scarlet fever patients in central Taiwan from 1996 to 1999. J Clin Microbiol 42,3998-4006.

16. Tenover, F. C., Arbeit, R. D., Goering, R. V., et al. (1995). Interpreting chromosomal DNA restriction parterns produced by pulsed-field gel electrophoresis: criteria for bacterial strain typing. J Clim Microbiol 33, 2233-2239.

17. Malhotra-Kumar, S., Lammens, C. Martel, A., 6 al. (2004). Oropharyngeall cartiage of macrolide-resistant viridans group streptococci: a prevalence study among healthy adults in Belgium, J Antimicrob Chentother 53, 271-276.

18. Molstad, S., Lundborg, C. S., Karlsson, A. K. et al (2002). Antibiotic prescription rates vary markedly between 13 European countries. Scand Infect Dis 34, 366-371.

19. Cars, O., Molstad, S. \& Melander, A. (2001). Variation in antibiotic use in the European Union. Lancet 357, $1851-1853$.

20. Seppala, $H_{2}$, Skurnik, M., Soini, H., er at. (1998). A novel erythromycin resistance methylase gene (ermTR) in Streptococous pyogenes. Antimicrob Agents Chemother $42,257-262$.

21. Portil to, A., Lantero, M., Olarte, I., ef al. (2001). MLS resistance phenotypes and mechanisms in beta-haemolytic group B, C and G Streptococcus isolates in La Rioja, Spain. I Anrimicrob Chemother 47, 115-116. 
22. MeDougal, L. K, Tenover, F. C, Lee, L. W, et al (1998). Detection of Tn917-like sequences within a Tn916-like conjugative transposon ( $\mathrm{Tn} 3872$ ) in erythromycin-resistant isolates of Streptococcus prewnonat. Antmicrob Agents Chemother 42, 2312-2318.

23. Roberts, A. P, Cheah, G., Ready, D, et al (2000). Transfer of TN916-like elements in mierocosm dental plagues. Antumicrob Agents Chemother 45, 2943-2946.

24. Cerda Zolezzi, P., Laplana, L. M. Calwo, C. R, et al (2004). Molecular basis of resistance to macrolides and other antibiotics in commensal vintans group streptococci and Gemella spp. and transfer of resistance genes to Streptococcus preumoniae. Antimicrob Agents Chenother 48, 3462.3467 .

25. SWAB. NethMap 2004-Consumption of antimicrobial agents and antimicrobial resistance among medically important bacteria in the Netherlands. 
.

皮 


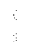

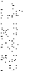
:
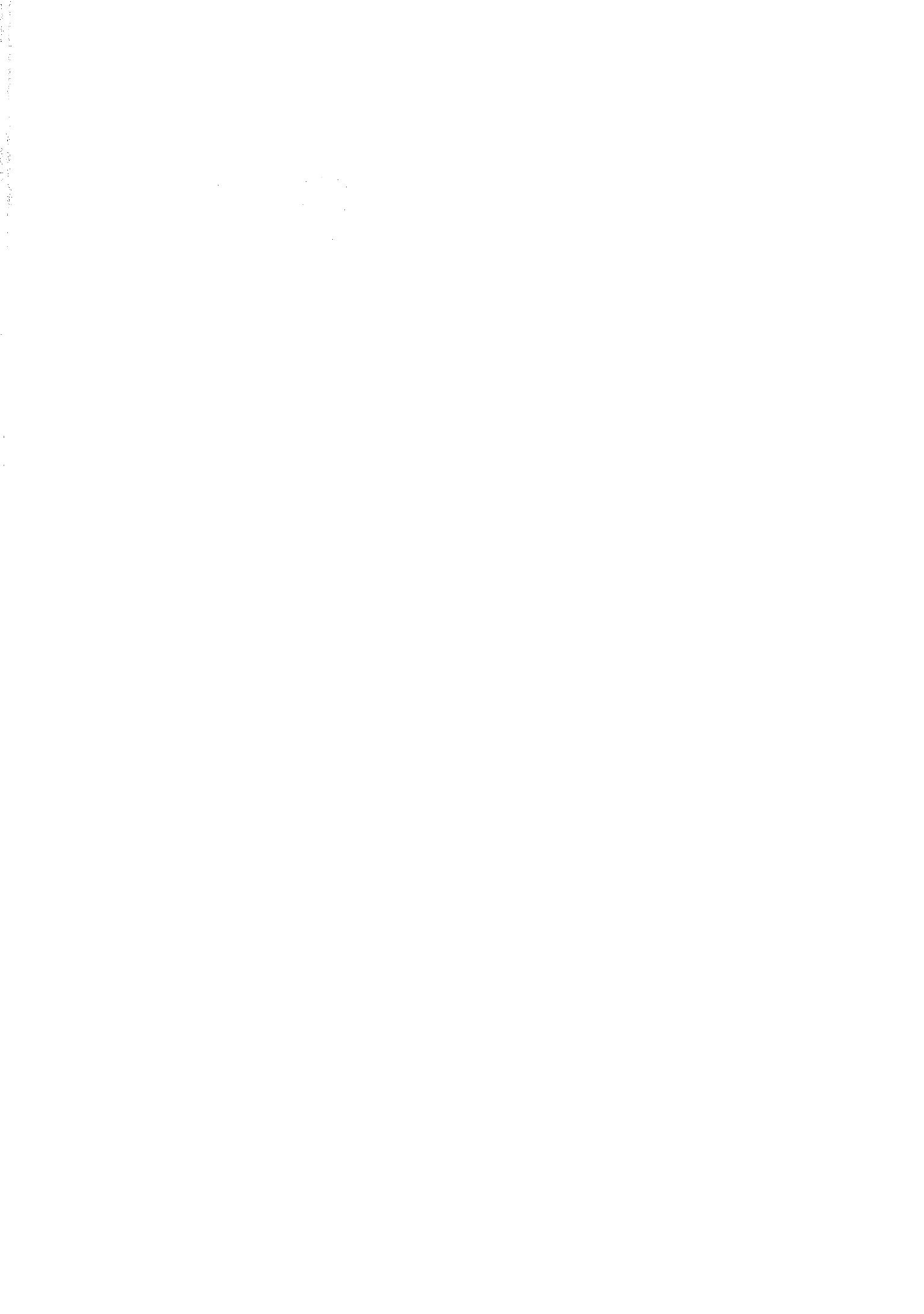


\section{Chapter 3}

Antibiotic resistance of faecal Escherichia coli in healthy volunteers from nine developing countries.

Joumal of Antimicrobial Chemotherapy (2004) 5:952-955. 


\begin{abstract}
In many developing countries antibiotics are frequently misused and overused resulting in resistant bacteria. However there is paucity of accurate data on the prevalence of antibiotic resistance that would be useful in the formulation of appropriate policies. In this study the prevalence of antibiotic resistant Escherichia coll in healthy volunteers from urban (U) areas in Kenya, Mexico, Peru, Philippines and non-urban (NU) locations in Curaça, Mexico, Venezuela, Tanzania, Ghana, Zimbabwe and Philippines was determined.

The collected 1474 faecal samples were analysed in one laboratory for the presence and antimicrobial resistance of $E$. coli. The susceptibility to 16 antibiotics was determined by the MIC-method. Genetic relatedness of the isolates was determined by PFGE of Xbal-digested genomic DNA.

Prevalence of resistance to oxytetracycline, ampicillin and trimethoprim was found in more than $50 \%$ of the samples. Ninety-six percent of the volunteers from NU Mexico carried $E$. coli resistant to oxytetracycline and trimethoprim. Ninety-five percent of the Peruvian participants had $E$ coli resistant to ampicillin; $82 \%$ of those from Ghana were resistant to chloramphenicol. Ciprofloxacin resistance ranged between $1-63 \%$ for the different countries. Significantly higher prevalences for ampicillin, oxytetracycline and trimethoprim were found for urban areas compared to non-urban ones. Ten percent of the $E$. coli were resistant to more than three antimicrobials. Genotyping of the multiresistant strains resulted in 53 unrelated PFGE-pattems.

In these populations the prevalence of antibiotic resistant faecal $E$. coll from healthy volunteers was high for most antibiotics. Furthermore, these high resistance prevalences were not caused by the spread of clonally related strains within these populations.
\end{abstract}

\title{
Introduction
}

The development and introduction of antimicrobial agents into clinical practice is one of the most important achievements of human medicine in the twentieth century. Antibiotics have, until recently, been used successfully for the management of most bacterial infections. In the last few decades there has been a growing concern about the increase in antibiotic resistance, especially in the developing countries. 'It is generally accepted that in a population antibiotic resistance and the frequency and amount of usage of a particular drug are related. ${ }^{2.3}$ In developing countries the availability of antibiotics over the counter without prescription, the use of subtherapeutic doses that are often of substandard quality, 4,5 insufficient emphasis on patient education concerning the consequences of antibiotic use and misuse, insufficient adherence of the medical profession to an antibiotic policy if available, are among factors that contribute to the emergence and spread of resistant strains. ${ }^{6,7}$ Increasing international travel also provides 
great opportunities for both pathogenic and non-pathogenic antibiotic resistant bacteria to be carried over long distances to other countries which might even be more important than the spread and dissemination of resistant bacteria within countries. ${ }^{8.9}$

The faecal hora of the general healthy population represents a potentially large reservoir of antimicrobial tesistant bacteria at sites where resistance genes can be transferred from the commensal flora to potentially pathogenic micro-organisms. ${ }^{8,9}$

In thiss study Escherichia coll, the predominant Gran-negative, facultative aerobic organism of the faecal florat ${ }^{10}$ was used as an indicator organism to determine the prevalence of antibiotic resistance in faecal samples of healthy adult volunteers in 9 developing countries in Africa, Asia and South-America. In addition genotyping of these strains was performed to determine possible spread of clonal strains within each popullation studied.

\section{Materials and Methods}

\section{Sample collection}

Faecal samples were randomly collected by medical students of the University of Maastricht in towns and villages of nine developing countries between November 1998 and July 2002. Participating countries were: Ghana, Kenya, Tanzania, Zimbabwe, Peru, Mexico (urban and non-urban), Venezuela, Curaçao, the Philippines (urban and nonurban). Samples were obtained from four urban (U) areas and from seven non-urban (NU) areas. Classification as urban or non-urban was based on information about the population size of the respective town. The cut-off value for the urban population was $\geq$ 150,000 inhabitants (Table 1). Healthy adult volunteers were asked to participate in the study by providing a fresh faecal sample (one sample per volunteer) and filling out a questionnaire on age, gender and antibiotic use. Criteria for exclusion were hospitalisation and presence of gastro-intestinal disease in the past month.

Because, as has been shown by mathematical modelling, "resistance rates increase exponentially, the emergence of resistance is more important from an epidemiological point of view than a small increase in resistance for example from $50 \%$ to $60 \%$. This assumption was used to calculate the minimum sample size. To find such a difference in resistance prevalence at least 90 evaltuable samples are needed in each group $(\alpha=0.05$ and $\beta=0.20$ ). Between 95 and 231 samples were therefore collected in each group.

\section{Sample processing}

On the day of collection the faecal samples were diluted $1: 10$ in sterile saline $(0.9 \%$ $(\mathrm{w} / \mathrm{v}) \mathrm{NaCl})$ with $20 \%(\mathrm{v} / \mathrm{v})$ glycerol in the local laboratory and stored at $-20^{\circ} \mathrm{C}$ until transported to the Medical Microbiology laboratory of the University Hospital 
Maastricht, The Netherlands in dry ice using shipping serwices. Weekly Eosin Methylene Blue (EMB) agar (Oxoid, CM 69, Basingstoke, England) plates with and without antibiotics were prepared and stored at $4^{\circ} \mathrm{C}$ until further use within one week. Ampicillin and oxytetracycline containing agar plates were prepared daily. The antibiotic concentrations were based on the resistance breakpoints of the National Committee for Clinical Laboratory Standards (NCCLS) ${ }^{12}$ guidelines and modified to make comparison with previous studies possible. ${ }^{3.13}$ The antibiotics tested and concentrations used were: ampicillin $25 \mathrm{mg} / \mathrm{L}$, cefazolin $32 \mathrm{mg} / \mathrm{L}$, ciprofloxacin $4 \mathrm{mg} / \mathrm{L}$, chloramphenicol $25 \mathrm{mg} / \mathrm{L}$, gentamicin $16 \mathrm{mg} / \mathrm{L}$, oxytetracycline $25 \mathrm{mg} / \mathrm{L}$ and trimethoprin $8 \mathrm{mg} / \mathrm{L}$. When using trimethoprim, $5 \%$ (v/v) lysed horse blood was added to the EMB-agar. Faecal samples were tenfold diluted and 40 ul from each dilution was inoculated on the EMB-agar plates with and without antibiotics, using a spiral plater (Eddy Jet, IUL Instruments, Leerdam, The Netherlands). After 18-24h of uncubation at $37^{\circ} \mathrm{C}$, E. coli appeared as purple colonies with a dark centre and a metallic green sheen. One colony of the dominant flora was randomly picked from each plate for identification using the indole and $\beta$-glucuronidase $(\beta$-glucuronidase discs, Rosco, Denmark) test. When both tests were positive the colony was considered $E$. coli. if there remained any doubt further biochemical tests were performed using API $20 \mathrm{E}$ strips (BioMérieux, Plainwiew, N.Y.).

The prevalence of resistance to a certain antibiotic was defined as the proportion of faecal samples showing growth of $E$. coli on agar plates containing that antibiotic compared to the totall number of samples tested.

\section{MIC Distributions}

Minimum inhibitory concentrations (MICs) of $E$. coli were determined according to the NCCLS-criteria. ${ }^{12}$ The microbroth dilution method was used with Mueller Hinton II broth cation adjusted (Becton, Dickinson and Company, Sparks, USA), an inoculum of $5 \times 10^{5} \mathrm{cfu} / \mathrm{ml}$ and an overnight incubation at $37^{\circ} \mathrm{C}$. The $\mathrm{M} 1 \mathrm{C}$-plates with freeze-dried antibiotics were provided by MCS Diagnostics BV (NLDMCS1 and NLDMCS2, MCS Diagnostics BV, Swalmen, The Netherlands). The MIC-plates were delivered after quality testing by the manufacturers and a shelf life of approximately one year was guaranteed. The following antimicrobial agents (range in $\mathrm{mg} / \mathrm{L}$ ) were tested: amoxicillin (0.06-128), amoxiclav (0.06-128), trimethoprim (0.03-64), co-trimoxazole $(0.03-64)$, gentamicin (0.03-64), norfloxacin $(0.03-64)$, ciprofloxacin $(0.008-16)$, nitrofurantoin (0.5-512), ceftazidime (0.06-128), cefuroxim (0.06-128), meropenem (0.03-64), piperacillin (0.25-512), piperacillin/tazobactan $(0.25-512 / 4)$, doxycycline $(0.06-128)$, amikacin $(0.12-256)$, and imipenem $(0.06-64)$. The reference strains $E$ coli ATCC 35218 and $\mathrm{ATCC} 25922$ were used as control strains. 


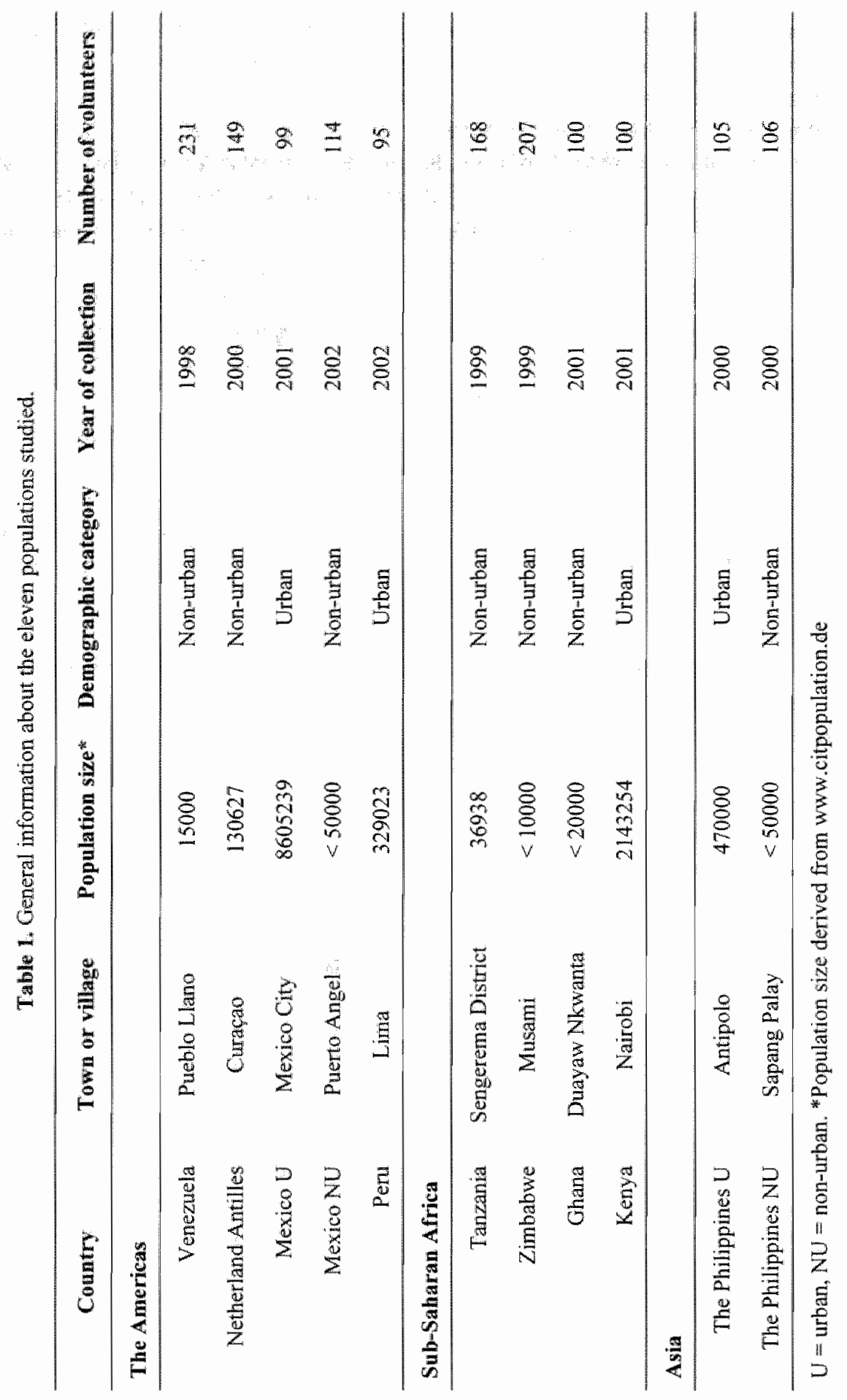




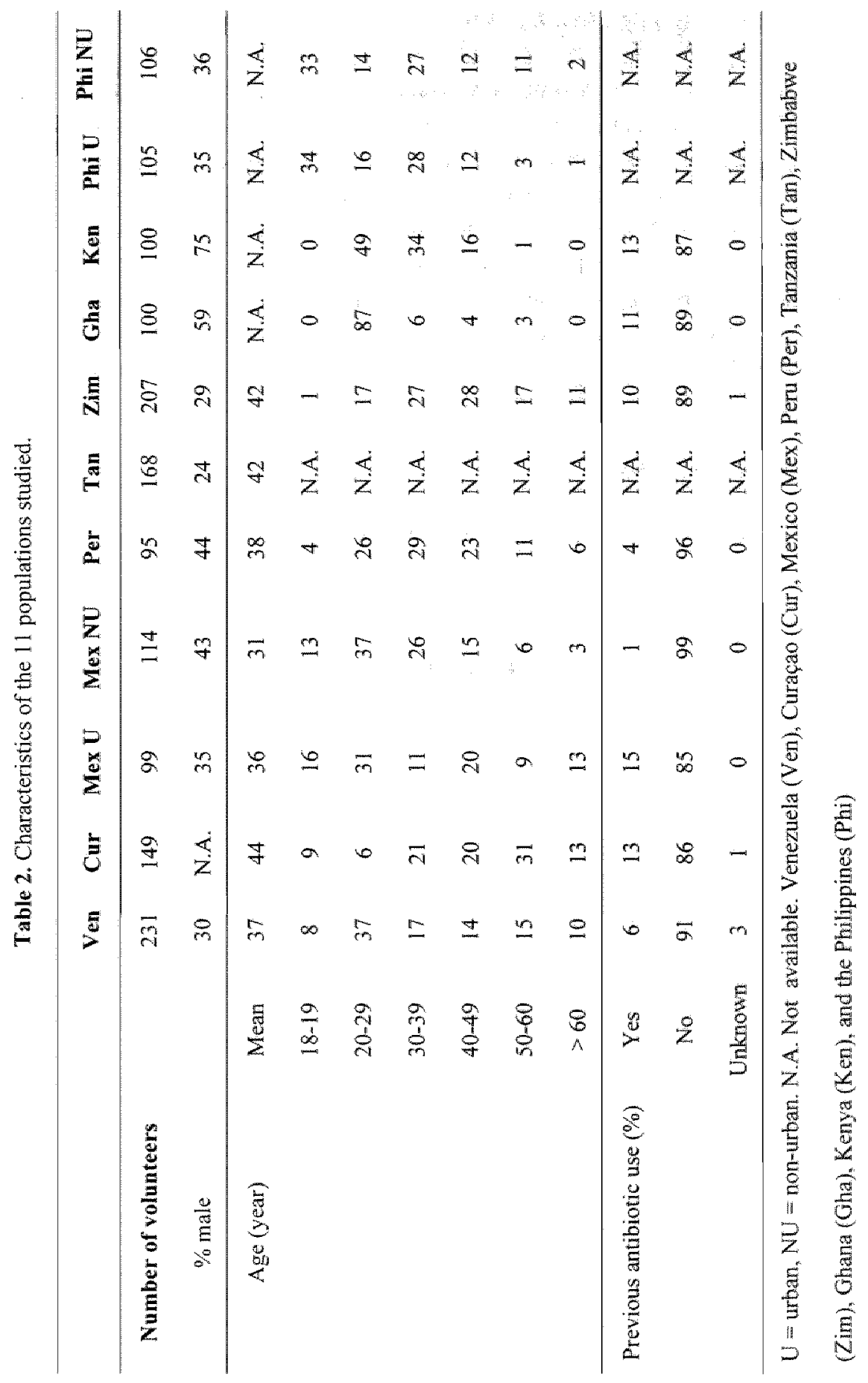




\section{Pulsed-field gel electrophoresis}

Sixty-two out of the $105 \mathrm{E}$. coll isolates resistant to at least amoxicillin, trimethoprim and doxycycline were at random chosen for genotyping by PFGE. For countries with 5 isolates meeting the resistance criteria all the isolates were genotyped, for countries with more multi-resistant isolates every other isolate was tested. Agarose plugs containing bacterial chromosomal. DNA were digested with Xbal (BioLabs Inc., New England, USA) for $2 \mathrm{~h}$ at $37^{\circ} \mathrm{C}$. Pulsed-field gel electrophoresis was carried out on a CHEF-DRII cell (Biom Rad Laboratories, Richmond, USA) as described previously with minor modifications. ${ }^{14}$ The gels were stained with ethidium bromide for $15 \mathrm{~min}$ and photographed uncler UV irradiation. The restriction endonuclease digest patterns were interpreted using the criteria of Tenover ef al. ${ }^{15}$

\section{Statistical analys is}

Statistical differences in the prevalences of antibiotic resistance between the different populations were detected using The Mann-Whitney-U test.

\section{Results}

\section{Study populations}

Demographic information about the populations studied is shown in Table 1. In total 1474 healthy volunteers participated in the study, from Venezuela $n=231$, Curacao $\mathrm{n}=149$, Mexico $U \mathrm{n}=99$, Mexico $N U \mathrm{n}=114$, Peru $\mathrm{n}=95$, Tanzania $\mathrm{n}=168$, Zimbabwe $\mathrm{n}=207$, Ghana $\mathrm{n}=100$, Kenya $\mathrm{n}=100$, the Philippines $\mathrm{U} \mathrm{n}=105$ and the Philippines $\mathrm{NU}$ $n=106$. The populations studied were derived from four urban (Mexico, Peru, Kenya and the Philippines) and seven non-urban regions.

The characteristics of the eleven populations studied are shown in Table 2 . The majority of the volunteers were between 18 and 50 years old, mostly female $(56 \%-76 \%)$, except in Ghana and Kenya ( $59 \%$ and $75 \%$ male respectively). One volunteer from Venezuela and 1.5 from the urban Mexico population did not deliver a faecal sample and were therefore excluded from further analysis.

\section{The prevalence of resistance}

The prevalences of resistance of the faecal $E$. coli for the antibiotics tested are shown in Table 3. Five percent (70/1458) of all volunteers showed no growth of faecal $E$. coli. The highest prevalence of resistance was found for the relatively inexpensive, broad spectrum, orally administered agents, particularly those that have been in use for several 


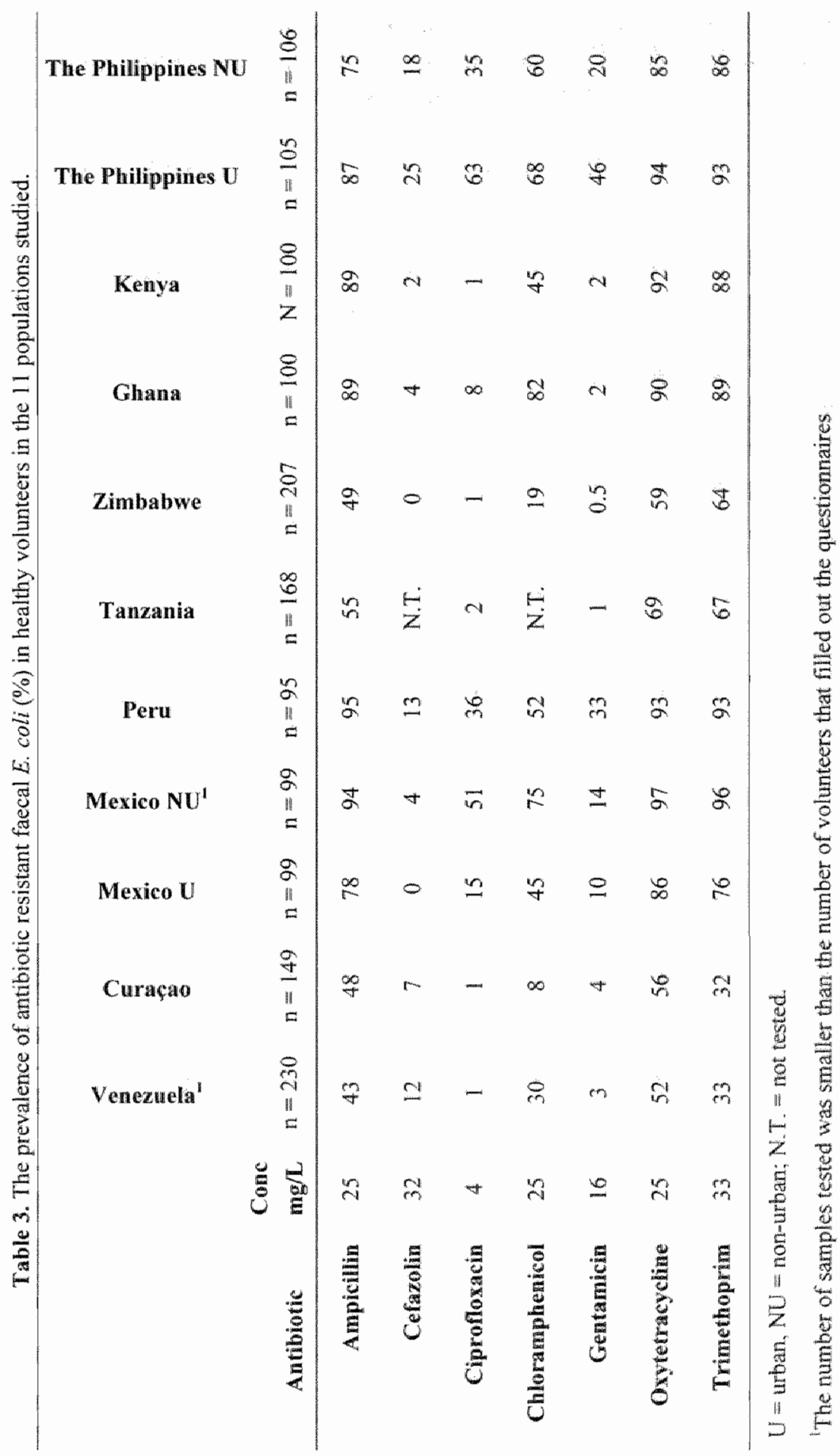


decades. For instance over $50 \%$ of the samples from most populations were resistant to oxytetracycline, ampicillin and trimethoprim. The samples from volunters of nonurban Mexico showed the highest prevalence of resistance to oxytetracycline $(97 \%)$ and trimethoprim $(96 \%)$, whereas participants from Peru and Ghana showed a high prevalence of resistance to ampicillin $(95 \%)$ and chloramphenicol $(82 \%)$, respectively. With the exception of Curagao and Zimbabwe, more than $30 \%$ of the faecal samples from the other areas had $E$, coll that showed resistance to chloramphenicol.

Resistance to cefazolin, gentamicin and ciprofloxacin was less common, with the exception of the Philippines $U$. There was considerable variation in the prevalence of ciprofloxacin resistance. It ranged from $2 \%$ or lower in the African countries, Curacao and Venezuela to over $30 \%$ in Mexico, Peru and the Philippines. Gentamicin resistance was the lowest in the African countries, Curacao and Venezuela. Samples from the Philippines had the highest prevalence of resistance for three out of seven antibiotics tested.

Using the demographic information of each country, the prevalences of resistance for the urban and non-urban areas respectivelly were combined for the Eastern as well as the Western hemisphere respectively. Although the time bias was greater in the data from the Western hemisphere, the trends seen were the same in both hemispheres (Figure 1).

The resistance percentages to ampicillin, oxytetracycline and trimethoprim were significantly higher in urban groups compared to non-urban groups $(p<0.01)$ in both hemispheres but no significant differences in antibiotic resistance could be detected between the two hemispheres.

Figure 1. The prevallence of antibiotic resistant faecal $E$. coli of 11 population of healthy volunteer in function of demographic differences

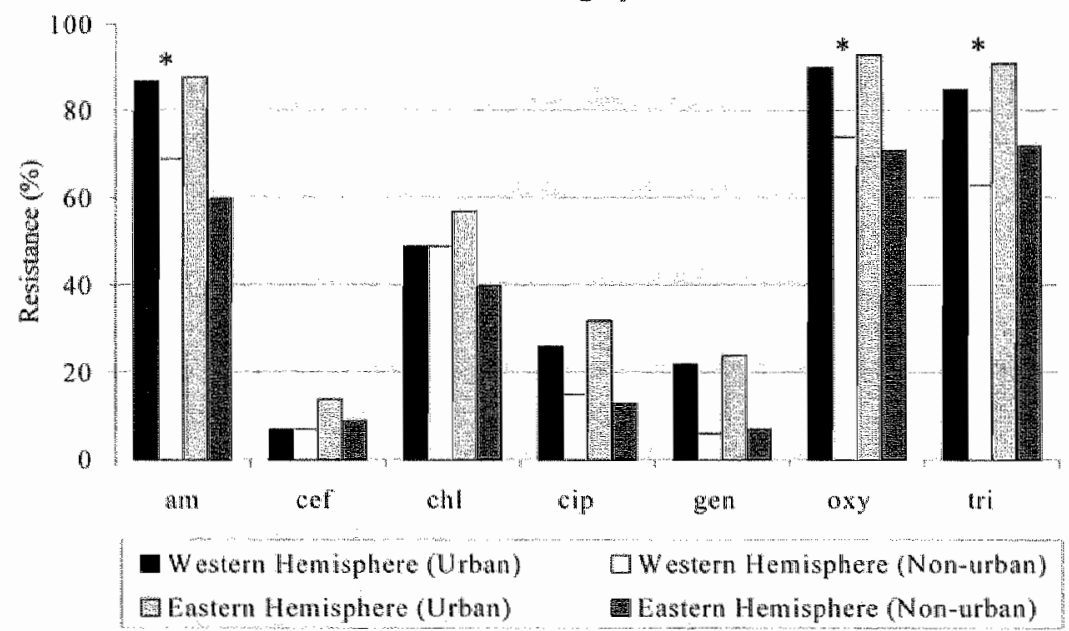

$\mathrm{am}=$ ampicillin, cef $=$ cefazolin, chl $=$ chloramphenicol, $\mathrm{cip}=$ ciprofloxacin, gen $=$ gentamicin, oxy $=$ oxytetracycline, and tri = trimethoprin.

* signiticantly higher resistance in urban groups compared to non-urban groups $(p<0.01)$ in both hemispheres. 


\section{Multi-drug resistance patterns}

Ten percent (129/1388) of all the $E$. coll isolates tested were resistant to three or more antimicrobial agents. Of these strains, 77 were resistant to the combination of amoxicillin, trimethoprim, co-trimoxazole and doxycycline. Twenty-eight isolates showed an additional resistance to up to four other antibiotics including piperacillin, coamoxiclav, gentamicin, norfloxacin, ciprofloxacin and nitrofurantoin. All isolates tested were sensitive to imipenem and only one urban Philippines isolate showed resistance to meropenem. This latter strain showed also resistance to cefuroxime and doxycyclime.

\section{Pulsed-field gel electrophoresis}

In total 62 E. colt isolates (the Philippines NU, $n=4$, Peru, $n=5$, Curaçao, $n=5$, Ghana, $\mathrm{n}=5$, Kenya, $\mathrm{n}=5$, the Philippines $\mathrm{U}, \mathrm{n}=5$, Mexico $\mathrm{U}, \mathrm{n}=6$, Venezuela, $\mathrm{n}=6$, Zimbabwe, $n=10$ and Tanzania, $n=11$ ) resistant to at least amoxicillin, trimethoprim and doxycycline were analysed using PFGE. Of these isolates, 44 were totally unrelated. The remaining 18 strains formed nine unrelated patterns.

\section{Discussion}

The prevalence of resistance of faecal $E$. coli isolated from eleven populations of healthy volunteers living in nine different developing countries was determined in one laboratory using the same method. A high prevalence of resistance to most agents was found in all populations, consistent with findings from previous developing-country studies. $9,13,16,17$ The highest prevalences of resistance were found for the orally administered, relatively inexpensive, broad-spectrum agents including ampicillin. trimethoprim and oxytetracycline. Furthermore, resistance to these antibiotics was the most common multi-resistance pattern seen in the $E$. coil isolates. This association has been found in previous studies with adults ${ }^{16,18}$ as well as children." The combination of resistance to these three antibiotics is very likely due to the fact that the genes encoding for resistance to these antimicrobials are located on the same plasmid. ${ }^{19}$ In order to rule out the possible spread of one or a few clonal strains in the populations studied we characterised multi-drug resistant $E$. colt isolates by $\mathrm{PFGE}$ and found that there were hardly any related strains in each population. The results indicate that the resistance prevalences found in this study were not derived from one common $E$. coli strain.

The prevalence of ciprofloxacin resistance ranged from one to more than sixty percent, in the Philippines U and NU, Mexico NU and Peru. A previous study by Rodriguez et al ${ }^{20}$ found lower resistance percentages for quinolones in Lima (Peru), i.e. $31-38 \%$; in Caracas (Venezuela) ${ }^{20}$ and in other studies ${ }^{3,6,21,22}$ resistance percentages ranged from 0 $15 \%$. An explanation for this high prevalence of resistance might be the use of 
ciprofloxacin for treatment of cholera and typhoid in adults as alternative for the standard therapy when strains are resistant to commonly used antimicrobials. ${ }^{23-25}$

To our knowledge the present study was the first in which nine different developing countries on different continents wete studied for the antibiotic resistance in healthy volunters. Although time bias could not be avoided, the methods used for deteeting faecal $E$. coll and determining the prevalence of antibiotic resistance were similar for the eleven populations studied. In their study van de Mortel et al ${ }^{3}$ also found higher oxytetracycline $(\mathrm{p}<0.05)$ and trimethoprim (not significant) resistances in the urban area of Mericla compared to the village of Grulla in Venezuela. In our study there were also significant differences in the prevalence of resistance between non-urban and urban areas for ampicillin, oxytetracycline and trimethoprim $(p<0.01)$. These differences in resistance between the rural and urban areas might be due to the availability of antibiotics ${ }^{20}$ and the easy access of the drugs afforded by the greater accessibility of healthcare facilities and drug distribution points. ${ }^{27}$ In cities a large variety of often inexpensive antibiotics are available in pharmacies, over the counter and in market stalls and most of them are inexpensive, ${ }^{7}$ whereas in rural areas only a few drugs are available and usually brought there by a visiting ${ }^{28}$ or a resident physician. ${ }^{29}$ Furthermore, crowding together with poor hygiene and poor sanitary facilities for sewage disposal in the cities might encourage the exchange of antibiotic-resistant bacteria in a population and the exchange of resistance genes among bacteria, thereby increasing the prevalence of antibiotic resistant strains. ${ }^{7,9,29}$

Mathematical modelling suggests that the prevalence of resistance over time follows a sigmoidal curve and approaches equilibrium." Depending on the antibiotic and the species involved it may take (some) time before the first resistant strain appears. Then, the resistance increases exponentially until equilibrium is reached. It may therefore be more effective to prevent the emergence of resistance than to reduce the prevalence of resistance once it has appeared, a factor that may account for the high levels of resistance in this study. ${ }^{30}$

A limitation of this study was the time bias in sample collection which might have influenced the results. Although different medical. students collected the samples each year, they were all instructed the same way with the same information and provided with the storage media they needed.

In conclusion, a high prevalence of resistance to most antibiotics tested among faecal $E$. coli from healthy individuals in developing countries was found. Moreover carriage of resistant $E$. coli was more common in urban than in rural areas. Unfortunately, we could not correlate these resistance prevalences to data on antibiotic use due to the lack of official data on the use of antibiotics and the over the counter sales. Also, the data provided by the volunteers on antibiotic use in the three months prior to the study were not consistent with percentages found in other studies. ${ }^{431,32}$

More surveillance studies are certainly necessary in developing countries to monitor the antibiotic use and the antibiotic resistance over time. These data are important as a basis 
for the implementation of an antibiotic policy. In addition, education of healthoare workers, patients and parents is also important in the control of antibiotic resistance over time.

\section{Acknowledgements}

This research was funded by the Department of Medical Microbiology of the University Hospital Maastricht, The Netherlands. Iruka Okeke is a Branco-Weiss Fellow of the Society in Science. We would like to thank the students, who collected the samples at the different sites, the deceased A.E. van den Bogaard for his assistance in the set-up of the study and his comments on the first draft of the manuscript and $N$. London and $L$. Hoffman for their technical assistance.

\section{References}

1. Farrar, W. E. (1985). Antibiotic resistance in developing countries. J Infect Dis 152, 1103-1106.

2. London, N., Nijsten, R., Mertens, P., et al. (1994). Eflect of antibiotic therapy on the antibiotic resistance of faecal Escherichia colt in patients attending general practitioners. J Antimicrob Chemosher 34, 239-246.

3. wan de Mortel, H. J., Jansen, E. J., Dinant, G. J., et al. (1998), The prevalence of antibioticresistant faecal Escherichia coli in healthy volunteers in Venezuela. Infection 26, 292-297.

4. Lansang, M. A., Lucas-Aquino, R. Tupasi, T. E., et af. (1990). Purchese of antibiotics without prescription in Manila, the Philippines. Inappropriate choices and doses. J Clin Epidemiol 43, $61-67$.

5. Risha, P. G., Vervaet, C., Vergote, G.. ef al. (2003). Drug formulations intended for the global market should be tested for stability under tropical climatic conditions. Fin I C/m Pharmacol $59,135-141$.

6. Calva, J. J., Sifuentes-Osomio, J. \& Ceron., C. (1996). Antimicrobial resistance in fecal flora: longitudinal community-based surveillance of children from urban Mexico. Anfiwnicrob Aggents Chemother 40, 1699-1702.

7. Okeke, I. N., Lamikanra, A. \& Edelman, R. (1999). Socioeconomic and behavioral factors leading to acquired bacterial resistance to antibiotics in developing countries. Ennerg Infect Dit $5,18-27$.

8. Okeke, I. N. \& Edelman, R. (2001). Dissemination of antibiotic-resistant bacteria across geographic borders. Clin Infect Dis 33, 364-369.

9. Amyes, S. G., Tait, S., Thomson, C. J., ef at. (1992). The incidence of antibiotic resistance in aerobic faecal hora in South India. J Antinicrob Chemoner $29,415-425$.

10. Lewy, S. B, Marshall, B., Schluederberg, S., at al. (1988). High frequency of antimicrobial resistance in human fecal fora. Antinnicrob Agents Chemother 32, $1801-1806$. 
11. Smith, D. Warris, A. D, Johnson, I. A, ef al (2002). Armal antibiotic wse has an early but mpontant mpact on the emergence of antibiotic resistance in humar commensal bacterial Pros.

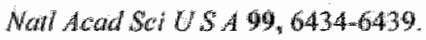

12. NCCLS (2002). National Committe for Chical Laboratory Standards. Menhods for ditump

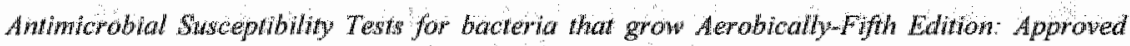

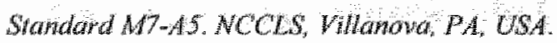

13. London, N., Nystem, R, wd Bogard, A., et al (1993). Antibiotic resistance of faecal

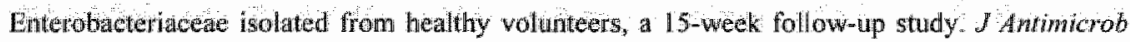
Chemolner $32,83-91$.

14. Conrad, S, Oethinger, $M_{\text {; }}$ Kaifel, $K_{\text {, }}$ et al (1996). gym mutations in high-levell

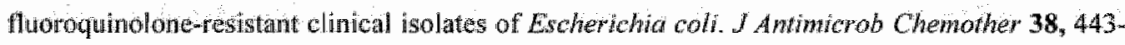
455.

15. Tenover, F, C., Arbeit, R. D., Goering, R. V. et al. (1995). Interpreting chromosomal DNA restriction patterns produced by pused-field gel electrophoresis: criteria for bacterial strain typing. J Clin Microbiol 33,2233-2239.

16. Shanahan, P. M., Wylie, B. A., Adrian, P. W. ef at (1993). The prevalence of antimicrobial resistance in human faecal flora in South Africa. Epidemiol Infect 111, 221-228.

17. Okeke, I. N., Faymka, S. T. \& Lamikanra, A (2000). Antibiotic resistance in Escherichia coli from Nigertan students, 1986 1998. Emerg Infect Dis 6, 393-396.

18. Adrian, P. V., Koornhof, H. J. \& Wylie, B. A. (1993). Trimethoprim resistance in South African isolaties of aetobic Gram-negatwe faecal flora. Eur J Clin Microbiol Infect Dis 12, 916 921.

19. Gulay, Z, Bicnen, M., Amyes, S. G. et al. (2000). Beta-lactamase patterns and betalactam/clavulanic acid resistance in Escherichia coli isolated from fecal samples from healthy volunteers. J Chemother 12, 208-21.5.

20. Rodriguez, A. ., Nino Cotrina, R. A., Neyra Perez, C., et al. (2001). Comparative study of antimicrobial resistance of Eschewichia coli strains isolated from uninary tract infection in patients from Caracas and Linuan J Antimicrob Chemother 47, 903-904.

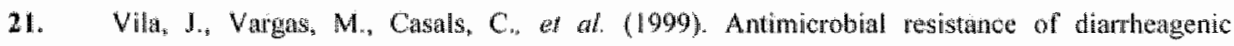
techerichia coll isolated from children under the age of 5 years from lfakara, Tamzania. Amtimicuob Agents Chemonhet 43,3022-3024.

22. Bonfighio, $\mathrm{G}_{\cdot *}$ simpore; J., Pignatelli, S., ef al. (2002). Epidemiology of bacterial resistance in gastro intestinal pathogens in a tropical area. Int J Amimicrob Agents 20, 387-389.

23. Gotuzzo, E., Seas, C., Echevaruia, I. et al. (1995). Ciprofloxacin for the treatment of cholera: a randomized, doublewblind, controlled climical trial of a single daily dose in Peruxiara adults. Clin Infect Dia 20, 1485-1490.

24. Butler, "T. (2001). New developments in the understanding of cholera. Cur Gastroevterol Rep 3, $3 \mid 5-321$.

25. Green, S \& Tillotson, G. (1997). Use of ciprofloxacin in developing countries. Pedhat Infect Dis $/ 16,150-159$; discussion $160-152$.

26. Hart, C. A. \& Kariuki, $\$$. (1998). Antimicrobial resistance in developing countries. Bnj 317, 647.650 
27. Walson, I. L., Marshall, B., Pokhrel, B. M., et al (2001) Carriage of antibiotic-resistant tecal bacteria in Nepal reflects proximity to Kathuandu. J Wfect Dis 184, $1163-1169$.

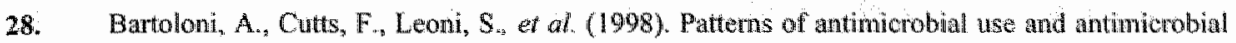
resistance among healthy children in Bolivia. Trop Med Wh Heath 3, 116-123.

29. Grenet, K. (2004). Antibacterial resistance, waympis amerindians, French guyana Energ lnfect Dis $10,1150-1153$.

30. Singer, R. S., Funch, R., Wegener, H. C. et al. (2003). Antibiotic resistance-whe interplay between antibiotic use in aninals and human beings. Lancer fofect Dis 3, 47\%51.

31. Calva, I. \& Bojalil, R. (1996). Antibiotic use in a periurban community in Mexicos a household and drugstore survey. Soc Sci Med 42, 1121-1128.

32. Trap, B., Hansen, E. H. \& Hogerzeil, H. V. (2002). Prescription habits of dispensing and non dispensing doctors in Zimbabwe. Health Pollicy Plan 17, 288-295. 


\section{Chapter 4}

Effect of hospitalization on the antibiotic resistance of fecal Enterococcus faecalis of surgical patients over time. 
CHAWR 


\section{Abstract}

The prevalence of antibiotic resistant Enterococcus faecalis was determined in feeal samples of 263 patients admitted to the surgical wards of three university-affiliated hospitals on admission, at discharge and 1 and 6 months after discharge.

A slight increase in the prevalence of antibiotic resistance of $E$. faecalis was found at discharge for the antibiotics tested compared to those on admission, vancomycin excepted. Six months after discharge the prevalence of resistance for amoxicillin $(0 \%)$, ciprofloxacin $(3 \%)$, erythromycin $(47 \%)$ and oxytetracycline $(60 \%)$ decreased to the level on admission (respectively $0 \%, 8 \%, 45 \%$ and $64 \%$ ). Gentamicin resistance was the same at discharge $(10 \%)$ as one month later $(12 \%)$, but decreased as well six months after discharge $(8 \%)$ to the level on admission $(7 \%)$.

In conclusion, hospitalization resulted in the study population in a slight increase in the prevalence of resistant fecal $E$. faecalis isolates at discharge which decreased again (slowly) to the level on admission six months after discharge. Thus the influence of hospitalization on the prevalence of antibiotic resistance in the extramural situation disappears between one and six months after discharge in this population.

\section{Introduction}

Despite the tremendous benefits of antibiotics for the treatment of a wide range of pathogens, an increase in antibiotic resistant bacteria has recently been observed worldwide. ${ }^{1-3}$ Of particular concern are the hospitals not only because of the antibiotic use both for therapy and prophylaxis ${ }^{4}$ but also because of the spread of resistant bacteria facilitated by a high patient population density and frequent contacts between health care workers and patients. ${ }^{3.5}$ Several studies addressed the relation between antibiotic use and antibiotic resistance $e^{6}$ in potential pathogenic micro-organisms as causative agents of nosocomial infections..$^{7-9}$ Up till now little attention has been paid to the effect of hospitalization and antibiotic use on the prevalence of resistance in the commensal fecal flora like E. coli and enterococci. The resistance of the commensal flora acquired during hospitalization may disseminate into the community after discharge just as community acquired resistance may act as a reservoir of antibiotic resistance for hospital outbreaks. Onlly limited studies addressed the dissemination of resistance between both populations. ${ }^{10}$

Enterococci belong to the commensal flora of the gastro-intestinal tract of humans and animals. "They are an important cause of nosocomial infections. ${ }^{12}$ Its success as a hospital pathogen is due to its intrinsic resistance to many antibiotics that are commonly used in hospitals such as cephalosporins and aminoglycosides ${ }^{\prime}$ and the emergence of glycopeptide resistance in this genus by mutation or transfer of resistance genes on plasmids or transposons. ${ }^{2,3}$ The ban of avoparcin, a glycopeptide like vancomycin 
widelly used as a growth promoter in animal husbandry, resulted already in a decrease in glycopeptide resistant enterococci in healthy volunteers without a recent (three-month) history of hospitalization. In hospitals the use of cephalosporins (and glycopeptides) selects for glycopeptide resistant enterococei. ${ }^{14,15}$

In this study the effect of hospitalization of patients admitted to surgical wards on the prevalence of antibiotic resistant $E$ faecalis, the dominant enterococcus species of the fecal flora, was studied in three university affiliated-hospitals in The Netherlands on admission, at discharge and 1 and 6 months thereafter. ln addition, the resistance patterns of the $E$ faecalis isolated at different points of time were determined. The study focused on surgical patients rather than on patients of other wards or Intensive Care patients as surgical patients are considered being representative for the average hospitalized patient.

\section{Materials and Methods}

\section{Patient population}

From March 1999 until February 2002 patients admitted to the surgical wards of the University Hospitals Maastricht (azM) and Groningen (azG) and the Erasmus Medical Center Rotterdam (azR) were asked to participate in the study. Upon inclusion, patients were requested to deliver a fecal sample on admission, at discharge, and one and six months thereafter. Patients' characteristics including gender, age and antibiotic use during hospital stay were registered. One and six months after discharge the patients were reminded to provide a fresh fecal sample and to complete a questionnaire on antibiotic use and re-hospitalization in the previous period. The Medical Ethical Committees of the University Hospitals Mastricht and Groningen and the Erasmus Medical Center Rotterdam approved the study.

\section{Exclusion criteria}

Patients were excluded if they were: 1) less than 18 years of age, 2) unable to give informed consent, 3) not living in The Netherlands during the last 6 months, 4) referred from a nursing home (long-term care facility), 5) transferred from/to another ward of the same or another hospital, or 6) hospitalized for less than two days. Moreover, if one of the first three fecal samples, i.e. the one on admission, discharge or 1 month after discharge was missing the patient was excluded as well. 


\section{Analysis of the fecal samples}

Fecal samples were diluted 1:10 in $0.9 \% \mathrm{NaCl}(\mathrm{w} / \mathrm{v})$ with $20 \%(\mathrm{v} / \mathrm{v})$ glycerol and stored at $-20^{\circ} \mathrm{C}$ at the microbiological laboratories of the respective thospitals. The samples of azR and azG were transported on dry ice to the microbiological laboratory of the azM for further analysis.

After thawing, $40 \mu \mathrm{l}$ of the $10^{-1}$ and $10^{-3}$ dilutions of the samples in $0.9 \% \mathrm{NaCl}(\mathrm{W} / \mathrm{V})$ were inoculated onto KF-Streptococcus agar ${ }^{\mathrm{TM}}$ plates (Oxoid CM 701, Basingstoke, England) with and without antibiotics using a spiral plater (Eddy Jet, IUL Instruments, I.K.S., Leerdam, The Netherlands) as described previously. ${ }^{16,17}$ The antibiotic concentrations incorporated in the agar plates (Table 1) were based on the NCCLS breakpoints. ${ }^{18}$ and adapted to make comparison with previous studies possible... ${ }^{16,17}$. After $48 \mathrm{~h}$ incubation at $42^{\circ} \mathrm{C}$ typical red or pink enterococci colonies were counted on the plates with and without antibiotics. The minimum detection level of enterococci was approximately 300 colony forming units per g feces. One typical colony was randomly picked from each plate showing growth and identified to the Enterococcus genus using tolerance to bile, esculin hydrolysis, growth in $6.5 \%(\mathrm{w} / \mathrm{v}) \mathrm{NaCl}$, and a positive pyrrolidonyl-arylamidase reaction (pyrrolidonyl-arylamidase tablets, Roseo, Taastrup, Denmark). For the identification of $E$. faecalis tellurite reduction was determined using tellurite tablets (Rosco, Taastrup, Denmark) on blood agar plates (Oxoid, Basingstoke, UK) after overnight incubation at $37^{\circ} \mathrm{C}$. In case of doubt, the identification was confirmed with the API 20Strep system ${ }^{\mathrm{TM}}$ (BioMérieux, Plainview, N.Y.). One $E$. faecalis isolate per fecal sample was stored at $-70^{\circ} \mathrm{C}$ in $0.7 \%$ peptone (w/v) with $30 \%$ glycerol $(v / v)$.

The prevalence of resistance was calculated as the number of samples with $E$. faecalis isolates resistant to a certain antibiotic divided by the total number of samples showing growth of $E$. faccalis multiplied by 100 . These percentages were determined for each point of time.

\section{MIC Distributions}

Minimum inhibitory concentrations (M\|Cs) of $E$ faecalis isolates of patients with this species in the first three samples $(n=40)$ were determined according to the Standard of the Dutch working Group on Antibiotic Policy (www.swab.nl). The microbroth dilution method with Iso-Sensitest broth ${ }^{\text {rm }}$ (Oxoid CM 473, Basingstoke, England), an inoculum of $5 \times 10^{5} \mathrm{cfu} / \mathrm{ml}$ and overnight incubation at $37^{\circ} \mathrm{C}$ was used. The following antimicrobial agents (range in $\mathrm{mg} / \mathrm{L}$ ) were tested: amoxicillin $(0.06-128$ ), wancomycin (0.12-256), teicoplanin (0.12-256), linezolid (0.03-64), ciprofloxacin $(0.03-32)$, clarithromycin (0.06-128), tetracycline (0.06-128), and chloramphenicol (0.12-256). High level resistance against gentamicin $(500 \mathrm{mg} / \mathrm{L})$ and streptomycin $(2000 \mathrm{mg} / \mathrm{L})$ was determined by the agar dilution method using BHI-agar (Oxoid CM 375, Basingstoke, 
England) according to NCCLS criteria: ${ }^{18}$ E faecalis $\mathrm{ATCC} 29212$ was used as reference strain.

\section{Statistical analysis}

Basic statistic were calculated using SPSS for Windows release 11.01 (SPSS inc., Chicago, Illinois). Confidence intervals for prewallences were calculated using the exact method $^{19}$ Calculations were performed using Microsoft Exicel 2000 (Microsoft Corporation) and StaTable version 1.0.1 (Cytel Software Corporation) to obtain the needed F-walues. If $95 \%$ confidence intervals (C) did not overlap differences were considered statistical significant. MIC-values were converted to a logarithmic scale with base 2 before statistical analysis. The non-parametric Spearmans Rho correlation coefficient was calculated to determine relations between the $\mathrm{MIC}$-values for the different antibiotics tested.

\section{Results}

\section{Patient population}

Of the 681 patients willing to participate in the study, 263 patients were included for the final analysis on admission, at discharge and one month thereafter. Six months after discharge 215 patients submitted a fecall sample. The main reasons for exclusion of patients were incompleteness of the samples (two or less), less than 2 days of hospital stay, and transfer to the ICU.

The number of patients on admission was comparable for the three hospitals as well as the mean age of the patients ( $58 \pm 15$ years). Furthermore, prophylactic antibiotics were used in $54 \%$ of the patients and $32 \%$ received antibiotics for therapy.

\section{Prevalence of antibiotic resistant $E$. faecalis}

Enterococei were isolated in $76 \%-88 \%$ of the fecal samples from the patient population at the different points of time. The most conmonly isolated species was $E$. faecalis $(47 \%-61 \%)$ followed by $E$. faecium $(26 \%-37 \%)$. Other species found in lower percentages were E. gallinarum $(3 \%), E$. casseliflavus $(3 \%), E$ avim $(3 \%)$, E. hirae $(7 \%)$ and $E$. mundri $(0,25 \%)$.

The prevalences of antibiotic resistance of the $E$. foecalis isolates at the different points of time are presented in Table 1. For all antibiotics tested vancomycin excepted, an increase in the prevalence of resistance was observed during hospitalization, i.e. between "on admission" and "at discharge". One month after discharge, the prevalence of resistance to ciprofloxacin and tetracycline decreased to a level being lower than that 
Table 1. The resistance percentage of fecal $E$ faecols isolates of surgical patients in thine

\begin{tabular}{|c|c|c|c|c|}
\hline $\begin{array}{l}\text { Antimicrobial } \\
\text { agent }(\mathrm{mg} / \mathrm{L})\end{array}$ & Time point & $\begin{array}{l}\text { Patients with } \\
\text { E. faecalis (n) }\end{array}$ & $\begin{array}{c}\text { Prevalence of } \\
\text { resistant } \\
\text { E. faecalis }(\%)\end{array}$ & $95 \% \mathrm{CI}$ \\
\hline Amoxicillin & admission & 97 & 0 & \\
\hline \multirow[t]{3}{*}{ (25) } & discharge & 136 & 5 & $2.7-12.6$ \\
\hline & 1 month & 109 & 2 & $0.6-12.3$ \\
\hline & 6 months & 104 & 0 & \\
\hline Ciprofloxacin & admission & 97 & 8 & $4.5-18.3$ \\
\hline \multirow[t]{3}{*}{ (4) } & discharge & 136 & 9 & $5.3-16.8$ \\
\hline & 1 month & 109 & 6 & $2.8-13.6$ \\
\hline & 6 months & 104 & 3 & $1.2=12.8$ \\
\hline Erythromycin & admission & 97 & 45 & $35.4-55.9$ \\
\hline \multirow[t]{3}{*}{ (10) } & discharge & 136 & 52 & $42.7-60.2$ \\
\hline & 1 month & 109 & 52 & $42.6-61.8$ \\
\hline & 6 months & 104 & 47 & $37.3-57.2$ \\
\hline Gentamicin HL & admission & 97 & 7 & $3.8-17.5$ \\
\hline \multirow[t]{3}{*}{$(500)$} & discharge & 136 & 10 & $5.9-17.4$ \\
\hline & 1 month & 109 & 12 & $7.3-21.6$ \\
\hline & 6 months & 104 & 8 & $4.2-17.2$ \\
\hline Oxytetracycline & admission & 97 & 64 & $53.6 \times 73.5$ \\
\hline \multirow[t]{3}{*}{ (25) } & discharge & 136 & 67 & $58.4-7.8 .8$ \\
\hline & II month & 109 & 59 & $49.0-68.0$ \\
\hline & 6 months & 104 & 60 & $49.5-691$ \\
\hline Vancomycin & admission & 97 & 3 & $1.3-13.6$ \\
\hline \multirow[t]{3}{*}{$(10)$} & discharge & 136 & 2 & $0.5-9.8$ \\
\hline & 1 month & 109 & 5 & $2.2-13.8$ \\
\hline & 6 months & 104 & 2 & $0.7-12.8$ \\
\hline
\end{tabular}

$H L=$ high level 
on admission ( $5,5 \%$ compared to $8 \%$ on admission for ciprofloxacin and $58 \%$ compared to $64 \%$ for tetracycline). For amoxicillin, erythromycin and gentamicin the resistance prevalences of the "on admission" samples was reached six months after discharge. Resistance to vancomycin decreased during hospitalization, increased one month after dischange, but decreased again six months thereafter to the same level as at discharge. for erythromycin $(45 \%, 52 \%, 52 \%$, and $47 \%$ respectively) and oxytetracycline $(64 \%$, $67 \%, 59 \%$, and $60 \%$ respectively) the highest prevalences of resistance were found for each point of time.

\section{MIC-distribution}

In total 120 E. faecalis isolates were tested (40 isolates on admission, at discharge and 1 month after discharge). All isolates were susceptible to amoxicillin, vancomycin, teicoplanin and linezolid. There were no differences in the number of multi-drug resistant $E$. faecalis isolates between the different points of time.

Analyzing the MIC-distribution patterns after conversion of the MIC-values to a logarithmic scale with base 2 a positive correlation was found between amoxicillin and respectively linezolid and ciprofloxacin. A positive correlation was also found between clarithromycin and respectively tetracycline and chloramphenicol.

\section{Discussion}

The rapid emergence of antibiotic resistant enterococci as important nosocomial pathogens has become a health care issue of great concern. ${ }^{2,3}$ The main reasons for resistance are selection by antibiotic use and dissemination of resistance genes and resistant bacteria, both factors which are important in a hospital setting.

The samples on admission, reflecting the extramural situation, did not show any significant differences in resistance prevalence between the three hospitals (data not shown). Similar results were obtained for the prevalences of resistance in the extramural situation for both $E$. coll and enterococci in the same three geographical regions. ${ }^{17}$ Based on these findings the total study population was analyzed as one group of patients. Furthermore only E. faecalis, the clinical most relevant species ${ }^{20.21}$ and the most isolated enterococcal species in this population, was analyzed.

The influence of hospitalization on the prevalence of antibiotic resistant fecal $E$. foccalis was determined in three university affiliated-hospitals in The Netherlands for patients admitted to the surgical wards on admission, at discharge and 1 and 6 months thereafter. The latter two samples were used to analyze the persistence of antibiotic resistance in the community over time.

Persistence of antibiotic resistance in the commensal flora of patients after discharge contributes to the reservoir of antibiotic resistant bacteria and resistance genes in the 
commumity. In addition, as $80 \%$ of the antibiotic use in humans is prescribed outside the hospital, in primary health care, selection and dissemination of cantibiotic resistance from the community into the hospital will contribute to the artibiotic resistance problems in hospitals.

In this study, the prevalence of resistance after discharge returned to the level before hospitalization within six months after discharge. Depending on the antibiotic tested, the time needed ranged from 1 month (ciprofloxacin and tetracycline) to six months (erythromycin and gentamicin). This difference might be explained by the difference in antimicrobials used in primary health care ${ }^{22}$ as well as differences in the properties of the antibiotics. In our patient population, unfortunately, no information was available on the individual use of antibiotics after discharge.

A limitation of the present study was that fecal samples were requested only one and six months after discharge. Therefore we do not know whether the level on admission was already reached shortly after one month. Monitoring the influence of hospitalization on the resistance prevalence after discharge collecting monthly fecal samples seens preferable but might negatively influence the compliance of the patients.

According to the power analysis $(\alpha=0,05$ and $\beta=0,2)$ the ninimum number of patients needed to detect a significant difference in the prevalence of resistance from $\mathbb{\|}$ $10 \%$ was $\sim 100$ for each point of time. To obtain this we included twice as many patients in each hospital. As the total number of patients in the final analysis was 263 and the number of patients with $E$. faccalis ranged from 97 to 136 sufficient patients were included at all time points. The large number of patients excluded was due to the lack of $\geq 2$ fecal samples/patient as the study had a long follow-up in the home enviromment.

The antibiotic susceptibility as MIC was performed only for E. faecalis isolates, which was the dominant species in three consecutive samples of the same patient. No significant differences in MIC-distribution between the different points were observed, which might be due to the low number of isolates tested. The positive correlation between amoxicillin and fluoroquinolone resistance in enterococci was found previously; $;^{23} 2491 \%$ of the ampicillin resistant enterococci in that study were ciprofloxacin resistant compared to $14 \%$ of the ampicillin susceptible strains. It is however not clear yet how this co-selection of ampicillin and ciprofloxacin resistance occurs. The relation between clarithromycin and tetracyeline resistance could be explained by the co-location of the resistance genes on the same plasmid. ${ }^{25.26}$ The positive correlation between amoxicillin and linezolid could neither be explained by a similar mode of action ${ }^{27}$ against bacteria nor by comparable mechanisms of resistance ${ }^{27}$ against both agents. Since linezolid has only been recently available on the market, similar findings were not yet found in the literature and further investigation is needed to determine whether this finding is a coincidence or a real relation between both agents exists.

In conclusion, hospitalization caused in the population studied a slight increase in the prevalence of antibiotic resistance after discharge, which decreased again to the level on 
admission within six months after discharge. In this population there is only a slight contribution of hospitalization to the persistence of antibiotic resistance in the commensal flora of patients after discharge. This might be due to the relatively short hospitalization period (mean \pm 8 days/patient) and the low antibiotic use in this group of patients. This group was analyzed as being representative for the average hospitalized patient in The Netherlands. Further antibiotic resistance surveillance studies both in the hospital and the community, with different patient populations, are necessary including the dissemination from the hospital into the community and vice versa to analyze their mutual interaction.

\section{Acknowledgements}

This investigation was financially supported by the foundation "ZorgOnderzoek Nederland" (grant no: : 97-1-104). We thank the patients for participating in the study, the nursing staff of the surgical wards for their assistance in collecting the fecal samples, C. Driessen, N. London and P.J.E. Roovers for their technical support.

\section{References}

1. van den Bogaard, A. E., Willems, $\mathbb{R}_{\text {, }}$ London, $\mathbb{N}$, et al (2002). Antibiotic resistance of faecal enterococci in poultry. poultry farmers and poultry slaughterers. I Antimicrob Chemother 49 , 497-505.

2. Gold, H. S. \& Moellering, R. C., Jr. (1996). Antimicrobial-drug resistance. N Engl J Med 335, 1445-1453.

3. Struelens, M. J. (1998). The epidemiology of antimicrobial resistance in hospital acquired infections: problems and possible solutions. Bmi 317, 652-654.

4. Gaynes, R. M Moniet, D. (1997). The contribution of artibiotic use on the frequency of antibiotic resistance in hospitals. Ciba foumd Symp 207, 47-56; discussion 56-60.

5. Levin, S. A. \& Andreasen, V. (1999). Disease transmission dynamics and the evolution of antibiotic resistance in hospitals and communal setings Proc Narl Acad Sci U S A 96, 800-801.

6. Donnan, P. T., Wei, L., Steinke, D. T. et al. (2004). Presence of bacteriuria caused by trimethoprim resistant backeria in patients prescribed antibiotics: multilevel model with practice and individual patient data. Bmj 328, 1297.

7. Bromawaer, S. L, Cars, O., Buchiolz, U., et al. (2002). A European study on the relationship batween antimicrobial use and antimicrobial resistance. Enterg infect Dis 8, 278-282.

8. Murzny, B. E. (1992). Problems and dilemnas of antimicrobial resistance. Pharnacotherapy 12, 865-93S,

9. Hospital Infection Control Policies Advisory Committee (H.l.C.P.A.C.) (1995). Recommendations for preventing the spread of wanconycin resistance. Emerg. Infect Dis 1, 66. 


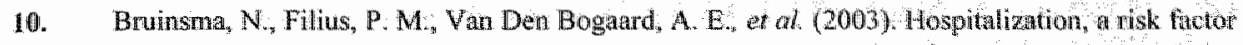

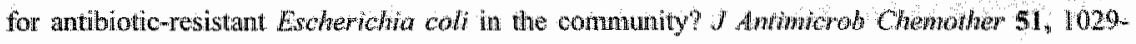
1032

11. Flahaut, $\mathrm{S}$, Frere, $\mathrm{I}$, Boutibonnes, $\mathrm{P}$, ef $\mathrm{al}$ (1996). Comparison of the bile salls and sodiun

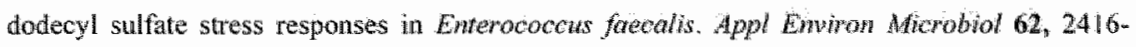
2420 .

12. Gordon, S., Swenson, J. M., Hill, B. C. ef al. (1992). Antimicrobial susceptibility patterins of common and unusual species of enterococci causing infections in the United States. Enteropoccal Study Group. I Clim Microbiol 30, 2373-2378.

13. van den Bogaard, A. E., Bruinsma, N. \& Stobberingh, E. E (2000). The effect of banuing avoparcin on VRE carriage in The Netherlands. J Anmicrob Chemonner 46, 146-148.

14. Chavers, L. S., Moser, S. A., Funkhouser, E, at al (2003). Assaciation between antecedent intravenous antimicrobial exposure and isolation of vancomycin-resistant enterocoeci. Microb Drug Resist 9 Suppl 1, \$69-77.

15. Rao, G. G., Ojo, F. \& Kolokithas, D. (1997). Wancomycin-resistant Gram-positive cocci: risk factors for faecal carriage. I Hosp Infect 35, 63-69.

16. London, N., Nijsten, R, vd Bogand, A. ex al. (1993). Antibiotic resistance of facenl Enterobacteriaceae isolated from healthy volnnteers, a 15 -week followmu study. $J$ Antimicrob Chemother 32, 83-91.

17. Bruinsma, N., Filius, P. M., De Smet, P. A., et al. (2002). Antilyiotic usage and resistance in different regions of the Dutch conmunity. Microb Drug Resist 8, 209-214.

18. NCCLS (2002). National Committee for Clinical Laborthory Standards. Merhods for dilution Animicrobial Susceptibility Tests for bacteria that grow Acrobically-Fifth Edition: Approved Standard M7.A5. NCCLS, Fillanova, PA, USA.

19. Armitage, P. \& Berry, G. (1991). Second Edition adn. Blackwell Scientific Publications.

20. Graninger, W. \& Ragette, R. (1992). Nosocomial bacteremia due to Enterococcus faecalis without endocarditis. Clin lnfect Dis $15,49.57$.

21. Patterson, J. E., Sweeney, A. H., Simms, M. ef an. (1995). An wnalysis of llo serious enterococal infectnons. Epidemiology, antibiotic susceptibility, and ontcome. Modicine (Balliwhore) $74,19-200$.

22. SWAB. NethMap 2004-Consumption of antimicrobial agents and antimicrobial resistance among medically important bacteria in the Netherlands.

23. Willamson, J. C., Craf, D. W., Butts, J. D., et al. (2002). In vitro assessment of urinary isolates of ampicillin-resistant enterococci. Ann Phomacoiher $36,246-250$.

24. Torell, E., Cars, O, Ofsson-Liljequist, B., et at. (1999). Near absence of valloomycin-lesistant enterococci but high carriage rates of quinolone-resistant ampicillin-resistant enterococci among hospitalized patents and non-hospitalized individuals in Sweder. I Clin Microbiol 37, 3509. 3513 .

25. Murray, B. E. (1991). New aspects of antimicrobial resistance and the resulting therapeutic dilemunas. J Infer Dis 163, 1184-1194. 
26. Strant, M. de Cespedes, G. \& Horad, T. (1996). Plesmid-borne high-\#evel resistance to gentamicin in Enterococcus hirae, Enterococcus avizm, and Enterococcus raffinosus. Antwicrob Agents Chemother 40, $1263-1265$.

27. Bozdogan, B \& Appelbaum, P. C. (2004). Oxazolidinones, activity, mode of action, and mechanism of resistance Int Anthicrob Agents $23,113-119$. 


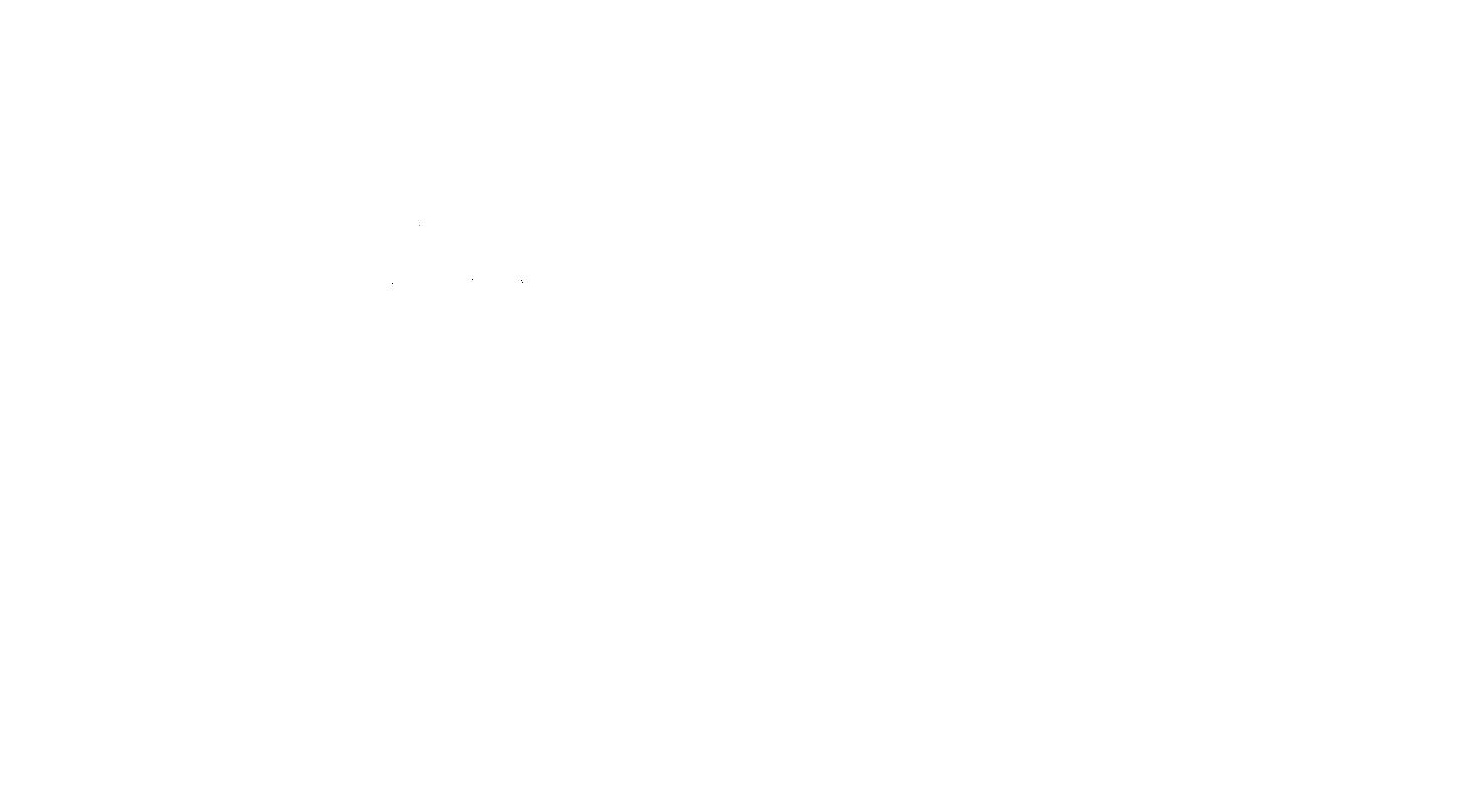


\section{Chapter 5}

Acute uncomplicated lower urinary tract infections in general practice: clinical and microbiological cure rates after three versus five day treatment with trimethoprim; a randomizedcontrolled trial 


\section{UANTWR}




\section{Abstract}

Epidemiological studies indicate that acute uncomplicated urinary tract infections (UTIs) in women can be successfully treated with short treatment regimens. However, the findings from the literature do not match the daily practice experience.

In this study the microbiological and clinical (self-reported) cure rate in a randomizedcontrolled trial of a three-day vs. five-day treatment regimen with trimethoprim for UTIs in women were evaluated.

No statistically significant difference in bacteriological cure rate was found between the three-day and the five-day regimen. One day after the shorter regimen $44 \%$ of women considered themselves as "not-recovered" due to persistence of the symptoms compared to $35 \%$ after the five-day treatment ( $p>0.05$ ). Three days after therapy these percentages were $30 \%$ and $25 \%$ respectively.

The relatively high percentage of persistent complaints one day after the three-day regimen might be responsible for the experience of general practitioners believing that short regimens are not successful. It is therefore advisable to control urine samples at least three days after finishing treatment.

\section{Introduction}

Acute uncomplicated urinary tract infections (UTIs) are a frequent cause of consulting a general practitioner (GP): $40 \%-50 \%$ of all women suffer at least once in their life from a UTI. ${ }^{1}$ Most lower urinary tract infections in women are caused by Escherichia coli. with Proteus spp., Staphylococcus saprophyticus and Klebsiella spp. as less frequent pathogens. $^{2}$

The optimal duration of antibiotic treatment remains a matter of debate. Single dose or short (three days) treatment improves compliance and reduces the chance of "selection of antibiotic resistance $e^{3}$ of the causative as well as the commensal micro-organisms, and is therefore more advantageous for both patient and doctor. Several studies have suggested good efficacy of three-day treatment as compared to regimens of seven to ten days. ${ }^{4-7}$ However, experiences of GPs 'in the field" suggest that patients after a three-day treatment regimens return more often because of persisting complaints. Therefore, some GP's still prescribe five to seven days of therapy.

In the present study we evaluated the microbiological and clinical (self-reported) cure rate of a 3-versus 5-day treatment course with trimethoprim for uncomplicated UTIs in a blinded randomized-controlled trial in women in the general population of the city of Maastricht, The Netherlands. Furthermore, the prevalence of trimethoprim resistant $E$. coli was assessed before the start of therapy as well as 1 and 3 days after the end of therapy. In addition, the percentage persistent infections with a trimethoprim resistant $E$ coli was determined. 


\section{Materials and Methods}

\section{Patients}

Non-pregnant female patients aged $13-77$ year presenting to their GP with either dysuria, stratiguria, urinary frequency or urgency in the past 24 hours were included in the study as shown in the flow chart (Figure 1). Exclusion criteria were known diabetes, known structural abnormalities of the urinary tract, indwelling catheters, use of immunosuppressive drugs and allergy to trimethoprim. Also patients with symptoms of acute pyelonephritis or with a known UTI within the last three months were excluded from the study. When the GP did not intend to treat the patient with an antibiotic the patient was not eligible for participation in the study. Informed consent was obtained from all participants before enrolment.

Upon inclusion, the patients received a prescription for either a three- or five-day regimen of trimethoprim in a closed envelope from their general practitioner. The reatment strategy was computer-aided randomized (www randomizer.org) for each general practice, and blinded for the physician. Before treatment $(t=0)$, a urinary sample was collected, as well as one and three days after completion of the therapy (respectively $t=1$ and $t=3$ ). On these days the patient filled out a questionnaire asking for (the relief of symptoms (Figure 1).

In order to detect a higher efficacy of the 5-day regimen of 10\% compared to the 3-day regimen with a cure rate of $90 \%$ for trimethoprim 142 patients per treatment regimen were needled ( $\alpha=0.05$ and $\beta=0.2$ ). In total 324 patients were included by 9 general practitioners.

\section{Sample Processing}

Fresh urine samples were used for the preparation of a standard dipslide culture and subsequently sent to the department of Medical Microbiology of the University Hospital Maastricht, The Netherlands. For identification of the micromorganisms standard laboratory methods were used. The antimicrobial susceptibility was performed according to the SWAB (Stichting Werkgroep Antibiotica Beleid) standard (www.swab.nl).

\section{Data Analysis}

Women stating in the questionnaires ( 1 question on general well being and 7 specific questions on UTI symptoms) after treatment that they had no more complaints were considered as "recovered", those mentioning still urinary complaints were considered "not-recovered". 
Figure 1. Flow chart of the study design

Female patients aged $13-80$ years

Complaints of UTI

No history of UTIs in the last 3 months.

No unine sample

$(n=68)$

$1=0$

No urine sample

$(n=13)$

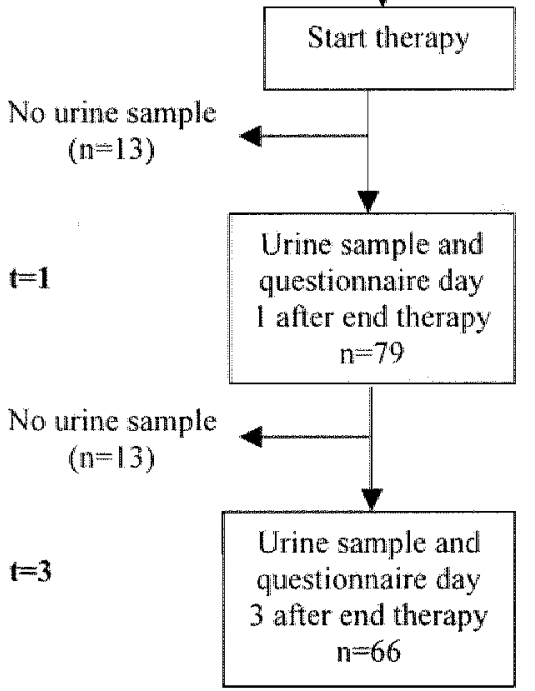

5-days

trimethoprim $n=164$

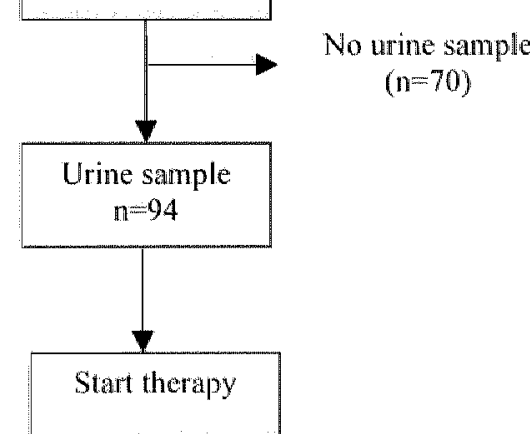

No urine sample $(n=18)$

Urine sample and questionnaire day $\|$ after end therapy $\mathrm{n}=76$

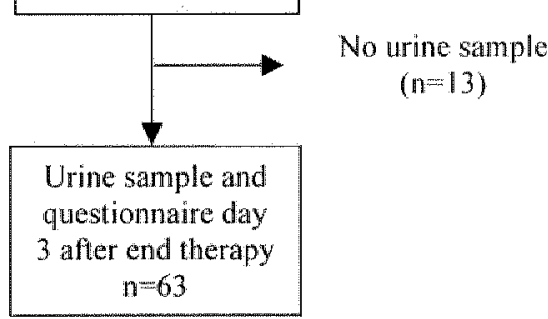


Only patients that completed both questionnaires and from whom all three urine samples were collected were included in the final analysis. Comparison of the treatment regimens; the prevalence of symptoms and side-effects were tested for statistical significance with the Pearson Chi-Square Test. A p-value $<0.05$ was considered as statistically significant.

\section{Results}

A total of 324 patients were randomly assigned to either treatment group: 160 to the 3day and 164 to the 5-day trimethoprim regimen (Figure 1). No baseline urine sample $(t=0)$ was received from 68 and 70 patients of the 3 - and 5-day treatment regimen respectively. Fifty-seven patients were excluded due to the lack of the follow-up urine samples $(t=1$ and $t=3)$. In the final analysis for the three-day regimen 66 women (mean age: $43 \pm 17$ years) and for the five-day treatment group 63 women (mean age: $44 \pm 16$ years) were included.

$E$. coli was isolated in almost $65 \%$ of the urine samples before antibiotic treatment was started (Table 1). Both one and three days after the 3-day antibiotic therapy nine samples $(14 \%)$ were still positive for $E$. coli. Trimethoprim resistant isolates were found in seven and eight of these follow-up samples respectively. One and three days after the five-day therapy course eleven out of twelve and nine out of ten samples respectively showed growth of trimethoprim resistant $E$. coli. Trimethoprim resistance observed before treatment persisted one and three days after both therapy regimens in all but two cases. In four patients trimethoprim resistance developed during therapy, two patients in each therapy reginen.

Table 1. Culture results of urine samples in numbers (percentages) respectively before, one day after and three days after treatment.

\begin{tabular}{|c|c|c|c|c|c|c|}
\hline \multirow[b]{2}{*}{ Micromorganism } & \multicolumn{2}{|c|}{$\begin{array}{c}\text { Before } \\
\text { treatment }\end{array}$} & \multicolumn{2}{|c|}{$\begin{array}{l}1 \text { day after } \\
\text { treatment }\end{array}$} & \multicolumn{2}{|c|}{$\begin{array}{c}3 \text { days after } \\
\text { treatment }\end{array}$} \\
\hline & $3 \mathrm{D}$ & 50 & $3 \mathrm{D}$ & SD & $3 \mathrm{D}$ & $5 D$ \\
\hline Total Escherichia coli & $42(64)$ & $38(60)$ & $9(14)$ & $12(19)$ & $9(14)$ & $10(16)$ \\
\hline Trimethoprim resistant $E$ coli & 4 & 9 & 7 & 11 & 8 & 9 \\
\hline Proteus mirabilis & $5(8)$ & $3(5)$ & - & - & - & - \\
\hline other & $6(9)$ & $5(8)$ & $8(12)$ & $2(3)$ & $13(19)$ & $1(2)$ \\
\hline Negative' $^{3}$ & $13(20)$ & $17(27)$ & $49(74)$ & $49(78)$ & $44(67)$ & $52(83)$ \\
\hline
\end{tabular}


Table 2 depicts the results from the questionnaires conbined with the number (percentage) of trimethoprim resistant $E$. coll isolated for both time points after the end of therapy. Twenty-two patients $(35 \%)$ reported "not-recowered" one day after a fiveday treatment regimen compared to twenty-nine patients $(44 \%)$ after a three-day regimen ( $p>0.05)$. Of those who considered themselves as "recovered" mimethoprin resistant $E$. coll were found in $10 \%$ to $24 \%$ of the patients. In the "mot-recovered" patient group these percentages ranged from $24 \%$ to $36 \%$.

Table 2. Recovery (rate) from urinary tract infections according to self-reported complaints in the questionnaires and the number (percentage) of trimethoprim resistant $E$. coli.

\begin{tabular}{llllll}
\hline & & \multicolumn{2}{c}{ 3-day regimen } & \multicolumn{2}{c}{ 5 day-regimen } \\
Self-reported & & Day after treatment & \multicolumn{2}{c}{ Day after treatment } \\
\hline recoveredl & patients & $33(50)$ & $39(59)$ & $35(56)$ & $39(62)$ \\
& Tri resistant & $8(24)$ & $9(23)$ & $6(17)$ & $4(10)$ \\
\hline \multirow{2}{*}{ not-recovered } & patients & $29(44)$ & $20(30)$ & $22(35)$ & $16(25)$ \\
& \begin{tabular}{l} 
Tri resistant \\
\cline { 3 - 6 }
\end{tabular} & $7(24)$ & $6(30)$ & $8(36)$ & $5(31)$ \\
\hline \multirow{2}{*}{ unclear } & patients & $4(6)$ & $7(11)$ & $6(10)$ & $8(13)$ \\
& Tri resistant & $2(50)$ & $3(43)$ & $1(17)$ & 0 \\
\hline
\end{tabular}

Tri = trimethoprin

\section{Discussion}

In the present study no significant differences in bacteriological cure rate were found between the three-day and five-day trimethoprim treatment regimen both one and three days after completion of the therapy. The percentage trimethoprim resistant $E$ coli was also similar in both groups. Results in this study stipport previous findings that short courses of 3 days of antibiotics are as effective as longer courses in the treatment of an uncomplicated UTI., In addition, a three-day treatment, with the advantages of lower costs, less side-effects and better patient compliance, is as effective as a longer treatment regimen. Similar findings were found for short treatment regimens with fluoroquinolones. ${ }^{3}$

However, relief of symptoms is also an important issue for the patient and for the GP. In the three-day treatment group twenty-nine patients $(44 \%)$ considered themselves "notrecovered" one day after the end of the therapy. Whis means that these patients were not symptom-free when they delivered their control urine sample. A non-recovery rate of 
$44 \%$ is considerable and unsatisfactory for the GP. Although the recovery rate between the two treatment groups was not significant different, we assume that the difference in self-reported cure rate, i.e. $56 \%$ versus $65 \%$, is very likely the reason why experienced (and older) GPs consider a three-day regimen as less reliable especially as recommendations for shorter treatment strategies are relatively recent.

The relatively high percentage of trimethoprim resistant $E$. coli isolates before treatment $(13 / 80,16 \%)$ however, raises the question whether trimethoprim is still a good agent of first choice for (emperic) therapy of UTIs in The Netherlands. In the present study the isolates were derived from samples from the Maastricht area only, but recent susceptibility data of $E$. coli isolated from unselected urine samples of general practice patients all over The Netherlands showed similar resistance percentages. ${ }^{10}$ The relatively high percentages of trimethoprim resistant $E$. coli isolates in the group of patients who considered themselves as "recovered" underscores the natural course of an acute uncomplicated UTI." Furthermore, patients who considered themselves as "recovered" more often showed a low count bacterial culture as those who considered themselves as "not-recovered". It might be that due to this low number of bacteria the clinical symptoms are not as obvious and the patients considered themselves as recovered.

One limitation of the study is that the number of patients in the final analysis were not large enough to reach statistical significant differences between both treatment groups. It proved to be difficult to perform this kind of study in general practices, mostly because of perceived lack of time of the doctors and nurses. Despite this limitation and based on the data presented an advice for daily practice might be that GPs inform their patients that a three-day antibiotic therapy is effective but it takes several days for complete relief of the complaints. Comparing the recovery rate 6 days after the start of therapy, i.e. 3 days after the 3-day course and 1 day after the 5-day regimen similar percentages of patients reported themselves as recovered. This is probably due to the natural course of the disease. Therefore, if control urine samples are tested this has to be done at leasist three days or more after the end of the treatment. Christiaens et al. ${ }^{11}$ used a seven-day period after treatment before samples were controlled. Control for clinical and bacteriological recovery directly after treatment will result in disappointment both for the patient and the GP.

\section{Acknowledgements}

We would like to thank the general practices of Dr. Lauw, Dr. Wielders, Dr. van Merode, Dr. Goudriaan, Dr. Peeters, Dr. Vissers, Dr. Raenaekers, Zuidweg, and Dr. Screever and all the patients participating in this study. 


\section{References}

1. Foxman, B., Barlow, R., D'Arcy, H., er at. (2000). Urinary tract infection: self-reponted incidence and associated costs. Am Epidemiol 10, 509-515.

2. Ronald, A. (2002). The etiology of urinary tract infection: traditional and emerging pathogens. Am J Med 113 Suppl 1A, 14S-19S.

3. Richard, G. A., Mathew, C. P., Kirstein, J. M., et al. (2002). Single-dose nuoroquinolone therapy of acute uncomplicated urinary tract infection in women: results from a randomized, double-blind, multicenter trial comparing single-dose to 3-day fluoroquinolone regimens. Urology 59, 334-339.

4. Henry, D. C., Nenad, R. C., Iravani, A., et al (1999). Comparison of sparfloxacin and ciprofloxacin in the treatment of community-acquired acute uncomplicated urinary tract infection in women. Sparfloxacin Multicenter Uncomplicated Urinary Tract Infection Study Group. Clin Ther 21, 966-981.

5. Trienekens, T. A., London, N. H., Houben, A. W., et al. (1993). Treating acute urinaty tract infections. An RCT of 3-day versus 7-day norfloxacin. Can Fam Plysician 39, 514-518.

6. Gossius, G. \& Vorland, L. (1984). A randomised comparison of single-dose vs. threewday and ten-day therapy with trimethoprim-sulfamethoxazole for acute cystitis in women. Scand J Infect Dis 16, 373-379.

7. Lutters, M. \& Vogt, N. (2002). Antibiotic duration for treating uncomplicated, symptomatic lower urinary tract infections in elderly women. Cochrane Database Syst Rev CD001535.

8. Trienekens, T. An, Stobberingh, E. E., Winkens, R. A. ef al. (1989). Different lengths of treatment with co-trimoxazole for acute uncomplicated urinary tract infections in women. British Medical Journal 299, 1319-1322.

9. Lawrenson, R. A. \& Logie, J. W. (2001). Antibiotic failure in the treatment of urinary tract infections in young women. J Antimicrob Chemother 48, 895-901.

10. SWAB. NethMap 2004-Consumption of antinicrobial agents and antimicrobial resistance among medically important bacteria in the Netherlands.

11. Christiaens, T. C., De Meyere, M., Verschraegen, G., et al. (2002). Rancomised controlled trial of nitrofurantoin versus placebo in the treatment of uncomplicated urinary tract infecion in adult women. Br.J Gen Pract 52, 729-734. 


\section{Chapter6}

Urinary tract infections in general practice patients: diagnostic tests versus bacteriological culture 
CUAMR 


\section{Abstract}

Urinary tract infections (UTIs) are common bacterial infections encountered in general practice. For the optimal treatment of a UTI the general practitioner (GP) should rely on the results of diagnostic tests and recent antimicrobial susceptibility percentages of unselected uropathogens.

In a study on acute momplicated UTls in 1993 female patients between $11-70$ years old in 2003-2004 in The Netherlands the performance characteristics of the diagnostic test(s) used by the GP were determined and compared with the antibiotic prescription rate. For different age groups the choice and duration of the antibiotic treatment; the uropathogens and the antibiotic susceptibility of Escherichia coli were determined.

The positive predictive value (PPV, 96\%) and the specificity $(94 \%)$ of the nitrite test were high for all samples. A negative nitrite with a positive leukocyte-esterase test showed a high PPV (79\%) and sensitivity (82\%). When both nitrite and leukocyteesterase tests were negative $\sim 50 \%$ of the samples were culture positive. Antimicrobial therapy was prescribed in $96 \%$ of the patients with a positive nitrite and in $71 \%$ of those with a negative nitrite and positive leukocyte-esterase test. Nitrofurantoin and trimethoprim were the agents mostly prescribed. Nitrofurantoin prescription rate decreased and that of fluoroquinolones increased with increasing age $(p<0.01)$. Nitrofurantoin was prescribed with the same frequency for 3,5 or 7 days in all patients. Trimethoprim was mostly prescribed for 3 days in patients 21-50 years and for 5 days in the other ones. $E$. coli, the tropathogen mostly isolated, decreased in frequency with increasing age. The trequency of Proteus mirabilis and Staphylococcus saprophyticus was age dependent, i.e. $P$. mirabilis was more found in the oldest patients and $S$ saprophyticus in the younger ones. The antimicrobial susceptibility of $E$. coli was not age related. The lowest percentages were found for amoxicillin $(67 \%)$ and trimethoprim. $(77 \%)$. Fluoroquinolones resistance was emerging in the older patients.

For female patients with symptoms of an acute uncomplicated UTI a positive nitrite or a negative nitrite with a positive leukocyte-esterase test confirmed a UTI whereas a negative nitrite together with a negative leukocyte-esterase test did not nule out infection. For the empiric treatment of a UTI the GP should take into account the changing etiology with increasing age. Furthermore, prudent use of antimicrobial agents in general and more specific of fluoroquinolones remains recommended. As trimethoprim resistance reached $20 \%$ it is advisable to no longer use this agent as first choice in the treatment of acute uncomplicated UTIs in The Netherlands. 


\section{Introduction}

An acute uncomplicated urinary tract infection (UTI) is one of the most common bacterial infections in women. ${ }^{1-3}$ It is estimated that as many as $60 \%$ of all women report having had a UTI at least once in their lifetime., The majority of UTIs are caused by Escherichic coli followed by Staphylococcus saprophyricus, mainly in yourger women. Klebsiella, Proteus and Enterobacter species are isolated less frequently. ${ }^{5,7}$

For the diagnosis of a UTI the general practitioner (GP) can rely on, besides the symptoms of the patient, the results of the nitrite and leukocyte-esterase dipstick tests performed on the urine sample. In the first revision of the "Urinary Tract Guidelines" of the Dutch College of General Practitioners $(\mathrm{NGH})^{8}$ a urine sample with a positive nitrite test is considered positive and a specimen with a negative nitrite together with a negative leukocyte-esterase test is considered negative. Furthermore, urine specimens of symptomatic female patients should be considered as culture positive at $\geq 10^{2} \mathrm{cfu} / \mathrm{ml}$ and are called low count bacteriuria. ${ }^{8}$

Several studies in The Netherlands on the antibiotic susceptibility patterns of uropathogens showed an increased resistance to widely used agents like trimethoprim and amoxicillin. ${ }^{9}$ However, most information concerning the isolated uropathogens and their antimicrobial susceptibility was derived from samples send in by the general practitioners (GPs), after prior (once or twice) therapy failure has occurred. ${ }^{10}$ Therefore, these samples are likely to reflect a sample bias. Consequently an underestimation of the antibiotic susceptibility percentages of uropathogens from patients with an acute uncomplicated UTI is to be expected. ${ }^{11-13}$

Recent data on the antimicrobial susceptibility of uropathogens isolated from patients with an acute uncomplicated UTI visiting their GP, i.e. the "unselected" uropathogens are needed for the setup of evidence-based guidelines such as those of the NHG.

Therefore a study on acute uncomplicated UTIs in non-pregnant female patients between 11 and 70 years of age attending 21 general practitioners from the Sentinel Station of The Netherlands Institute for Health Services Research (NIVEL) was performed. In these patients care as usual of the GP concerning diagnostic procedures (i.e. nitrite and leukocyte-esterase tests) and the treatment prescribed (choice and duration of the antimicrobial agent) were compared with the bacteriological culture results and the antimicrobial susceptibility of all the unselected $E$. coli isolates, the most important uropathogen, was determined. 


\section{Materials and Methods}

\section{Patients and urine sample processing}

The patient population of the 21 general practices (GPs) from the Sentinel Station of The Netherlands Institute for Health Services Research (NIVEL) participating in the study accounts for about $1 \%$ of the Dutch population and is representative according to age, gender, regional distribution, and degree of urbanization.

From January 2003 until December 2004 the GPS recorded for non-pregnant female patients between 11 and 70 years old with symptoms of an acute uncomplicated UTI the care as usual, i.e. the results of the diagnostic tests (nitrite and leukocyte-esterase test) and the therapy prescribed (agent and duration). An acute uncomplicated UTI was defined as an infection with one or more of the following symptoms: dysuria, stranguria, urinary frequency, or urgency without the presence of fever $>38^{\circ} \mathrm{C}$.

A fresh voided (midstream) urine sample was used for diagnostic purpose by the GP, i.e. nitrite dipstick and/or leukocyte-esterase test. Subsequently a dipslide (Uriline, 56508, BioMérieux, Plainview, N.Y) was prepared according to the manufacturer's instructions and send to the laboratory of Medical Microbiology of the University Hospital Maastricht; The Netherlands for isolation and identification of the uropathogens and antibiotic susceptibility testing.

On the day of arrival, the dipslide was incubated overnight at $37^{\circ} \mathrm{C}$ (if necessary). Bacterial growth on the dipslides was recorded from no growth to $10^{7} \mathrm{cfu} / \mathrm{ml}$ according to the manufacturer's instructions and considered positive at $\geq 10^{3} \mathrm{cfu} / \mathrm{ml}$. Identification was performed using standard biochemical tests. ${ }^{14}$ If there remained any doubt about the identification API 20E, API20 NE, API 20 Strep or API Staph (BioMérieux, Plainview, NY) were used depending on the Gram-stain of the micro-organism. The isolated uropathogens were stored at $-70^{\circ} \mathrm{C}$ until further analysis.

\section{Antimicrobial susceptibility testing}

Minimum inhibitory concentrations (MICs) of the E. coli isolates were determined according to the CLSI-criteria (formerly the NCCLS) ${ }^{15}$ using the microbroth dilution method with Mueller Hinton II broth cation adjusted (Becton, Dickinson and Company, Sparks, USA), an inoculum of $5 \times 10^{\circ} \mathrm{cfu} / \mathrm{ml}$, and overnight incubation at $37^{\circ} \mathrm{C}$. The MIC-plates with freeze-dried antibiotics were provided by MCS Diagnostics BV (NLDMCS1, MCS Diagnostics BV, Swalmen. The Netherlands) and delivered after quality testing by the manufacturers and a shelf life of approximately one year was guaranteed. The following antimicrobial agents (range in $\mathrm{mg} / \mathrm{l}$ ) were tested: amoxicillin (0.06-128), co-amoxiclav (0.06-128), trimethoprim (0.03-64), co-trimoxazole (0.03-64), norfloxacin (0.03-64), ciprofloxacin (0.008-16), and nitrofurantoin (0.5-512). The reference strains $E$. coli ATCC 35218 and ATCC 25922 were used as control strains. 
The breakpoints for susceptibility were according to the CLSI-guidelines (formerly the NCCLS). ${ }^{13}$

\section{Statistical analysis}

The performance of the diagnostic tests, i.e. the positive predictive value (PPV), the negative predictive value (NPV), the sensitivity and the specificity of all samples was calculated for the nitrite test alone and for the leukocyte-esterase test in case of a negative nitrite test using culture $\geq 10^{3} \mathrm{cfu} / \mathrm{ml}$ as gold standard. Samples with a negative nitrite and an unknown leukocyte-esterase test result or both test results unknown were excluded for this analysis. For the analysis of the therapy prescribed (agent and duration), the causative uropathogens and the susceptibility of the $E$. coli isolates the patients were divided in three age categories: $11-20$ year, 21-50 year and 5 $\$-70$ year. ${ }^{16}$ For the analysis of the prescribed therapy norfloxacin, ciprofloxacin and ofloxacin therapy were totalized as the group of fluoroquinolones.

For the statistical analysis the program SPSS 11.0 for Windows was used. To detect significant differences between the age groups and the prescribed treatment, the bacteriological culture results and the antimicrobial susceptibility of the $E$. coli isolates the Mann-Whitney $U$ test was performed. A p-value of $p<0.05$ was considered significant.

\section{Results}

In total 1993 non-pregnant women with a mean age $( \pm S D)$ of $43 \pm 17$ year were enrolled in the study, half of which belonged to the age group 21-50 year.

The performance characteristics of the diagnostic tests performed by the GP for all patients are shown in Table 1 as there were no significant differences between the different age groups. The positive predictive value (PPV) of the nitrite test was $96 \%$ and the specificity $94 \%$. The negative predictive value (NPV) and sensitivity were $30 \%$ and $44 \%$ respectively. In case of a negative nitrite test result, the PPV of the leukocyteesterase was $79 \%$ and the sensitivity $82 \%$.

The prescription rate of the GPs for all patients in function of the nitrite and leukocyteesterase test results is shown in Table 2. Ninety-four percent of the patients with a nitrite positive urine sample received antimicrobial therapy. The majority of patients (71\%) with urine samples negative for the nitrite test and positive for the leukocyteesterase test did receive antimicrobial therapy. One fifth of the patients with urine samples showing both a negative nitrite and leukocyte-esterase tests were prescribed antibiotics. 
Table 1. Performance characteristics of the diagnostic tests performed by the GP in ail patients.

A. The performance of the nitrite vest:

\begin{tabular}{|c|c|c|c|c|c|c|}
\hline \multirow[b]{2}{*}{ Diagnostic test result } & \multicolumn{2}{|c|}{ Urine culture } & \multirow[b]{2}{*}{ PPV } & \multirow[b]{2}{*}{ NPV } & \multirow[b]{2}{*}{ Sens } & \multirow[b]{2}{*}{ Spee } \\
\hline & $\begin{array}{c}\geq 10^{3} \\
\mathrm{cfu} / \mathrm{m} !\end{array}$ & $\begin{array}{c}<110^{3} \\
\mathrm{cfu} / \mathrm{ml}\end{array}$ & & & & \\
\hline Nitrite positive & 662 & 25 & \multirow{3}{*}{96} & \multirow{3}{*}{30} & \multirow{3}{*}{44} & \multirow{3}{*}{94} \\
\hline & & & & & & \\
\hline Nitrite negative & 845 & 360 & & & & \\
\hline
\end{tabular}

B. The performance of the leukocyte-esterase test in case of a negative mitrite test:

\begin{tabular}{|c|c|c|c|c|c|c|}
\hline \multirow[b]{2}{*}{ Diagnostic test result } & \multicolumn{2}{|c|}{ Urine culture } & \multirow[b]{2}{*}{ PPV } & \multirow[b]{2}{*}{ NPV } & \multirow[b]{2}{*}{ Sens } & \multirow[b]{2}{*}{ Spec } \\
\hline & $\begin{array}{c}\geq 10^{3} \\
\text { cfu/mI }\end{array}$ & $\begin{array}{l}<110^{3} \\
\text { cfu/ml }\end{array}$ & & & & \\
\hline Leukocyte-esterase positive & 693 & 186 & & & & \\
\hline Leulocyfe-esterase negative & 152 & 174 & 79 & 53 & 82 & 48 \\
\hline
\end{tabular}

Table 2. The number (rate) of prescriptions of the general practitioner compared with the diagnostic test results.

Therapy preseribed

\begin{tabular}{lccc}
\multicolumn{1}{c}{ Diagnostic test result } & Yes & No & Unknown \\
\hline Nitrite positive & $648(94)$ & $28(4)$ & $11(2)$ \\
\hline $\begin{array}{l}\text { Nitrite negative } \\
\text { Leukncyte-esterase positive }\end{array}$ & $623(71)$ & $233(27)$ & $23(3)$ \\
Leukocyte-esterase negative & $64(20)$ & $240(74)$ & $22(7)$ \\
\hline Unknown & $63(62)$ & $16(16)$ & $22(22)$ \\
\hline
\end{tabular}


Figure 1. The percentage antimicrobial agents prescribed as therapy in patients with acute uncomplicated UTI per age category.

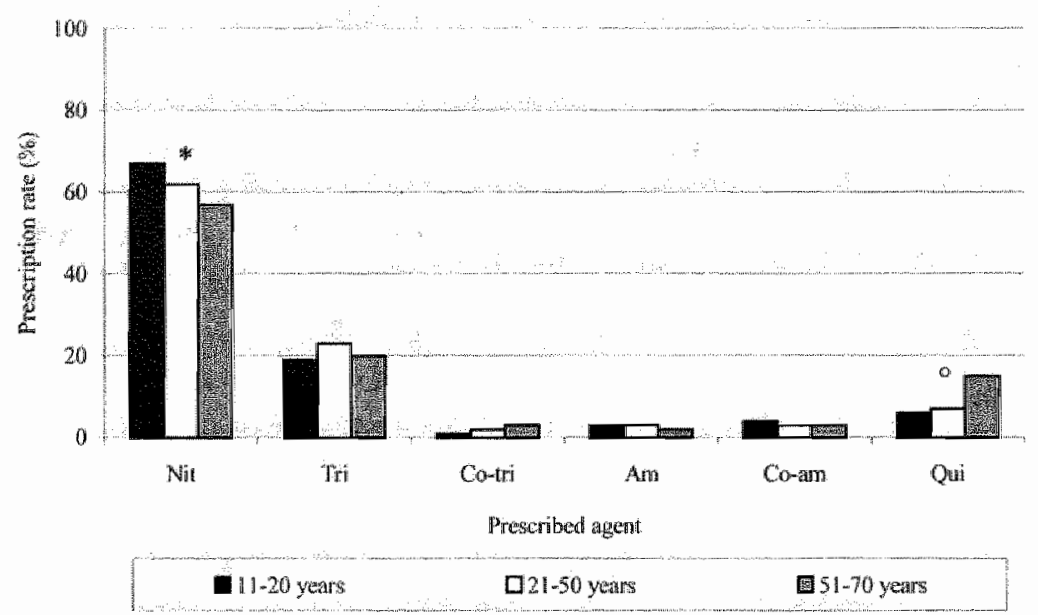

Nit $=$ nitrofurantoin, tri $=$ trimethoprim, co-tri $=$ co-trimoxazole, am = amoxicillin, co-am = co-amoxiclav, quil = fluoroquinolones

* significant decrease in the prescription rate between the youngest and the oldest patients $(p<0.05)$

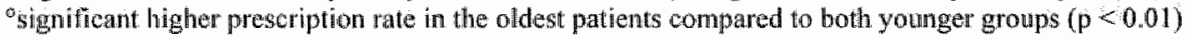

Figure 2. The duration of the antimicrobial therapy per age group for the three agents mostly prescribed.

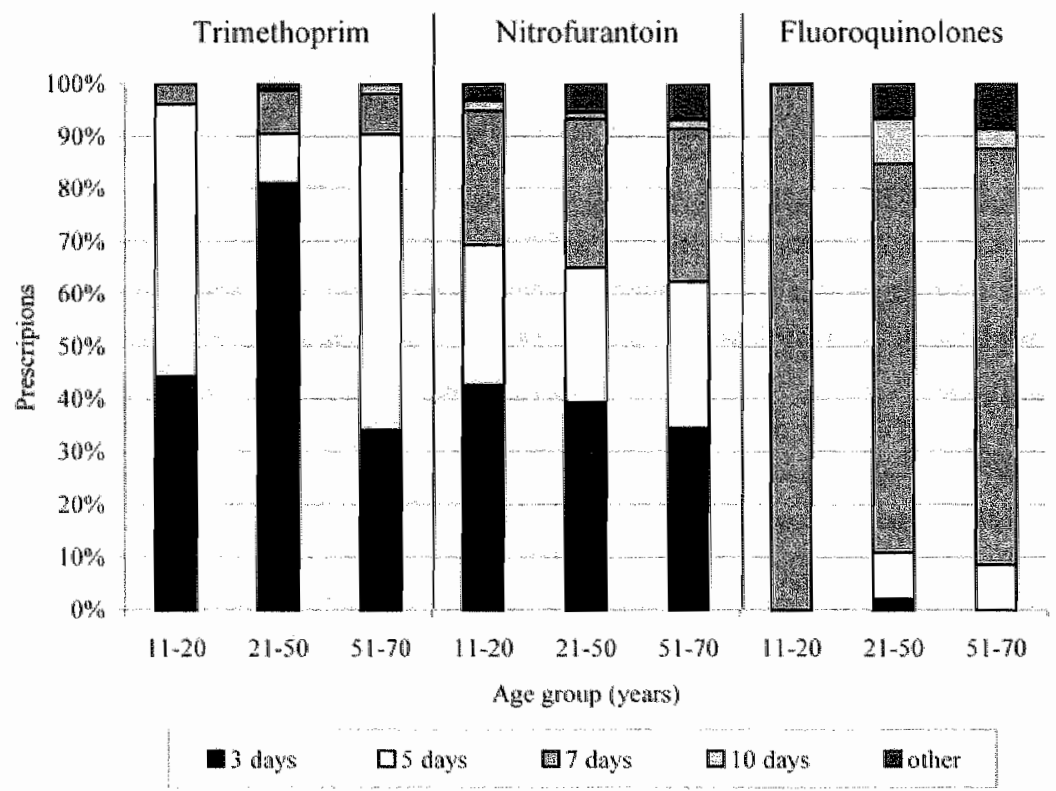


Seventy percent of all the patients were preseribed antibiotic therapy. Thmethoprim and nitrofurantoin were the agents prescribed most frequently in all the patients (Figure 1). The latter agent was significantly less prescribed in the oldest age category as compared to the youngest one $(\mathrm{p}<0.05)$. The prescription rate of the fluoroquinolones increased with increasing age $(\mathrm{p}<0.0 \mathrm{l})$. The duration of the treatment regimen prescribed in this patient population ranged from 3 to 7 or more days. Nitrofurantoin therapy was in all age groups prescribed with the same frequency as a 3-, 5- or 7-day regimen (Figure 2). The majority of the patients 21-50 years old ( $80 \%)$ were prescribed a 3 -day course of trimethoprim; a 5-day therapy was given to the other patients. Fluoroquinolones were mostly prescribed for 7 days in all the patients.

E. coli, the uropathogen isolated most frequently in all age groups, was proportionally less found in the oldest patients (Table 3). The frequency of isolation of Protews mirabilis and $S$. saprophyicus was age dependent, i.e. the prevalence of $P$. mixabilis increased and that of $S$. saprophyricus deceased with increasing age. The highest frequency of isolation of $S$. saprophricus: was found for the youngest age group.

The antimicrobial susceptibility percentages of the $E$. coli isolates from patients of the three age groups are shown in Table 4 . No significant differences in susceptibility percentages were found between the three age groups. The lowest susceptibility percentages were found for amoxicillin (67\%) and trimethoprim $(77 \%)$ Fluoroquinolone susceptibility was slightly lower in the patients over the age of 21 year.

Table 3. Percentage isolated uropathogens for each age group.

\begin{tabular}{|c|c|c|c|c|}
\hline \multirow[b]{3}{*}{ Micro-organism } & \multicolumn{3}{|c|}{ Age category (years) } & \multirow{3}{*}{$\begin{array}{c}\text { Total } \\
n^{=1583}\end{array}$} \\
\hline & $11-20$ & $21-50$ & $51-70$ & \\
\hline & $\mathrm{n}=165$ & $n=789$ & $n=629$ & \\
\hline E. coll & 69 & 66 & 65 & 66 \\
\hline P. mirabilis* & 1 & 4 & 6 & 5 \\
\hline K. pnewmoniae & 1 & 4 & 4 & 4 \\
\hline Psewdomonas spp. & 2 & 2 & 2 & 2 \\
\hline Acinetobacter spp. & 2 & 4 & 4 & 4 \\
\hline Other Gram-negatives & 7 & 7 & 9 & 8 \\
\hline S. saprophyricus & 7 & 4 & 0.5 & 3 \\
\hline Ef faecalis & 4 & 3 & 3 & 3 \\
\hline Other Gram-positives & 6 & 6 & 7 & 6 \\
\hline
\end{tabular}

* significant difference between the youngest and oldest patient group (Mann-Whitney U test; $p<0.02$ )

'significant lower percentage in the oldest patients compared to both other groups (Mann-Whitney U test; $\mathrm{p}=0.000$ ) 
Table 4. Susceptibility percentages of $E$. col isolated per age category.

\begin{tabular}{|c|c|c|c|c|}
\hline \multirow[b]{3}{*}{ Antibiotic } & \multicolumn{3}{|c|}{ Age cutegory (years) } & \multirow{3}{*}{$\begin{array}{l}\text { Totall } \\
\mathbf{n}=962\end{array}$} \\
\hline & $11-20$ & $21-50$ & $51-70$ & \\
\hline & $n=103$ & $\mathrm{n}=489$ & $n=370$ & \\
\hline Amoxictllin: & 75 & 65 & 68 & 67 \\
\hline co-amoxiclay & 98 & 98 & 98 & 98 \\
\hline Trimethoprim & 81 & 77 & 78 & 77 \\
\hline Co-trimoxazole & 83 & 80 & 80 & 80 \\
\hline Norfloxacin & 100 & 97 & 97 & 97 \\
\hline Ciprofloxacin & 100 & 97 & 97 & 97 \\
\hline Nitrofurantoin & 99 & 99 & 100 & 99 \\
\hline
\end{tabular}

\section{Discussion}

This study on acute uncomplicated urinary tract infections in non-pregnant female patients of 11 to 70 years of age among 21 general practices throughout The Netherlands was a nationwide study on acute uncomplicated UTIs dealing with the care as usual of the general practitioner, i.e. nitrite and leukocyte-esterase tests and the antibiotic therapy prescribed, bacteriological culture and the antimicrobial susceptibility of unselected $E$. coli isolates.

The nitrite dipstick test was very accurate in predicting a UTI $(\mathrm{PPV}=96 \%)$ and GPs prescribed in $>90 \%$ of the patients with a positive nitrite test antimicrobial therapy as recommended by the $\mathrm{NHG}^{8}{ }^{8}$ A negative nitrite test combined with a positive leukocyteesterase test showed a PPV of $79 \%$ whereas the NPV of a negative nitrite combined with a negative leukocyte-esterase test was moderate $(53 \%)$. According to the NHGguidelines the leukocyte-esterase test can be used to exclude a UTI in combination with a negative nitrite. However, our data showed that a positive leukocyte-esterase test with a negative nitrite test was predictive for a UTI in $79 \%$ of the patients and that in case of a negative leukocyte-esterase test (with a negative nitrite test) the chance on UTI was $53 \%$. The daily practice data of this study showed that the GP used the leukocyteesterase test often as diagnostic tool as $71 \%$ of the patients with a negative nitrite and positive leukocyte-esterase test were treated with antibiotic therapy. When both diagnostics test showed a negative result about $20 \%$ of the patients were treated with antibiotics whereas in almost $50 \%$ of these samples a positive culture $\left(\geq 10^{3} \mathrm{cfu} / \mathrm{ml}\right)$ was found. This discrepancy between the prescription rate $(20 \%)$ and the percentage culture positive urine samples $(50 \%)$ might be explained by the low cut-off value we used for 
positive culture. In the latest recommendation of the $\mathrm{NHG}^{8}$, however, it is stated that for symptomatic women a "low count" bacteriuria can be caused by $10^{2}-10^{4} \mathrm{cfu} / \mathrm{ml}$ and these infections should be considered a UTI. Furthermore, as bacteria need over 4 hours to convert nitrate into nitrite at a level that is reliably detectable, the time span might have been too short before collection of these urine samples and false negative test results could be obtained. ${ }^{17}$ Also, the biochemical reaction detected by the nitrite test is associated with members of the Enterobacteriaceae family but not with other uropathogens like $S$ saprophyticus, Psetidomonas spp. or enterococei. ${ }^{17}$ Indeed, in the nitrite and leukocyte-esterase negative samples of this study significantly less frequent $E$. coli, but more often Acinetobacter spp., other Gram-negatives and -positives and $E$. faecalis were found (Data not shown). In addition, by lowering the cut-off value for a positive urine sample to $\geq 10^{3} \mathrm{cfu} / \mathrm{ml}$ more low count urine samples are considered culture positive in which insufficient bacteria might be present to reduce nitrate in adequate amounts of nitrite for detection by the dipstick test. False positive nitrite test results were seen in $4 \%$ of the patients and might be due to anaerobic or fastidious micro-organisms not able to grow on the uricult dipslide. ${ }^{18}$ False positive leukocyteesterase results when the nitrite test was negative were found in $186(21 \%)$ urine samples and might be caused by the presence of bacteria of the vaginal fluid in the urine or the specimen might contain eosinophils which can act as a source of esterases. ${ }^{17}$

The antibiotic treatment prescribed most frequently in our patient population was according to the national guidelines. ${ }^{8}$ However the oldest patients were prescribed significantly less often nitrofurantoin and more frequently fluoroquinolones as compared to both younger groups. One reason for the GP to change his prescribing might be that nitrofurantoin is known to cause side-effects like nausea and vomiting, allergic, pulmonary, hepatic, neurological and hematological reactions, especially in older women. ${ }^{19}$ Another reason might be that older women more often have a history of $U T I^{20}$ and thus received more often therapy in the past. Fluoroquinolone therapy was also prescribed for longer durations in these older women probably to be sure of full eradication of the more resistant uropathogen. However, it is very likely that the increased prescription rate resulted in an increase in fluoroquinolone resistance in these patients. ${ }^{9}$

The uropathogens isolated in this patient population were similar to those in other studies. ${ }^{6,21-23} E$. coli, still the most prevalent uropathogen was proportionally less isolated in the oldest patients. $P$. mirabilis was more frequently found with increasing age. In post-menopausal women due to the loss of estrogen and consequently the depletion of vaginal colonization with lactobacilli ${ }^{16,18}$ other Gram-negative bacteria than $E$. coli can enter more easily the urinary tract and cause an infection. The percentage $S$. saprophyticus in the study of Christiaens et al. ${ }^{24}$ among patients between $15-50$ years old $(9 \%)$ was similar to the $7 \%$ found in our youngest age group (11-20 years) but higher than in our $21-50$ years old ( $4 \%$ ). This difference with our patients was probably caused by the differences in the age groups. 
The antimierobial stisceptibility data were analyzed for the $E$. coli isolates only as this was the most prevalent uropathogen isolated in all age groups. The susceptibility percentages of the unselected $E$. coli isolates for the three age groups were similar for all agents tested (amoxicillin in the youngest age group excepted). However, a tendency to an increasing fluoroquinolone resistance was found in the patients who were more often prescribed these agents. The susceptibility percentages of isolates from public health laboratories were lower compared to our data. ${ }^{9,10}$ As in both studies most urine specimens analyzed were send in by the GP after prior therapy failure or recurrent UTI, these "selected" isolates were more often exposed to antibiotics and thus more resistant. In conclusion, for symptomatic femalle patients between 11-70 years of age a urine sample with a positive nitrite test or with a negative nitrite test together with a positive leukocyte-esterase test should be considered having a UTI and treated accordingly. However, when both nitrite and leukocyte-esterase tests were negative, a UTI cannot be excluded and the samples should be further investigated by culture. Furthermore, the GP should take into account the age of the patient when prescribing antibiotic treatment as the etiology of a UTI is influenced by it. Prudent use of fluoroquinolones is strongly recommended as resistance is already emerging in the patients who use these agents more frequently. In addition, for an optimal empiric therapy the availability of actual clata on antimicrobial resistance percentages of unselected uropathogens are required and these data should be made available to the GPs for implementation in their daily practice. Finally, as trimethoprim susceptibility in E. coli isolated in this study decreased to $\sim 80 \%$ it might be advisable to limit its use as first agent in the treatment of an acute uncomplicated urinary tract infection in The Netherlands.

\section{Acknowledgements}

This research was funded by the Dutch Foundation of the Working Party on Antibiotic Policy (SWAB). We would like to thank all the General Practitioners of the Sentinel Station of The Netherlands Institute for Health Services Research (NIVEL) for their participation in the study and L. Hoffman and S. Tonnaer for their technical assistance. 


\section{References}

1. Warren, J. W., Abrutyn, E., Hebel, J. R, el od. (1999). Guidelines for antimicrobial treatment of uncomplicated acute bacterial cystitis and acute pyelonephritis in women. Infectious Diseases Society of America (IDSA). Clin Wnfect Dis 29,745-758.

2. Hooton, T. M., Besser, R., Foxman, B., et al. (2004). Acute uncomplicated cystitis in an era of increasing antibiotic resistance: a proposed approach to empirical therapy. Chin Infect Dis 39, 7580.

3. Huang, E. S. \& Stafford, R. S. (2002). National patterns in the treatment of urinary tract infections in women by ambulatory care physicians. Awoh Lnterm Med 162, 41-47.

4. Foxman, B. (2002). Epidemiology of urinary tract infections: incidence, morbidity, and economic costs. Am J Med 113 Suppl 1A, 5S-13S.

5. Foxman, B., Barlow, R., D'Arcy, H., et al. (2000). Urinary tract infection: self-reported incidence and associated costs. Amn Epidemiol 10,509-515.

6. Gupta, K., Hooton, T. M. \& Stamm, W. E. (2001). Increasing antimicrobial resistance and the management of uncomplicated community-acquired urinary tract infections. Am Interm Med $135,41-50$.

7. Fihn, S. D. (2003). Clinical practice. Acute uncomplicated urinary tact infection in women. $N$ Engl J Med 349, 259-266.

8. Wiersma, T. J. \& Timmermans, A. E. (200 I). [Sumnary of the 'Urinary tract infections' guideline (first revision) of the Dutch College of General Practitioners]. Ned Tijdschr Geneeskd 145, 735-739.

9. Goettsch, W., van Pelt, W., Nagelkerke, $N_{\text {, }}$ et al. (2000). Increasing resistance to fluoroquinolones in Escherichia coli from urinary tract infections in the Netherlands. $J$ Antimicrob Chemother 46, 223-228.

10. Fluit, A. C., Jones, M. E., Schmitz, F. J., et al. (2000). Antimicrobial resistance among urinary tract infection (UTI) isolates in Europe: results from the SENTRY Antimicrobiai Surveillance Program 1997. Antonie Van Leewwenhoek 77, 147-152.

11. Does, M. C. V. d., Duijn, N. P. V., Timmernan, C. P., er al. (1998). Antibioticaresistentic bij ongecompliceerde urineweginfecties. Hhisarts Wet 41, 421-423.

12. Hillier, S. L., Magee, J. T., Howard, A. J., ef at (2002). How strong is the evidence that antibiotic use is a risk factor for antibiotic-resistant, community wacquired urinary tract infection? $J$ Antwricrob Chemother 50,241-247.

13. Alos, 1. 1., Serrano, M. G., Gomez-Garces, J. L., et al. (2005). Antibiotic resistance of Escherichia coli from community-acquined urinary tract infections in relation to demographic and clinical data. Clin Microbial Infect 11, 199-203.

14. Isenberg, H. D. \& Panter, B. G. (1971). Comparison of Convetional Methods, the R / B System, and modified R/B System as Guides to the Major Diwisions of Enterobacteriaceae. Appl Microbiol 22, 1126-1134. 


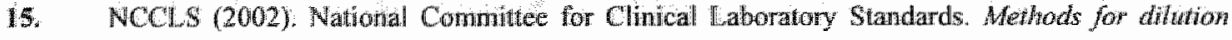

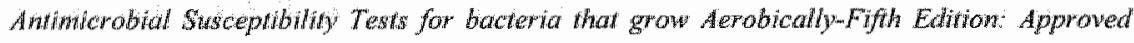
Wandard MT AS. NCCL, Willanowa, PA. USA.

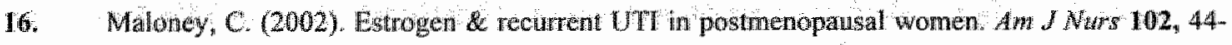
5.

17. Whison, M. L. \& Gado, L. (2004). Laboratory diagnosis of urinary tract infections in adult patents. Chm Infect Dis $38,1150-1158$.

18. Slamm, W. E. R Norby, S. R. (2001). Urinary tract infections: disease panorama and chitlenges. I Wfect Dis 183 suppl 1; \$ $1-4$.

19. Kunin, C. M. (2004). Inappropriate medication use in older adults: does nitrofurantoin belong on the list for the reasons stated? Anch Intern Med $164,1701$.

20. Nicolle, L. L. (1994) Urinary tract infection in the elderly. J Ammwcrob Chemolher 33 Suppl A. $99-109$.

21. Verest, L. F., van Esch, W. M., van Ree, J. W., et al (2000). Management of acute moomplicated urinary tract infections in general practice in the south of The Netherlands. Bit" $J$ Gen Pract 50, 309-310.

22. Kallmeter, G. (2003). An international surwey of the antimicrobial susceptibility of pathogens from uncomplicated urinary tract infections: the ECO.SENS Project. I Animicrob Chemorime $51,69-76$.

23. Arredondo-Garcia, J. L.. Figueroa-Damian, R., Rosas, A. ef at. (2004). Comparison of shortterm treatment regimen of ciprofloxacin versus long-term treatment reginens of trimethoprim/sulfamethoxazole or norfloxacin for uncomplicated lower urinary tract infections: a randomized, multicentre, open-label, prospective study. I Awimicrob Chenother 54, 840-843.

24. Chrigtimens, $\mathrm{T}$. H., Heytens, $\mathrm{S}$, Verschraegen, $\mathrm{G}_{\mathrm{n}}$ ef al (1998). Which bacteria are found in Belgian women with uncomplicated urinary tract infections in primary health care, and what is their susceptibility pattern anno 95-96? Acta C/m Belg 53, 184-188. 


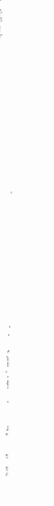

:

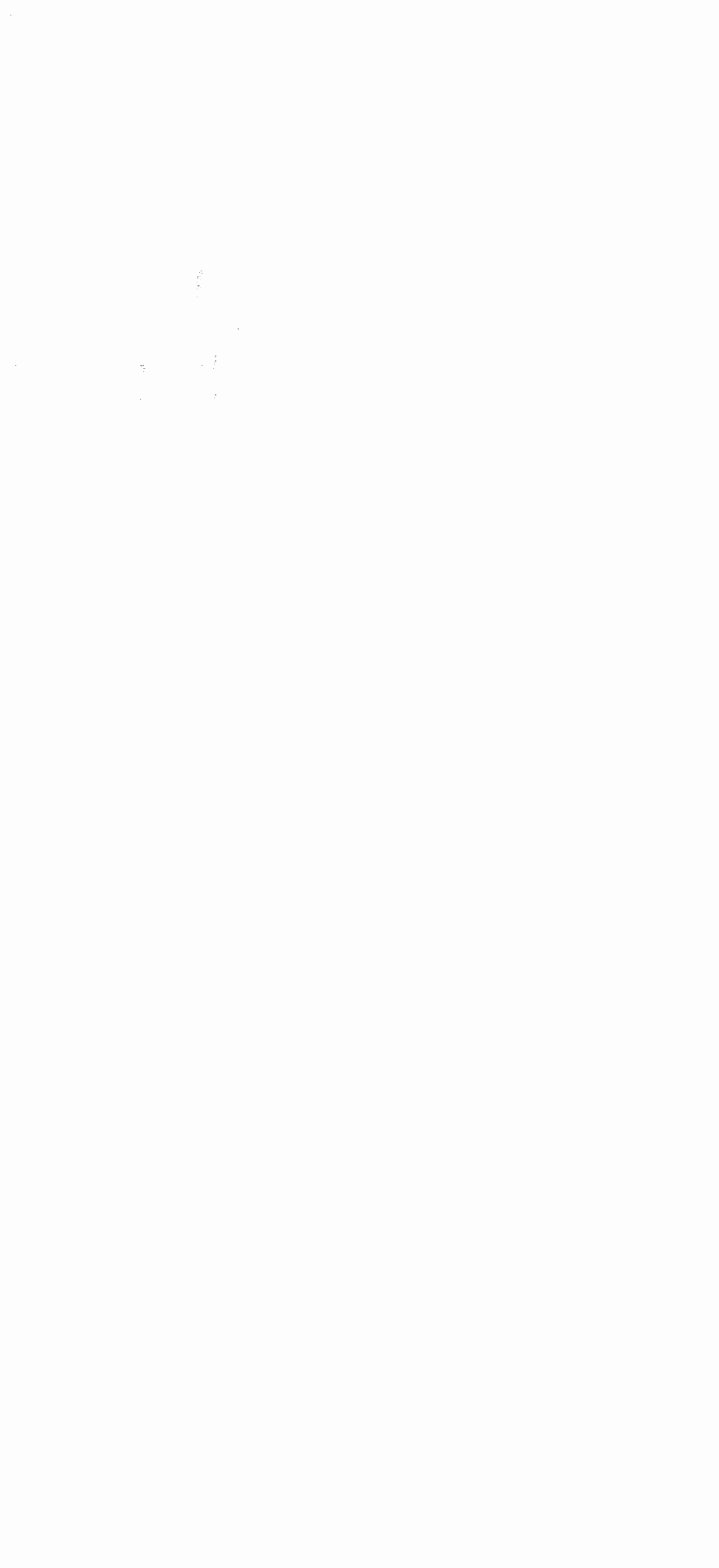




\section{Chapter 7}

Acute uncomplicated urinary tract infections in communitydwelling elderly females: care as usual of the general practitioner and antimicrobial resistance. 
CHAPIU⿴囗十 


\begin{abstract}
Abstraet
Urinary tract infections (UTIs), the most common bacterial infections in women, are more prevalent with increasing age. However, the care as usual of the general practitioner and the antimicrobial susceptibility of the causative uropathogens in acute uncomplicated UTIs in non-institutionalised elderly females have not been studied well. Therefore, a population-based study was conducted among women over the age 70 years with complaints of acute uncomplicated UTls attending 21 GPs throughout The Netherlands. The performance of the nitrite and leukocyte-esterase tests, the treatment strategies used by the GP, the aetiology of infection and the antimicrobial susceptibility of the three most frequently isolated uropathogens were determined.

A positive nitrite test alone or a negative nitrite test in combination with a positive leukocyte-esterase test was very accurate in predicting a UTI ( $83 \%-99 \%)$ in these patients. The antimicrobial therapy most frequently prescribed in this population was nitrofurantoin, however its prescription rate decreased with increasing age. Fluoroquinolone and co-amoxiclav prescriptions increased (significantly) with increasing age. Escherichia coli was the uropathogen mostly isolated in all urine samples followed by Proteus mirabilis and Klebsiella pnewmonicte. The etiology of infection was age clepending: the former micro-organism decreased and the later increased in frequency with increasing age. For $E$. coli, $P$. mirabilis, and $K$ pnewmoniae the lowest susceptibility percentages and the highest $\mathrm{MIC}_{50}$ and $\mathrm{MIC}_{90}$ values were found for amoxicillin, trimethoprim and co-trimoxazole. $K$. pnewmoniae showed the lowest susceptibility for nitrofurantoin and the highest $\mathrm{MIC}_{50}$ and $\mathrm{MIC}_{90}$ values for both fluoroquinolones as well.

In conclusion, for the confirmation of a UTI in elderly females the GP can also rely on the results of both diagnostic tests. Furthermore, as trimethoprim susceptibility in these patients reached $-75 \%$, it might be advisable to no longer use this agent as first choice in the treatment of acute uncomplicated UTIs.
\end{abstract}

\title{
Introduction
}

Uninary tract infections (UTIs) are among the most common infections in women and the prevalence increases substantially with increasing age, i.e. from $5-10 \%$ for those until the age of 70 years to $\sim 20 \%$ for those 80 years and older. ${ }^{2,3}$ Also, recurrent UTIs are more prevalent among postmenopausal women than among younger ones, and these infections are uncomfortable, costly and affect negatively the quality of life."

The diagnosis of an acute uncomplicated UTI in older female patients is more complex than in younger women ${ }^{6,7}$ as older women often have an atypical clinical presentation and many common urinary symptoms (i.e. frequent urimation and incontinence) are already present. Furthermore, obtaining a clean-catch (midstream) urine specimen is 
more difficult ${ }^{6}$ and co-morbidities common to the elderly, such as neurologic, hepatic and cardiac conditions, can complicate the diagnosis and treatment of a UTI. ${ }^{7}$ Also, a positive culture, with or without the presence of pyuria, may be an asymptomatic bacteriuria, a condition similar to colonization which might not always benefit from antibiotic treatment. ${ }^{6,7}$ The nitrite and leukocyte-esterase dipstick test showed to be a reliable diagnostic tool to detect a UTI in young female general practice patients $(<70$ years old ). ${ }^{8-10}$ However, no data are available on the performance of both diagnostic tests in the elderly community dwelling female population.

The etiology of UTI among the elderly includes a broad range of Gram-negative and positive micro organisms. Consequently these infections require longer treatment duration with broad-spectrum antimicrobial agents for optimal treatment. Also, the uropathogens isolated in the elderly are more likely to be resistant to conventional antibiotic agents as trimethoprim probably by selection of more resistant strains by frequent antibiotic use in this population. ${ }^{711}$

Most antibiotic surveillance studies on. UTIs in the elderly female population however did focus on institutionalized patients or patients living in long-term care facilities. ${ }^{2.12}$ Acute uncomplicated UTIs in female patients of older age residing (independently) in the community have not been well studied. Therefore, this community-based study on female patients over 70 years of age attending 21 general practitioners from the Sentinel Station of the National Institute of Health Services Research in The Netherlands with complaints of a UTI was performed. In this surveillance study the antibiotic susceptibility of the most prevalent uropathogens was determined. Furthermore, the care as usual of the general practitioner, i.e. the nitrite and leukocyte-esterase test (if performed) and therapy prescribed, was evaluated.

\section{Materials and Methods}

\section{Participating General Practitioners}

Twenty-one General Practices from the Sentinel Station of The Netherlands Institute for Health Services Research (NIVEL) participating in the study were located all over The Netherlands. Their patient population accounts for approximately 1\% of the Dutch population and is representative according to age, gender, regional distribution and degree of urbanization. Female patients over 70 years of age suffering from an acute uncomplicated UTI were included by the General Practitioners (GPs) from January 2003 until December 2004. The GPS were asked to include all patients with a UTI defined as the presence of one or more of the following complaints: acute signs of dysuria, stranguria, urinary frequency or urgency without the presence of fever $>38^{\circ} \mathrm{C}$. For each patient, age and the care as usual performed by the GP (i.e. nitrite and leukocyte-esterase test and the therapy prescribed) were recorded. All patients received 
care as usual, i.e. diagnostic tests and empirical therapy according to the daily practice of the GP.

\section{Urine Sampling and Processing}

A fresh voided urine sample provided by the patients was used for nitrite dipstick and / or leukocyte-esterase by the GP (when part of the care as usual). Subsequently a dipslide (Uriline, 56508, BioMerieux, Plainview, N.Y) was prepared according to the manufacturer's instructions and send to the laboratory of Medical Microbiology of the University Hospital Maastricht, The Netherlands for identification and susceptibility testing of the uropathogens.

On the day of arrival, if necessary, the dipslide was incubated at $37^{\circ} \mathrm{C}$ for $16-20 \mathrm{~h}$. Thereafter the growth on the dipslides was compared with a chart provided by the manufacturer and recorded (from no growth to $\geq 10^{7} \mathrm{cfu} / \mathrm{mL}$ ). Bacterial growth on the dipslides of $\geq 10^{3} \mathrm{cfu} / \mathrm{mL}$ was identified using standard biochemical tests. ${ }^{13}$ If there remained any doubt about the identification further biochemical tests were performed API 20E, API20 NE, API 20 Strep or API Staph (BioMérieux, Plainview, N.Y.). The bacteria isolated were stored at $-70^{\circ} \mathrm{C}$ until further analysis.

\section{Antimicrobial Susceptibility Testing}

Minimum inhibitory concentrations (MICs) of the three uropathogens most frequently isolated were determined according to the CLSI-criteria (formerly the NCCLS) ${ }^{14}$ using the microbroth dilution method with Mueller-Hinton II broth cation-adjusted (Becton, Dickinson and Company, Sparks, USA), an inoculum of $5 \times 10^{5} \mathrm{cfu} / \mathrm{mL}$ and an overnight incubation at $37^{\circ} \mathrm{C}$. The MIC-plates with freeze-dried antibiotics (NLDMCS1, MCS Diagnostics BV, Swalmen, The Netherlands) were delivered after quality testing by the manufacturer and a shelf-life of approximately one year was guaranteed. The following antmicrobial agents (range in $\mathrm{mg} / \mathrm{L}$ ) were tested: anoxicillin $(0.06-128$ ), co-anoxiclav (0.06-128), trimethoprim (0.03-64), co-trimoxazole (0.03-64), norfloxacin $(0.03-64)$, ciprofloxacin $(0.008-16)$, and nitrofurantoin $(0.5-512)$. The reference strains $E$ coli ATCC 35218 and ATCC 25922 were used as control strains. CLSI-guidelines formerly the NCCLS) ${ }^{14}$ for resistance breakpoints were used. 


\section{Statistical Analysis}

For the analysis of the culture results and the susceptibility percentages the patients were divided in three age groups: $71-80,81-90$ and $>90$ years.

The statistical program used was SPSS 11.0 for Windows. To detect significant differences in therapy prescribed, isolated uropathogens, and antibiotic susceptibility of the three uropathogens most frequently isolated the Mann-Whitney $U$ test was performed. A p-value $<0.05$ was considered significant.

\section{Results}

\section{Care as usual of the General Practitioner}

In total 917 female patients were included in the study with a mean age of 80.1 years (range 71-104 years). The performance characteristics of the diagnostic tests performed by the GP are shown in Table 1. The nitrite test alone showed a high positive predictive value (PPV) and a high specificity, respectively $99 \%$ and $97 \%$. Furthermore, for urine samples with a negative nitrite test the leukocyte-esterase test showed a PPV of $83 \%$ and a sensitivity of $78 \%$.

Table 1. Performance characteristics of the diagnostic tests performed by the GP in all patients.

A. The performance of the nitrite test:

\begin{tabular}{|c|c|c|c|c|c|c|}
\hline \multirow[b]{2}{*}{ Dingnostic test resullt: } & \multicolumn{2}{|c|}{ Urine culture } & \multirow[b]{2}{*}{ PPV } & \multirow[b]{2}{*}{ NPV } & \multirow[b]{2}{*}{ Sens } & \multirow[b]{2}{*}{ Spec } \\
\hline & $\begin{array}{c}\geq 10^{3} \\
\text { cfu/mil }\end{array}$ & $\begin{array}{c}<10^{3} \\
\text { cfu/mi }\end{array}$ & & & & \\
\hline Nitrite positive & 409 & 3 & \multirow{2}{*}{99} & \multirow{2}{*}{22} & \multirow{2}{*}{52} & \multirow{2}{*}{97} \\
\hline Nituite negative & 373 & 103 & & & & \\
\hline
\end{tabular}

B. The performance of the leukocyle-esterase test in case of a negative nitrite vest:

\begin{tabular}{lccccccc}
\hline & \multicolumn{3}{c}{ Urine culture } & & & & \\
\cline { 2 - 5 } Diagnostic test result & & $\begin{array}{c}210^{3} \\
\text { cfu/ml }\end{array}$ & $\begin{array}{c}<10^{3} \\
\text { cfu/ml }\end{array}$ & PPV & NPV & Sens & Spec \\
\hline Leukocyte-esterase positive & 285 & 59 & 83 & 34 & 78 & 42 \\
Leulocyte-esterase negative & 82 & 42 & & & & \\
\hline
\end{tabular}

$\mathrm{PPV}=$ positive predictive value, NPV = negative predictive value, Sens = sensitivity, Spec $=$ specificity "samples with a negative nitrite and unknown leukocyte-esterase test result or boih unknown test results were excluded. 
Ninety percent of the patients with a nitrite positive urine sample were prescribed antibiotics by their GP (Table 2). Two third of the patients whose urine samples showed a negative nitrite test and a positive leukocyte-esterase test received an antibiotic prescription as well. Of the patients with a urine sample with both the nitrite and the leukocyte-esterase test negative $27 \%$ received antibiotic therapy.

Table 2. The number (rate) of prescriptions of the general practitioner compared with the diagnostic test results.

\begin{tabular}{lccc}
\hline \multicolumn{1}{c}{ Diagnostic test result } & Yes & No & Unknown \\
\hline Nitrite positive & $372(90)$ & $30(7)$ & $10(2)$ \\
\hline $\begin{array}{l}\text { Nitrite negative } \\
\text { Leukocyte-esterase positive }\end{array}$ & $221(64)$ & $113(33)$ & $10(3)$ \\
$\quad$ Leukocyte-esterase negative & $33(27)$ & $84(68)$ & $7(6)$ \\
\hline Unknown & $9(56)$ & $2(13)$ & $5(31)$ \\
\hline
\end{tabular}

Figure 1. The percentage antimicrobial agents prescribed as therapy in patients with acute uncomplicated UTI per age category.

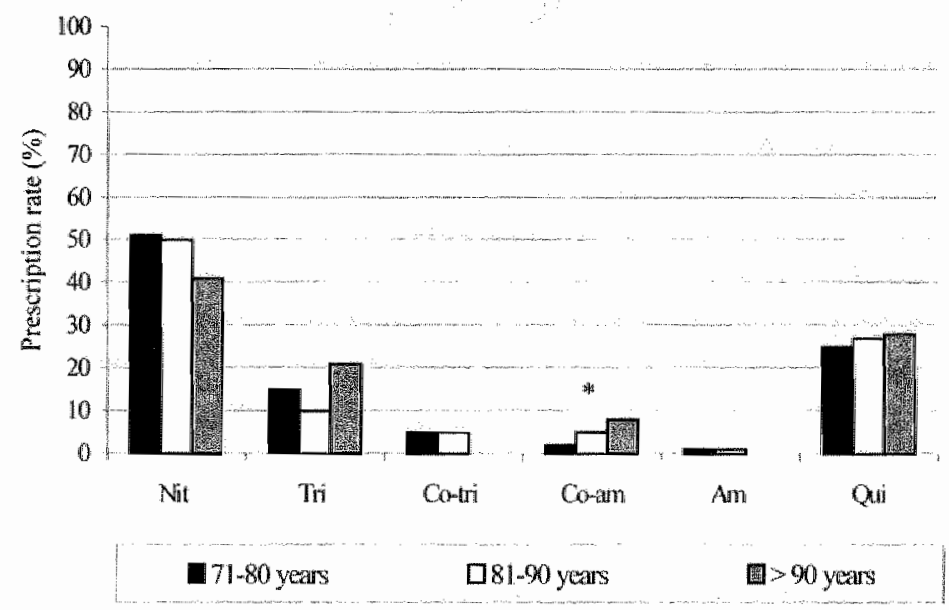

Nit $=$ nitrofurantoin; $\mathrm{Tri}=$ trimethoprim; $\mathrm{Co}$-tri $=$ co-trimoxazole; $\mathrm{Co}$-am $=$ co-amoxiclav; $\mathrm{Am}=$ amoxicillin; $\mathrm{Qui}=$ quinolones.

* significant difference between the youngest and both other age groups (Mann Whitney $U$ test; $p<0.05$ ) 
The antimicrobial agent most frequently prescribed in patients of all age groups was witrofurantoin (Figure 1). lis prescription rate ranged from $41 \%$ in the oldest $1051 \%$ in the youngest patients. One forth of the patients received fluoroquinolones and trimethoprim was prescribed in $10 \%-21 \%$ of all patients. The prescription rate of coamoxiclav increased significantly from $2 \%$ to $8 \%$ with increasing age.

Nitrofurantoin therapy was equally prescribed as a 3-, 5- and 7-day regimen (Figure 2). A seven-day course of fluoroquinolones was most frequently prescribed whereas trimethoprin was most frequently prescribed for 5 days in the patients of all age groups.

Figure 2. The duration of the antimicrobial therapy per age group for the three agents mostly prescribed.

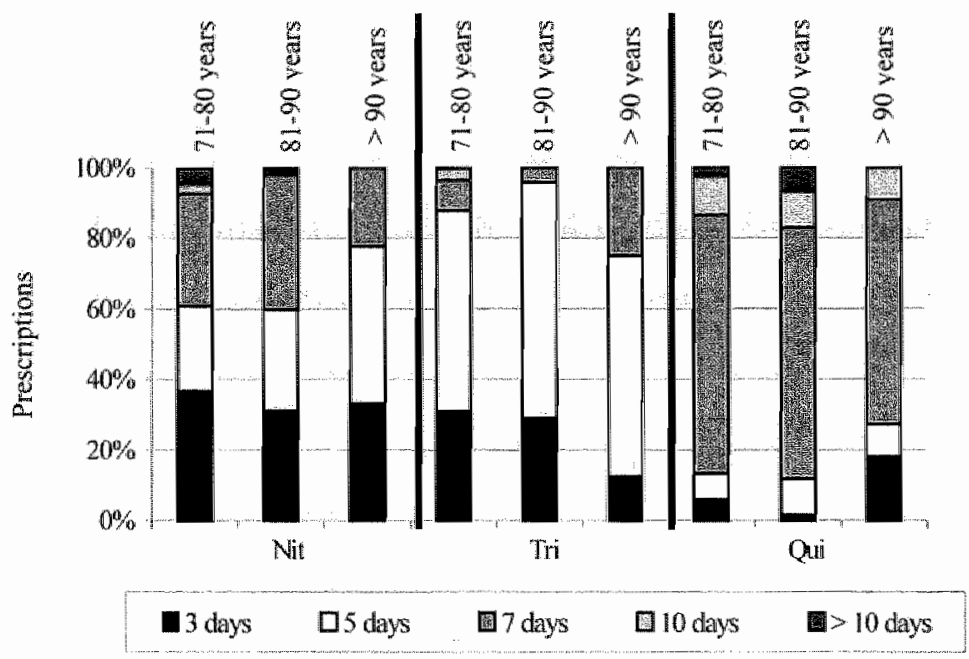

Nit = nitrofurantoin; Tri $=$ trimethoprim; Qui $=$ fluoroguinolones.

\section{Culture Results}

In total $88 \%(808 / 917)$ of the urine samples yielded a positive culture of $\geq 10^{3} \mathrm{cfu} / \mathrm{mL}$ (Table 3). Escherichia coli was the most frequently isolated uropathogen in all age groups $(57 \%-62 \%)$. Protens mirabilis was more frequently isolated in the younger patients $(10 \%)$. Klebsiella pneumoniae was significantly more found with increasing age, i.e. from $3 \%$ in the patients $71-80$ years of age to $16 \%$ in the patients $>90$ years old No Staphy/ococcus saprophyicus was isolated in this population.

\section{Susceptibility Data}

Susceptibility percentages of the three uropathogens most frequently isolated per age group are shown in Table 4. The lowest susceptibility percentages for the three microorganisms were found for amoxicillin ( $K$. pneumoniae is intrinsic resistant to this 
agent), trimethoprim and co-trimoxazole. $K$ pmemomae suseeptibility for nitrofurantoin $\left(53 \%-78 \%\right.$ ) was the lowest ( $P$. morcilis excluded) and the $\mathrm{MIC}_{50}$ and $\mathrm{MIC}_{90}$ of this micro-organism for this agent were higher compared to those of the $E$ coll isolates. Furthermore, $K$ pneumoniae showed the highest MlCo for both fluoroquinolones (respectively 16 and $0.5 \mathrm{mg} / \mathrm{L}$ ). On the other hand, for trimethoprim and co-trimoxazole this uropathogen showed the lowest $\mathrm{MIC}_{90}$, respectively 16 and 4 $\mathrm{mg} / \mathrm{L}$

Table 3. Percentage isolated uropathogens for each age group.

\begin{tabular}{|c|c|c|c|c|}
\hline \multirow[b]{3}{*}{ Micro-organism } & \multicolumn{3}{|c|}{ Age category (years) } & \multirow{3}{*}{$\begin{array}{l}\text { Total } \\
\mathrm{n}=808\end{array}$} \\
\hline & $71-80$ & $81-90$ & $>90$ & \\
\hline & $n=460$ & $n=292$ & $\mathrm{n}=56$ & \\
\hline E. coli & 62 & 60 & 57 & 61 \\
\hline P. mirabilis & 10 & 6 & 4 & 8 \\
\hline K. pnewnoniae* & 3 & 8 & 16 & 6 \\
\hline$P_{\text {seudomonas }} s p p$ & 5 & 4 & 7 & 5 \\
\hline Acinetobacter spp. & 4 & 2 & 2 & 3 \\
\hline Other Gram-negatives & 12 & 13 & 11 & 12 \\
\hline E. faecalis & 3 & 3 & 2 & 3 \\
\hline Other Gram-positives & 3 & 3 & 2 & 3 \\
\hline
\end{tabular}

\section{Discussion}

This study is to the best of our knowledge the first community-based study on acute uncomplicated UTIs in more than 900 non-institutionalized elderly females over the age of 70 years in The Netherlands.

The diagnosis of a UTI in elderly female patients is not always very straightforward. In younger female patients it is known that the nitrite and leukocyte-esterase have a high positive predictive value for infection. ${ }^{8-10}$ The performance characteristics of the nitrite and leukocyte-esterase dipstick tests showed that in this elderly female population a positive nitrite test result predicted an infection with a very high specificity. Furthemore, when the nitrite test was negative, a positive leukocyte-esterase test still predicted a UTI in more than $80 \%$ of the urine samples positive in culture. The sensitivity of this test was also high $(78 \%)$. Therefore, both tests have proven to also accurately predict a UTI in the elderly non-institutionalized female population. 
Inble 4. Susceptibility percentages, the MICs and the MIC of the three uropathogens most frequently isolated.

\begin{tabular}{|c|c|c|c|c|c|c|}
\hline \multirow{2}{*}{ Uropathogen } & \multirow[b]{2}{*}{ Antibiotic } & \multicolumn{3}{|c|}{ Age wategory (years) } & \multirow[b]{2}{*}{$\mathrm{MIC}_{58}$} & \multirow[b]{2}{*}{$\mathrm{MIC}_{\mathrm{g}}$} \\
\hline & & $71-80$ & $81-90$ & $>90$ & & \\
\hline E coll & & $n=254$ & $n=137$ & $n=25$ & $n=416$ & $\mathrm{n}=416$ \\
\hline \multirow[t]{7}{*}{$8: 4$} & Amoxicillin & 69 & 74 & 80 & 4 & $>128$ \\
\hline & Co-amoxiclav & 95 & 96 & 96 & 4 & 16 \\
\hline & Trimethoprim & 76 & 80 & 84 & 0.5 & $>64$ \\
\hline & Co-trimoxazole & 79 & 83 & 84 & 0.06 & $>64$ \\
\hline & Norfloxacin & 93 & 98 & 96 & 0.06 & 0.25 \\
\hline & Ciprofloxacin & 93 & 98 & 96 & 0.015 & 0.06 \\
\hline & Nitrofurantoin & 98 & 97 & 100 & 16 & 32 \\
\hline \multirow[t]{8}{*}{ P. mirabilis } & & $\mathrm{m}=\mathbf{3 0}$ & $n=7$ & $n=1$ & $n=38$ & $n=38$ \\
\hline & Amoxicillin & 70 & 86 & 100 & 1 & 128 \\
\hline & Co-amoxiclav & 93 & 100 & 100 & 1 & 8 \\
\hline & Trimethoprim & 73 & 86 & 100 & 4 & $>64$ \\
\hline & Co-trimoxazole & 77 & 86 & 100 & 0.12 & $>64$ \\
\hline & Norfloxacin & 100 & 100 & 100 & 0.06 & 0.12 \\
\hline & Ciprofloxacin & 100 & 100 & 100 & 0.03 & 0.06 \\
\hline & Nitrofurantoin & 17 & 14 & 0 & 128 & 256 \\
\hline \multirow[t]{8}{*}{$\kappa_{+}$preumorrate } & & $n=8$ & $n=15$ & $\mathbf{n}=9$ & $n=32$ & $\mathrm{n}=32$ \\
\hline & Amoxicillin & 13 & 20 & 22 & 64 & $>128$ \\
\hline & Co-amoxiclav & 100 & 100 & 100 & 2 & 8 \\
\hline & Trimethoprim & 75 & 80 & 100 & 1 & 16 \\
\hline & Co-trimoxazole & 88 & 80 & 100 & 0.12 & 4 \\
\hline & Norfloxacin & 100 & 80 & 100 & 0.12 & 16 \\
\hline & Ciprofloxacin & 100 & 80 & 100 & 0.03 & 0.5 \\
\hline & Nitrofurantoin & 75 & 53 & 78 & 64 & 512 \\
\hline
\end{tabular}


However, the combination of both diagnostic tests resulted in $17 \%$ of the urine samples in a false negative test result which might be explained by contaminating microorganisms as obtaining a clean-catch urine specimen in the elderly is difficult? Furthermore, for the production of nitrite from nitrate at a reliable level bacteria need $\geq$ 4 hours, so the nitrite dipstick test requires preferably first moming urine. ${ }^{10}$ If the time span was too short for this conversion false negative test results will be obtained. Furthermore, the biochemical reaction detected by the nitrite test is associated with members of the family of Enterobacteriaceae, but not with other uropathogens like Pseudomonas spp. or enterococci. ${ }^{10}$ As the etiology of UTIs in this elderly population shifted toward more Pseudomonas spp. and other Gram-negatives as compared with a younger patient population (Unpublished data) false negative test results could be obtained.

For the prescription of antimicrobial therapy the general practitioner did rely on the outcome of the diagnostic tests as $90 \%$ of the patients with a nitrite positive urine sample received antinicrobial therapy. For patients with a negative nitrite and positive leukocyte-esterase urine sample the prescription rate of the GP dropped to $68 \%$ and went even further down to $56 \%$ in patients for whom both tests were not performed. As shown from the results of this study the GP can rely even more on the diagnostics tests available for the detection of a UTI in the elderly community dwelling female population and subsequently the prescription of antimicrobial therapy.

Even though nitrofurantoin was mostly prescribed in the three age groups, there was an inverse relation between the prescription rate of this agent and the increasing age of the patients. In contrast, the number of patients prescribed co-amoxiclav and fluoroquinolones increased (significantly) with increasing age. Similar results were described by Goettsch et al. ${ }^{15}$ The oldest patients in that study received more often a prescription of fluoroquinolones compared to the younger ones. There might be several reasons for the GP to choose in this older patient population another first line agent than those recommended by the $\mathrm{NHG}^{16}$ i.e. nitrofurantoin and trimethoprim. First, nitrofurantoin treatment regimens might have several adverse effects, especially in older women, including nausea and vomuting, allergic, pullmonary, hepatic, neurological and hematological reactions. ${ }^{17}$ In addition, elderly females are more likely to have experienced several UTls in their life-time and therefore they might have received more often antimicrobial therapy in the past. ${ }^{2-4}$ Therefore it is to be expected that the GP considered the standard agents as no longer effective and preferred to use co-amoxiclav or fluoroquinolones. These agents are also prescribed for longer durations to be sure of full eradication of the causative uropathogen.

The etiology of UTIs among the non-institutionalized elderly women differed from that of younger female adults (Unpublished data), i.e. $E$. coll, still the most common isolated uropathogen, was proportionally less detected but more $P$. mirabilis, $K$. pneunoniae. and other Gram-negatives were isolated. Due to the depletion of hormones in these 
elderly patients the vaginall fora is no longer dominated by the presence of lactobacillis and it might be easier for wropathogens to enter the urinary tract.

The lowest susceptibility percentages for the three most frequently isolated uropathogens were found for amoxicillin and trimethoprim, agents very often used in general practice. Resistance for fluoroquinolones was emerging in these three uropathogens as well. However, $E$. coll isolated in this patient population showed higher susceptibility percentages for amoxicillin, co-trimoxazole, norfloxacin and nitrofurantoin as compared to uropathogenic $E$. colit isolated from residents of 2 nursing homes in the South of The Netherlands. ${ }^{12}$ The differences in antibiotic susceptibility between the isolates from GP patients and nursing home residents is very likely due to the presence of additional risk factors for the development of antibiotic resistance in the latter population including antibiotic use, crowding, underlying pathology and the presence of invasive devices. ${ }^{12,18}$

In conclusion, as the elderly community dwelling females mostly present to their GP with vague clinical symptoms of a UTI, it is important for the GP to perform the nitrite and leukocyte-esterase dipstick tests to confirm their perception of a UTI. Furthermore for the treatment of UTIs in these elderly females actual data on the susceptibility of pathogens isolated from this group of patients is essential for making an empiric choice. Therefore, as trimethoprim and co-trimoxazole susceptibility percentages for the three most frequently isolated uropathogens in this population ranged from $73 \%-86 \%$ it might be advisable to no longer use this antibiotic as an agent of first choice for the treatment of acute uncomplicated urinary tract infections in The Netherlands. Furthermore, national surveillance studies generating data on the resistance percentages of the agents currently used for the treatment of UTIS in patients of different age groups should be continued in the future and should be made available to the GPs for implementation into their daily practice.

\section{Acknowledgements}

This research was funded by the Dutch Foundation of the Working Party on Antibiotic Policy (SWAB). We would like to thank all the General Practitioners of the Sentinel Station of The Netherlands Institute for Health Services Research (NTVEL) for their participation in the study. We would like to thank L. Hoffman and S. Tonnaer for their technical assistance. 


\section{References}

1. Nicolle, L. E. (1994). Urinary tract infection in the elderly. J Antmicrob Chenoiluer 33 Sippll A, 99-109.

2. Boscia, J. A., Kobasa, W. D., Knight, R. A. et al. (1986). Fpidemiology of bateriuria in an elderly ambulatory population. Am $J$ Med 80, $208-214$.

3. Brown, J. S., Vittinghoff, E., Kanaya, A. M. et at (2001). Uninary tract infections in postmenopausal women: effect of homone therapy and risk factors. Obster Gymecol 98,1045 . 1052.

4. vam Geelen, J. M. van de Weijer, P. H. \& Arnolds, H. T. (2000). Urogenital symptoms and resulting discomfort in non-institutionalized Dutch women aged $50-75$ years. In Unoggnecol $J$ Pelwic Floor Dysfunc: 11, 9-14.

5. Maloney, C. (2002). Estrogen \& recurrent UTI in postmenopausal women. Am J Nums 102, 44 52.

6. Nicolle, L. E. (2000). Urinary tract infection in long-term-care facility residents. Clin Infect Dis 31, 757-761.

7. Shortliffe, L. M. \& McCue, J. D. (2002). Urinary tract infection at the age extremes: pediatrics and geriatrics. Am $J$ Med 1.13 Suppl 1A, 55S-66S.

8. Christiaens, T., De Meyere, M. \& Derese, A. (1998). Disappointing specificity of the leucocyteesterase test for the diagnosis of urinary tract infection in general practice. Eur $J$ Gen Pract 4 , 144-148.

9. Verest, L. F., van Esch, W. M., van Ree, J. W, et at. (2000), Management of acule uncomplicated urinary tract infections in general practice in the south of The Nethertands. $B r^{n} J$ Gen Pract 50, 309-310.

10. Wilson, M. L. Gaido, L. (2004). Laboratory diagnosis of urinary tract infections in adult patients. Clin Infect Dis 38, 1150-1158.

11. Gupta, K., Hooton, T. M., Roberts, P. L., et al (2001). Patient-initiated treatment of uncomplicated recurrent urinary tract infections in young women. Am LWhor Med 135, 9-16.

12. Vromen, M., van der Ven, A. J., Knols, A., et al. (1999). Antimicrobial resistance patterns in urinary isolates from nursing home residents. Fifteen years of data reviewed I Antimicrob Chemother 44, 113-116.

13. Martin, W. J., Birk, R. J., Yu, P. K... ef al. (1970). Identification of members of the family Enterobacteriaceae by the R-B system. Appl Microbiol 20,880-883.

14. NCCLS (2002). National Committee for Clinical Laboratory Standards. Methods for dhitution Antimicrobial Sxascepribility Tests for bacteria that grow Aerobically figh Edition: Approved Standard M7-A5. NCCLS, Villamova, PA. USA.

15. Goetsch, W., van Pelt, W., Nagelkerke, N., at (2000). Increasing resistance to fluoroquinolones in Escherichia coli from urinary tract infections in the Netherlands. I Antixnicrob Chemorher" 46, 223-228. 
16. Wiersma, T. J. \& "Tinmermans, A. E. (2001). (Summary of the 'Urinary tract infections' guideline (first revision) of the Dutch College of General Practitioners]. Ned Tijdschr Geneeskd 145, 735-739.

17. Kunin, C. M. (2004). Inappropriate medieation use in older adults: does nitrofurantoin belong on the list for the reasons stated? Arch Intem Med 164, 1701.

18. Nicolle, L. E., Strausbaugh, L. J. \& Garibaldi, R. A. (1996). Infections and antibiotic resistance in nursing tomes. Clin Microbiol Rev $9,1-17$.

119. Deville, W. L., Yzermans, J. C., van Dugn̈, N. P., et al. (2004). The urine dipstick test useful to rule out infections. A meta-analysis of the accuracy. BMC Urol $4,4$. 


\section{Chapter 8}

General Discussion \& Summary 


\section{CHA T T}


The role of the commensal flora of healthy volunteers and patients attending their general practitioner in the epidemiology of antimicrobial resistance, in particular the development and spread of resistance was studied. The commensal fora at different body-sites constitutes a large reservoir of antimicrobial resistance (genes) and some aspects which might be of influence on the increase of antimicrobial resistance in the commensal bacteria were analyzed. Furthermore, the consequences of this reservoir of antibiotic resistance (genes) for potentially pathogenic bacteria was enlightened as well.

In a case-controlled study the prevalence of erythromycin resistant streptococci, the predominant species of the oropharyngeal commensal flora, was studied (Chapter 2). Almost $60 \%$ of the patients attending their general practitioner (GP) for anr acute respiratory tract infection (cases) and controls carried erythromycin resistant streptococci in their commensal throat flora. One fifth of all patients studied carried commensal streptococci that were highly resistant not only for erythromycin and other macrolides but also for lincosamides and streptogramin antibiotics due to crossresistance conferred by the $e r m \mathrm{~B}$ gene. The $60 \%$ erythromycin resistance percentage in the GP patients was lower compared to the $71 \%$ macrolide-resistant viridans group streptococci found in Belgian healthy volunteers in $2003^{1}$ and the rate reported in Spain in $2001 .^{2}$ The lower resistance percentage in the Dutch population might be due to the lower antibiotic use in general ${ }^{3}$ and especially of nacrolides ${ }^{4}$ in The Netherlands compared to both other countries. In addition to demonstrating this reservoir of erythromycin resistance (genes) in the commensal throat flora, transfer of erythromycin resistance by conjugation to a Streptococcus pneumomiae with a frequency of $1 \times 10^{-2}$ was demonstrated. The conjugation experiment in this study was performed with bacterial donor and recipient strains mixed in a small volume to mimic the in wivo situation of close contact. Although transfer of macrolide resistance by transformation has been previously described ${ }^{5}$ it is to be expected that conjugation is a more common phenomenon in vivo than transformation. This transfer of resistance genes emphasizes the risk of antibiotic resistance in the commensal flora as reservoir for resistance for potentially pathogenic bacteria.

Besides the respiratory tract, the gastro-intestinal tract, with the second largest body surface area, ${ }^{6}$ comprises another enormous reservoir of commensal bacteria $\left(10^{12}-10^{14}\right.$ $\mathrm{cfu} / \mathrm{g})^{7}$ and consequently resistance (genes). To asses the magnitude of this reservoir of resistance in populations with different selective pressure for resistance, i.e. populations with a variable antibiotic use the prevalence of antimicrobial resistance in faecal Escherichia coli isolates from healthy volunteers in nine developing countries was determined (Chapter 3 ). A high prevalence of resistance to most agents tested was found in all populations, consistent with findings from other studies. ${ }^{8-10}$ The highest prevalences of resistance were found for the orally administered, relatively inexpensive, broad-spectrum agents including ampicillin, trimethoprim and oxytetracycline. 
Resistance to these antibiotics was the most common multi-drug resistance pattem in the $E$.coli isolates and has been found previously both in adults ${ }^{8,11}$ and children." The combination of resistance to these three antibiotics is very likelly due to the localization of the resistance genes on the same plasmid. ${ }^{13}$ In addition, resistance to fluoroquinolones was alleady emerging in some populations of Asia and Latin-America where ciprofloxacin is used for treatment of cholera and typhoid fever in adults as alternative in case of resistance. ${ }^{14-16}$ Furthermore, there were significant differences in the prevalence of resistance between non-urban and urban areas for ampicillin, oxyletracycline and trimethoprim. This might be due to crowding together with poor hygiene and poor sanitary facilities for sewage disposal, ${ }^{10,17,18}$ the easy availability ${ }^{19}$ and over the counter sales ${ }^{17}$ of antibiotics in the cities whereas in rural areas only a few drugs are available and usually brought there by a visiting ${ }^{20}$ or a resident physician.

Another population experiencing a selective pressure for resistance, i.e. high antibiotic use and crowding are patients admitted to the hospital. In patients admitted to the surgical wards of the University Hospital Groningen, Maastricht and Rotterdam an increase in the prevalence of resistance in the faecal Enterococcus faecalis isolates was found during hospitalization compared to the situation on admission (Chapter 4 ). However, when the patients returned to the community and the selective pressure of the hospital environment disappeared the prevalence of resistance in their commensal flora decreased over time. Depending on the antibiotic tested, the time needed to return to the pre-hospitalization level ranged from 1 montl (ciprofloxacin and tetracycline) to six months (erythromycin and gentamicin). This difference might be explained by the difference in antimicrobials used in primary health care ${ }^{21}$ as well as differences in the properties of the antibiotics.

As commensal bacteria from the gastro-intestinal tract are able to cause urinary tract infections (UTIS) via the ascending route $\mathrm{C}^{22-24}$ the reservoir of resistance (genes) in the faecal flora poses a risk for antibiotic resistant uropathogens. Antibiotic therapy administered for UTls might select for resistant commensal bacteria in the gut therefore the optimal duration of therapy for one of the drugs of first choice according to the guidelines of the $\mathrm{NHG}^{25}$ was studied. The results of a three-versus five-day treatment regimen of trimethoprim on the bacteriological and clinical cure rate have been described in Chapter 5 . No significant differences in bacteriological cure rate were found between the two treatment regimens both one and three days after treatment. These findings support a shorter treatment with the advantages of lower cost, less sideeffects and better patient compliance. However, relief of symptoms is an equally important issue for both the patient and the GP. In the 3-day regimen group 29 patients $(44 \%)$ considered themselves "not-recovered" one day after treatment and were thus not symptom-free when they delivered their control urine sample. Although the recovery rate between the two regimens was not significant different, we assume that the 
difference in self-reported cure is very likely the reason why experienced GPS consider at three-day regimen as less reliable: One day after the end of both treatment regumens trimethoprim resistant $E$. coli was more often isolated from patients who considered themselves as "not-recovered" compared to the "recovered" patients. The relatively high percentages of trimethoprim resistant $E$. coli isolates in the latter patients underscores the natural course of an acute UTI. ${ }^{26}$ Due to the relatively low numbers of patients included in the final analysis no fim conclusions could be drawn.

For the treatment of patients with symptoms of a UTI the choice of the empiric therapy is mainly based on the recommendations of the $\mathrm{NHG}^{25}$ For these recommendations the data on the susceptibility of unselected uropathogens have to be taken into account. Until now most studies performed determined the susceptibility of selected isolates as samples were send in after priot therapy failure. ${ }^{27,28}$ Therefore a national study was conducted on female patients visiting their general practitioner with acute complaints of UTIs. The studies described in Chapter 6 and Chapter 7 described the results of the antimicrobial susceptibility of unselected uropathogens in different age groups. In addition the care as usual of the general practitioner, i.e. the accuracy of the nitrite and leukocyte-esterase test and the antimicrobial prescription rate in relation with bacteriological culture results, were determined.

For symptomatic women between 11 and 70 years (Chapter 6) a urine sample with a positive nitrite test (PPV $=96 \%$ ) or a negative nitrite test together with a positive leukocyte-esterase test (PPV $=79 \%$ ) should be considered as having a UTI and the patient should be treated accordingly. However when both nitrite and leukocyte-esterase tests are negative (NPV $=53 \%$ ), a UTI cannot be excluded and urine samples should be further investigated by culture. Furthermore, the GP should take into account the age of the patient when prescribing antibiotic treatment as the causative uropathogen is age related. Prudent use of fluoroquinolones is recommended as resistance is already emerging in these patients. As trimethoprim susceptibility in $E$. coli isolates of this study decreased to $-80 \%$ it might be advisable to limit its use as agent of first choice in the treatment of an acute uncomplicated UTI in The Natherlands.

As elderly community dwelling females mostly present to thein general practitioner with vague clinical symptoms of a UTI it is important that the GP performs diagnostic tests like the nitrite and leukocyte-esterase test (Chapter 7). Both test have proven to accurately predict a UTI in this elderly population. However, when both tests were negative, a UTI could not b excluded and bacteriological culture of the urine specimen is required. To prevent false negative test results the use of urine samples in which the micro-organism(s) present have sufficient time to convert nitrate in to nitrite (such as morning urine samples) is strongly recommended. The antimicrobial therapy prescribed by the GP was age related as less nitrofurantoin and more fuoroquinolones and coamoxiclav were prescribed in these elderly women. These changes in the prescribing behavior of the G.P might be due to the fact that elderly females have more often suffered from a UTI in the past and probably more often received antibiotic therapy. 
Both agents were also prescribed for longer durations to be sure of full eradication of the probably more resistant uropathogen. The lowest susceptibility percentages for the three uropathogens most frequently isolated in these women ( $>70$ years) were found for trimethoprim and anoxicillin. Resistance for fluoroquinolones was emerging in this age group. As trimethoprim susceptibility decreased to $\sim 70 \%$ it is questionable whether this it should be further used as agent of first choice in the treatment of acute uncomplicated UTIs in The Netherlands. Nitrofurantoin susceptibility remained high in patients of all ages and can be further used as agent of first choice in the treatment of acute uncomplicated UTIs in The Netherlands.

In conclusion, the commensal flora of different sites of the human body constitutes a large population of micro-organisms regularly exposed to antimicrobial agents prescribed for the treatment of bacterial infections. Due to this repetitive exposure the commensal bacteria might become resistant to commonly used antibiotics and form a large reservoir of resistance genes. The resistance present in potentially pathogenic micro-organisms is only the tip of the "resistance" iceberg as compared to the resistance in the normal flora. Therefore the availability of actual susceptibility percentages of the most prevalent commensal bacteria as well as potentially pathogenic bacteria causing common infections is important to be able to tune in with empiric treatment on the rapidly changing and emerging resistances.

Optimal antibiotic treatment for bacterial infections will directly lead to a reduction in the antibiotic resistance. However, other approaches which will also contribute to control the problem of antibiotic resistance are optimization of the diagnosis of bacterial infections and the use of alternative agents instead of antibiotics for the prevention and / or treatment of bacterial infections.

Optimization of the diagnosis of a bacterial infection is especially a problem in case of respiratory tract infections (RTIs) as these infections have in most cases a viral etiology for which the prescription of antimicrobial therapy is not beneficial. However, more than half of the patients with a common cold presenting to their general practitioner receive antimicrobial therapy. ${ }^{29}$ Clinical differentiation between viral and bacterial RTIs will contribute substantially to reduce the unnecessary use of antibiotics. The detection of C-reactive protein (CRP) in a blood sample may be predictive for bacterial infections. ${ }^{30}$ However, the cost-effectiveness of implementation of this test in general practice is necessary. It should be determined whether application of this test results in a reduction of the antibiotic prescriptions and thus in antibiotic resistance.

Another field of interest for optimization of the diagnostic tests currently used are the urinary tract infections (UTIs). In case of an acute uncomplicated urinary tract infection most general practitioners decide whether to prescribed antibiotic therapy after evaluation of the patients complaints. Also, they can rely on diagnostic tests like the nitrite and leukocyte-esterase dipstick tests, for this decision. The efficacy of most tests 
available has been separately evaluated. However, there is great need to study low the test results of the different diagnostic tests relate to each other, what is their additional value to the medical history of the patient and how accurate are they in predicting an infection as compared to urine culture.

Next to the accurate diagnosis of bacterial infections, the prevention of infectious diseases is a major issue of interest in order to control antibiotic use and antibiotic resistance. As urinary tract infections are the most common bacterial infection seen in women in general practice and women often suffer from recurrent UTIs ( $\geq 3$ episodes within one year) this is a large population that would benefit from effective (nonantibiotic) prophylaxis. In post-menopausal women, recurrent UTIs can also occur due to the loss of estrogen and consequently the depletion of vaginal colonization with lactobacilli. Currently, the prophylaxis available for women suffering from recurrent UTIs is a low dose of antibiotics, also used to treat actual infections, for 6 months or longer. However, this treatment poses a risk for the development of antibiotic resistance. Therefore, the use of alternative agents like probiotics (lactobacilli) or cranberry extract for the prevention of UTIs are good alternatives. The former prophylaxis is based on the concept that "good" bacteria will prevent vaginal colonization with potentially pathogenic micro-organisms and consequently infection by these micro-organisms. The latter one prevents adhesion of bacteria to epithelial cells of the urogenital tract. The efficacy of both non-antibiotic prophylaxis treatments in the prevention of recurrent urinary tract infections as well as in the reduction of the development of antimicrobial tresistance should therefore be studied.

\section{References}

1. Malhora-Kumar, S., Lammens, C., Martel, A., el al. (2004). Oropharyngeal carriage of macrolide-resistant viridans group streptococei: a prevalence study among healthy adults in Belgum, I Animicrob Chenother $53,271-276$.

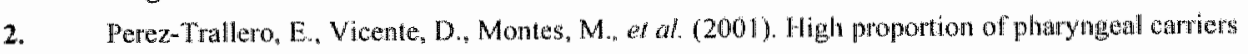
of commensal streptococci resistant to erythomyein in Spanish adults. I Amimicrob Chorhower 48, $225-229$.

3. Molstad, S., Lundborg. C. S., Karlsson, A. K., ef al. (2002). Antibiotic prescription rates vary markedly between 13 European countries. Scand J Iffect Dis 34, 366-371.

4. Cars, O., Molstad, S. \& Melander, A. (2001). Variation in antibiotic use in the Europeran Union. Lancet $357,1851-1853$.

5. Cerda Zolezzi, P., Laplana, L. M, Calvo, C. R. w al. (2004). Molecular basis of resistance to macrolides and other antibiotics in commensal viridans group streptococei and Gemella spp. and. transfer of resistance genes to Streptococcus phewnomiae. Antwicrob Agents Chemoher 48 , $3462-3467$. 
6. Bengmark, \$999). Eeologieal control of the gaistromtestinal tract. The rote of probiotic flora. Gint $2,2.7$.

7. Barta, M. Travers, K. (2002). Excess infectons die to antimictobial nesistance: the "Atributable Fraction". Clin linfect Dis 34 Suppl 3, 5126-130.

8. Shanahan, P. M, Wyle, B. A. Adrian, P. V, ef al (1993). The prevalence of antimicrobiall reststance in human faecal Hora in South Africa. Eprdemal Infect 111, 221 228.

9. Okeke, I. N. Faymka, S. T. Lamilanra, A (2000). Antibiotic resistance in Bschericha coh from Nigerhan students, 19861998 . Energ Infiect Dis 6, 393-396.

10. Anyes, $\mathrm{S}, \mathrm{G}, \mathrm{Tat}, \mathrm{S}$, thomson, $\mathrm{C}$. J, at al (1992). The incidence of antibichic resistance in aerobic faecal thora in south India. I Ammicrab Chemower $29,415-425$.

11. Adran, P. V, Koomhol, H. I. \& Wylie, B. A. (1993), Trimethoprim resistance in South African isolates of acrobic Oram-negative faecal flora. Eur J Clin Wicrobiol Kafect Dis 12, 916-921.

12. Calva, J. $j$. Sifuentes-Osomio, J. \& Ceron, C. (1996). Antimicrobial resistance in fecal thora: longitudinal community-based surveillance of children from urban Mexico. Amimictab Agenss Chemother 40, 1699-1702.

13. Gulay, $Z$, Bicmen, M., Amyes, $S . G$, et al. (2000) Beta-lactanase patterns and betalactam/clavulanic acid resistance in Escherichia coli isolated from fecal samples from healthy volunteess. $I$ Chemother 12, 208-2115.

14. Gatuzzó, E. Seas, C., Echevaria, J., et al. (1995). Ciprofloxacin for the treatment of cholera: a randomized, double-blind, controlled clinical trial of a single dally dose in Peruvian adults. Clm Infect Dis 20, 1485,1490 .

15. Butler, T. (2001). New developments in the understanding of cholera. Cur Gastroenterol Rep 3, $315-321$.

16. Green, S. \& Tillotson, G. (1997). Use of ciprotloxacin in developing countries. Pediatr Infect Dis J 16, 150-159; discussion 160-152.

17. Okeke, I. N., Lamikanta, A. \& Edelman, R. (1999). Socioeconomic and behavioral factors

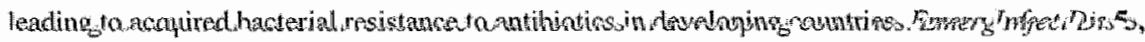
$18-27$

18. Grenet, K. (2004). Antibacterial resistance, Wayampis Amerindians, French Guyana. Emerg Itofect Dis $10, \| 150-1153$

19. Hart, C. A. e kariuki. S. (1998). Antimicrobial resistance in deweloping countries. Bm 317 , $647-650$

20. Bartoloni, A., Cutts, F., Leoni, S., et al (1998), Patterns of antimicrobial use and antimicrobial resistance among healtiry children in Bolivia. Trop Med hot Health 3, 116-123.

21. SWAB. NathMap 2004-Consunption of antimicrobial agents and antimicrobial resistance among medically important bacteria in the Netherlands.

22. Hooton, T. M. (2000). Pathogenesis of thinary tract infections: an update. $J$ Amtimicrob Chemother 46 Suppl 1, 1.7; discussion 63-65.

23. Hooton, T. M., Besser, R., Foxman, B. et al. (2004). Acute uncomplicated cystitis in an era of increasing antibiotic resistance: a proposed approach to empirical therapy. Chin Infect Dis 39, 75 80. 
24. Muratam, T. \& Matsumoto, T. (2004). Bacterial resistance to antimionobials in urimary isolates. In $J$ Antimicrob Agents 24 Suppl 1, S28-31.

25. Wiersma, T. J. Timmermans, A. E. (2001). [Summaty of the "Urinary tract dinfections" gudeline (furst revision) of the Dutch College of General Practitioners]. Ned Tijdschr Geneeskd $145,735-739$

26. Christiaens, T. C., De Meyere, M., Verschraegen, G. et al. (2002). Randomised conmolled trial of nitrofinantoin versus placebo in the treatment of uneomplicated urinary tract infection in adult women. Br J Gen Pract 52, 729-734.

27. Goettsch, W. van Pelt, W., Nagelkerke, N., ef al. (2000), Increasing resistance to fluoroquinolones in Escherichia coli from urinary trat infections in the Netherlands. $J$ Antimicrob Chemother 46, 223-228.

28. Fluit, A. C., Jones, M. E., Selnmitz, F. J., et al. (2000). Antimicrobial resistance anong urinary tract infection (UTI) isolates in Europe: results from the SENTRY Antimicrobiall Surveillince Program 1997. Anonie Fan Leewwenhoek 77, 147-152.

29. Makela, M. I., Puhakka, T.y Ruskanen, O, ef al. (1998). Viruses and bacteria in the etiology of the common cold. I Clin Microbiol 36, 539-542.

30. Hopstaken, R. M., Muris, J. W., Knottnerus, J. A., ef al (2003). Contributions of symptoms, signs, erythrocyte sedimentation rate, and C-reactive protein to a diagnosis of pnetumonia in acute lower respiratory tract infection. $B x^{*} J$ Gen Pract $53,358-364$. 
Nederlandse Samenvatting 
De roll van de commensale flora van gezonde mijwilligers en huisartspatienten in de epidemiologie van antibioticumresistentie, en in het bijzonder de ontwikkeling en verspreiding van de resistentie, werd onderzocht in dit proefschrift. De commensale flora aanwezig in / op verschillende delen van het lichaam vornt een groot reservoir van antibioticumresistentie genen en antibioticurnresistente bacteriën. Een aantal aspecten van belang voor de stijging van de antibioticumresistentie in de commensale flort werden geanalyseerd. Bovendien werden enkele gevolgen van dit "commensaal reservoir" van antibioticumresistentie (genen) voor potentieel pathogene microorganismen toegelicht.

De prevalentie van erythromycine resistente streptokokken, de meest voorkomende species van de oropharyngeale commensale flora, werd bestudeerd in een case-control studie uitgevoerd onder huisartspatiënten in Nederland. De huisartsen (van het NIVEL peilstation project) includeerden patiënten met klachten van een acute luchtweginfectie en controle patiënten van dezelfde leeftijdscategorie. Bijna $60 \%$ van de geincludeerde patiènten (cases en controles) waren drager van erythromycine resistente streptokokken. Bij een vijfde van alle patiënten waren de streptokokken niet alleen resistent voor erythromycine en andere macroliden maar ook voor lincosamiden en streptogramin antibiotica. Deze kruisresistentie werd veroorzaakt door de aanwezigheid van het $\mathrm{erm} B$ gen in de streptokokken. Het resistentie percentage van erythronycine bij de huissartsenpatiënten was lager in vergelijking met dat van gezonde vrijwilligers in Belgiê $(71 \%)$ en het resistentie percentage in Spanje in 2001 . Verder werd overdracht van het erythromycine resistentie gen ermB van een commensale streptokok naar een Streptococcus pneumoniae isolaat door middel van conjugatie met een frequentie van $1 \times 10^{-9}$ aangetoond. Deze transfer van resistentiegenen benadrukt de rol van de commensale flora als reservoir van antibioticumresistentie genen voor potentieel pathogene micro-organismen.

Het gastro-intestinale stelsel is naast het luchtwegstelsel een tweede groot reservoir van commensale bacteriën (10 $12-10^{14}$ kolonie vormende eenheden per gram darminhoud) en dus ook van antibioticumresistentie genen en antibioticumresistente bacteriën. Om een indruk te krijgen van de onvang van het antibioticumresistentie reservoir in de darmflora in populaties met een variabele selectiedruk voor resistentie werd de prevalentie van antibioticaresistente fecale Escherichia coli van gezonde vrijwilligers uit negen ontwikkelingslanden bepaald. In de onderzochte populaties werd voor de meerderheid van de geteste antibiotica een hoge resistentie prevalentie gevonden. Voor de orale, relatief goedkope, breed spectrum middelen zoals ampicilline, trimethoprim en tetracycline werden de hoogste resistentie percentages gevonden. Verder werden significante verschillen gevonden in de prevalentie van resistentie voor deze drie middelen tussen stedelijke en landelijke populaties. Opmerkelijk was de resistentie tegen fluoroquinolonen in verschillende populaties in Azie en Latijns-Amerika 
(Filippijnen, Mexico en Peru). Mogelijk dat het gebruik van ciprofloxacin als alternatief voor de behandeling van cholera en tyfus aan deze resistentie heeft bijgedragen.

Ziekenhuizen vormen door het antibioticagebruik en door de "concentratie" van relatief veel patiënten met verminderde weerstand in een beperkte nuimte een belangrijke bron voor antibioticaresistentie. In patiënten opgenomen op de afdeling chirurgie van het Academisch Ziekenhuis Maastricht, het Universitair Medisch Centrum Groningen en het Erasmus Medisch Centrum in Rotterdam werd een stijging gevonden in de prevalentie van antibioticaresistentie in fecale Enterococcus faecalis isolaten tijdens het ziekenhuisverblijf in vergelijking met de situatie voor opname. Na ontslag uit het ziekenhuis en dus na het verdwijnen wan de selectie druk van het ziekenhuis verminderde de prevalentie van de resistentie in de commensale darmflora in de tijd. Afhankelijk van het geteste antibioticum verschilde de tijd nodig voor de resistentie om terug te keren naar het niveau voor opname tussen 1 maand (ciprofloxacine en tetracycline) en 6 maanden (erythromycine en gentamicin).

Aangezien de commensale bacteriën van het gastro-intestinaal stelsel in staat zijn om via de opstijgende route urineweginfecties te veroorzaken is de fecale flora het belangrijkste reservoir voor antibioticaresistente uropathogenen. In de laatste drie hoofdstukken werd voor acute ongecompliceerde urineweginfecties de optimale therapieduur en de prevalentie van antibioticaresistente uropathogenen in relatie tot de leeftijd onderzocht. In de studie naar de optimale therapieduur werd zowel op dag 1 als op dag 3 na het einde van een 3- en een 5-daagse kuur met trimethoprim geen significant verschil gevonden in het bacteriologisch genezingspercentage. Deze bevindingen ondersteunen een korte behandelingsduur met de voordelen van lagere kosten, minder nevenverschijnselen en betere compliance van de patiënt. Echter, voor de patiënt en dle huisarts is een negatieve bacteriële kweek (afwezigheid van bacteriën in de urine) even belangrijk als het verdwijnen van de symptomen/klachten van de patiènt. Bij de patiëntem in de 3-daagse kuur beschouwde $44 \%$ zichzelf als "nietgenezen" 1 dag na het beëindigen van de therapie. Alhoewel het percentage herstelde patiënten niet significant verschillend was tussen beide therapiegroepen ( $50 \%$ vs. $58 \% 1$ dag na het stoppen van de kuur) is het aannemelijk dat het verschil in zelf gerapporteerde genezing de oorzaak is waarom huisartsen een drie daagse kuur als minder betrouwbaar ervaren. Opvallend is dat het percentage trimethoprim resistente $E$. coli in de controle urines van patiënten die zich wel en niet-genezen beschouwen gelijk was. Verder werd een aanzienlijk percentage trimethoprim resistente $E$. coli isolaten gevonden in de urine van zowel de patiënten die zichzelf als niet-genezen beschouwden als ook bij diegene die zichzelf opgeknapt vonden. Deze resultaten onderstrepen het natuurlijk verloop van een urineweginfectie. Helaas konden geen harde conclusies getrokken worden door het verlies van patiënten in de follow-up periode waardoor het aantal patiènten dat uiteindelijk geanalyseerd kon worden relatief klein werd. 
Voor de empirische behandeling wan patienten met een UWI in de huisarisenpraktijk zijn richtlijnen gebaseerd op de gewoeligheidspercentages van ongeselecteorde uropathogenen nodig. Aangezien deze gegevens in Nederland slechts beperkt beschikbaar zijn werd een nationale studie uitgevoerd bij vrouwelijke patienten die hun huisarts bezochten met klachten van een ongecompliceerde UWl De antibioticagevoeligheid van de ongeselecteerde uropathogenen ( $E$. coli) geisoleerd bij patiënten van verschillende leeftijdscategorieën werd bepaald en vergeleken met de door de huisarts voorgeschreven therapie. Tevens werd de door de huisarts uitgevoerde diagnostiek (nitriet en leukocyten-esterase test) vergeleken met de bacteriele kweekuitslag, het voorschrijven van antibiotica door de huisartsen en de bacteriele kweekuitslag.

Bij symptomatische vrouwen tussen de 11 en 70 jaar oud wordt een positieve nitriettest $(\mathrm{PPV}=96 \%)$ of een negatieve nitriettest in combinatie met een positieve leukocytenesterase test (PPV $=79 \%$ ) als een urineweginfectie beschouwd en zou als dusdanig behandeld moeten worden. Echter, indien beide testen een negatief resultaat opleveren $(\mathrm{NPV}=53 \%)$ is verder bacteriologisch onderzoek van de urine vereist. Voor het voorschrijven van de empirische therapie zal de huisarts rekening moeten houden met de leeftijd van de patiënt aangezien deze gerelateerd is met de etiologie van de infectie. Vanwege de toename van resistentie tegen norfloxacin en ciprofloxacin in deze patiënten categorie lijkt het beter het gebruik van fluoroquinolonen te beperken. Aangezien het gevoeligheidspercentage van $E_{\text {coli }}$ voor trimethoprim gedaald is tot $80 \%$ is te overwegen d 3 middel niet langer als middel van eerste keuze te gebruiken in deze patiëntenpopulatie in Nederland.

Aangezien oudere patiënten ( $>70$ jaar) in de huisartsenpraktijk meestal vage klachten / symptomen van UWIs vertonen, is het verrichten van de diagnostiek met behulp van de nitriet en / of leukocyten-esterase test ook in deze populatie belangrijk. Gebruik van ochtendurine (bacteriën hebben immers minimaal 4u nodig om nitrat on te zetten in een detecteerbare hoeveetheid nitriet) ter voorkoming van een vals negatieve testuitslag is daarom essentieel. Alhoewel nitrofurantoine nog steeds de therapie van eerste keuze was in deze groep, daalde het percentage voorschriften met een stijgende leeftijd en was er een stijging in het voorschriffpercentage co-amoxiclav en fluoroquinolonen met een stijgende leeftijd. Deze verandering in voorschrijfgedrag bij de oudere vrouwen kan veroorzaakt zijn doordat deze vaker in het verleden wen UWI gehad hebben en dus waarschijnlijk ook vaker antibiotische therapie kregen. Daarom wordt in deze populatie ook vaker een antibioticakuur van $\geq 5$ dagen voorgeschreven. Deze veranderingen in voorschrijfgedrag $z \mathrm{ijn}$ verwant met de verschuivingen in de etiologie van een UWI in de oudere populatie; er werd proportioneel minder vaak een $E$. coli, mar vaker een $P$. mirabilis en een $K$ pneumoniae geïsoleerd. De laagste gevoeligheidspercentages werden voor de drie uropathogenen het meest geisoleerd bij deze oudere patiënten 
gevonden voor amoxicilline en trimethoprim. Resistentie voor fluoroquinolonen werd in deze drie micro-organismen ook reeds gevonden. Aangezien trimethoprim resistentie ook in de meest frequent voorkomende uropathogenen van de 70 plussers $30 \%$ benaderde is het de vraag of dit antibioticum een middel van eerste keuze moet blijven voor de behandeling van acute ongecompliceerde UWI in Nederland.

Samengevat vormt de commensale flora van de luchtwegen en het maagdarm kanaal een grote populatie aan micro-organismen die vaak wordt blootgesteld aan antimicrobiële agentia tijdens de behandeling van bacteriële infecties. Door deze herhaaldelijke blootstelling kunnen de commensale bacteriën resistent worden tegen vaak gebruikte antibiotica en een groot reservoir aan resistentiegenen en resistente bacteriën vormen. De resistentie aanwezig in potentieel pathogene micro-organismen is dus slechts de tip van de "resistentie" ijsberg in vergelijking met de resistentie aanwezig in de normale flora. Daarom is de beschikbaarheid van actuele gevoeligheidspercentages van de meest voorkomende commensale bacteriën als ook van potentieel pathogene micro-organismen van groot belang om de empirische therapie snel te kunnen aanpassen aan de veranderende en beginnende antibioticumresistenties (een "early-warning" systeem). 
$$
a_{0}
$$

$$
\text { ( }
$$

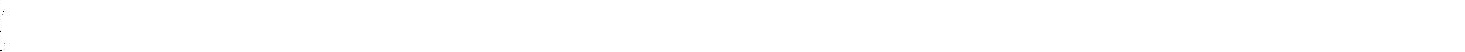

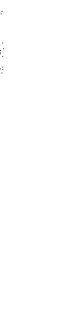
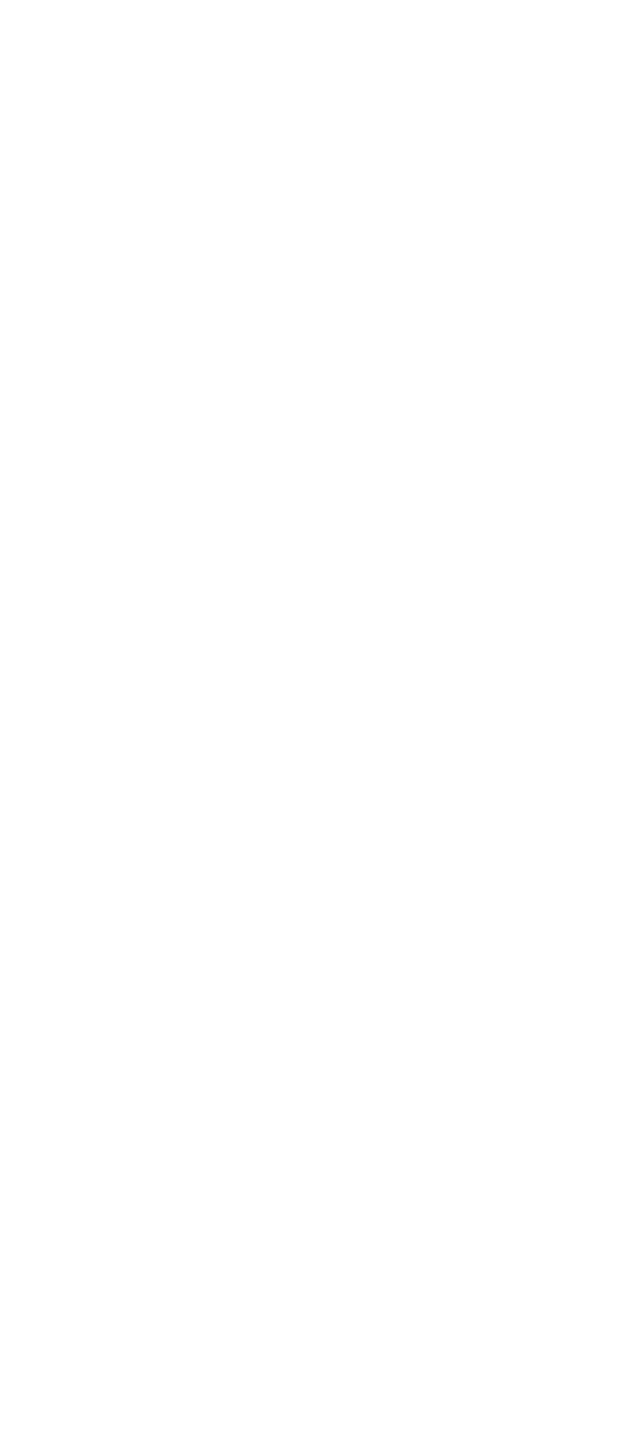
Dankwoord, Curriculum vitae \& List of Publications 


\section{Dankwoord}

Ik heb lange tijd nagedacht over wat ik hier zou gaan schrijwen. Het is misschien miet meteen geworden wat jullie verwacht hadden, naar het is dan ook mijn dankwoord! Oké, zullen we maar van start gaan? Diegenen die ik tijdens de afgelopen drie (ondertussen bijna 4) jaar echt dankbaar ben geweest weten het, daar zijn geen woorden voor nodig. Toch zal ik hier nog enkele bijzondere mensen vernoemen.

Dit zijn in de eerste plaats de mensen die bij mijn sollicitatiegesprek aanwezig waren want zonder jullie was ik hier nooit aan de slag gegaan. Bedankt on mij die kans te geven!! Ellen, jou wil ik in het bijzonder nog bedanken ondat je in het eerste jaar meer in mij en deze promotie geloofde dan ik zelf; dat je me telkens weer voor de deadlines zet(te) die ilk blijkbaar nodig heb om te schrijven, en dat je elke keer opnieuw een weg vond (vindt) om mijn aanstelling te verlengen! Verder, Cathrien bedankt dat je mij de kans hebt gegeven om op deze afdeling te promoveren en clat je steeds geinteresseerd bent in mijn onderzoek (ook al is het niet virologisch).

Als we het rijtje verder aflopen komen we bij het lab: Bac-Research. Alhoewel het lab gedurende de 3,5 jaar dat ik hier ben veranderd is van een $90 \%$ vrouwengroep naar een fifty-fifty verdeling qua geslacht is er 1 regel die nog steeds geldt:"Women are the best"! Allemaal bedankt voor de leuke werksfeer, het bijspringen in de werkzaamheden indien nodig en naturrlijk de onvergetelijke labuitjes... Lucy, heel erg bedankt on mij in te wijden in het praktisch reilen en zeilen van de Microbiologie, al het werk dat je in de verschillende studies hebt gestopt en in het bij|zonder voor de leuke tijden die we samen hebben doorgebracht. Verder natuurlijk Ruud en Christel, mijn paranimfen, jullie weten wat jullie voor mij betekenen! Heel erg bedankt ook voor alle hulp ivm de promotie.

Inge en Ellen, mijn twee Belgische (ex)kamergenootjes, ja er zijn geen woorden die beschrijven hoe zeer ik jullie gezelschap en steun (op het werk en er buiten) waardeer, MERCIEKES!

Om het werkrijtje af te sluiten volgen de onmisbare mensen van de voedingsbodem - en spoelkeuken. Verius, bedankt on steeds weer oplossingen te bedenken als ilk met een bestelling of ander probleem zat. En Ans, jij bent de meest vrolijke persoon die ik ken; ik wordt altijd goed gezind als ik jou zie!

Om dit stuk af te sluiten wil ik nog graag mijn vitenden en familie bedanken on steeds weer naar mijn "sappige" werkverhalen te luisteren die voornamelijk tijdens het eten een leuk gespreksonderwerp vorm(d)en en natuturlijk ook ondat ik bij jullie mijn gedachten even helemaal op andere dingen kan zetten en mij ontspannen. 


\section{Curriculum vitae}

Sita Nys werd geboren op 21 juni 1977 te Genk, België. Ze behaalde het diploma van het secundair onderwijs (Wetenschappen-Wiskunde) in 1995 aan het Koninklijk Atheneum I te Hasselt. Na een verblijf van 11 maanden in Chagrin Falls Ohio (US) als uitwisselingsstudent behaalde ze het diploma van "High School". In 1996 begon ze met de opleiding Biologie aan het Limburgs Universitair Centrum te Diepenbeek. Na het behalen van het diploma Kandidaat in de Biologie zette ze haar studie in 1999 verder aan de Universiteit Antwerpen waar ze in 2001 de graad Licentiaat in de Algemene Biochemie behaalde. In januari 2002 trad ze in dienst bij de afdeling Medische Microbiologie van het Academisch Ziekenhuis Maastricht als onderzoeker in opleiding. Daar was zij werkzaam in het gebeid van de antibioticumresistentie in de commensale flora van de mens. De resultaten van die onderzoeksperiode staan beschreven in dit proefschrift. Sinds april 2005 is haar onderzoek gericht op de preventie van wederkerende urineweginfecties met behulp van niet-antibiotische profylaxe. 


\section{List of Publications}

\section{Papers}

Bruinsma N, Filius PM, van den Bogaard AE, Nys S, Degener J, Endtz HP, Stobberingh EE. (2003) Hospitalization, a risk factor for antibiotic-resistant Escherrichia coli in the community? Joumal of Antimicrobial Chemotherapy 51(4):1029-3

S. Nys, IN. Okeke, S. Kariuki, G.J. Dinant, C. Driessen, and E.E. Stobberingh (2004) Antibiotic Resistance of Faecal Escherichia coli from Healthy Volunteers from Eight Developing Countries. Jownal of Antimicrobial Chemotherapy 54 (5), 952-955

S. Nys, N. Bruinsma, P.M.G. Filius, A.E. van den Bogaard, L. Hoffman, P.H.W. Terporten, A.C.M. Wildeboer-Veloo, J. Degenere, H.P. Endtz, E.E. Stobberingh (2005) Effect of hospitalization on the antibiotic resistance of fecal Enterococcus faecalis of surgical patients over time. Microbial Drug Resisfance 11(2), 154-158

S. Nys, J.H. Tjhie, A.I. Bartelds, M.L. Heijnen, M.F. Peeters, E.E. Stobberingh (2005) Erythromycin resistance in the commensal throat flora of patients visiting the general practitioner: a reservoir for resistance genes for potential pathogenic bacteria. International Journal of Antimicrobial Agents (Available online 15 June 2005)

E. Stobberingh, S. Nys (2005) Urineweginfecties in de huisartsenpraktijk. Analyse 60 (5), 136-139

\section{Abstracts}

S. Nys, N. Bruinsma, M. Filius, J. Degener, A.E. van den Bogaard and E.E. Stobberingh (2003) Effect of hospitalization on the antibiotic resistance of faecal Enterococci after discharge. NvMM voorjaarsvergadering, Amhem, Netherlands.

S. Nys, N. Bruinsma, M. Filius, J. Degener, A.E. van den Bogaard and E. E. Stobberingh (2003) Effect of hospitalization on the antibiotic resistance of faecal Enterococci after discharge. ASM 103rd General Meeting, Washington DC. USA.

S. Nys, E.E. Stobberingh, S. Kariuki, V. Chihota, A.E. van den Bogaard (2003) The Prevalence of Antibiotic Resistant Faecal Escherichia coli in Healthy Volunteers in Nine Developing Countries. ASM 103 rd General Meeting, Washington DC, USA. 
Nys S., Tjhie J.H.T., Spee K, Bartelds A.IM., Heijnen M.L.A., Peeters M.F., Stobberingh E.E. (2004) The potential risk of erythromycin as emperic therapy for therapy failure in acute respiratory tract infections. WONCA, Amsterdam, Netherlands.

Nys S. Tjhie J.H.T, Spee K., Bartelds A.I.M., Heijnen M.L.A., Peeters M.F. Stobberingh E.E. (2004) The potential risk of erythromycin as emperic therapy for therapy failure in acute respiratory tract infections. World Conference on magic bullets, Neurenberg, Germany.

Nys S., Tjhie J.H.T., spee K., Bartelds A.I.M., Heijnen M.L.A., Peeters M.F., Stobberingh E.E. (2004) The potential risk of erythromycin as emperic therapy for therapy failure in acute respiratory tract infections. Joint Scientific Meeting on Infectious Diseases and Microbiology, Amsterdam, Netherlands. 